\title{
Experimentação baseada em Simulação em Sistemas para Cidades Inteligentes
}

\author{
Lucas Kanashiro Duarte
}

\author{
DISSERTAÇÃO APRESENTADA AO \\ INSTITUTO DE MATEMÁticA E EsTATÍSTICA \\ DA UNiversidade de SÃo Paulo \\ PARA OBTENÇÃO DO TÍTULO DE \\ Mestre EM Cî̂NCIAS
}

Programa: Ciência da Computação

Orientador: Prof. Dr. Fabio Kon

Durante o desenvolvimento deste trabalho o autor recebeu auxílio financeiro do $\mathrm{CNPq}$

São Paulo

7 de março de 2019 



\title{
Experimentação baseada em Simulação em Sistemas para Cidades Inteligentes
}

\author{
Lucas Kanashiro Duarte
}

Esta versão da dissertação contém as correções e alterações sugeridas pela Comissão Julgadora durante a defesa da versão original do trabalho, realizada em 7 de março de 2019.

Uma cópia da versão original está disponível no Instituto de Matemática e Estatística da Universidade de São Paulo.

Comissão Julgadora:

- Prof. Dr. Fabio Kon (orientador) - IME-USP

- Prof ${ }^{a}$. Dra . Denise Stringhini - UNIFESP

- Prof. Dr. Paulo Roberto Miranda Meirelles - UNIFESP 
Autorizo a reprodução e divulgação total ou parcial deste trabalho, por qualquer meio convencional ou eletrônico, para fins de estudo e pesquisa, desde que citada a fonte. 


\section{Agradecimentos}

Várias pessoas contribuiram para que fosse possível a conclusão deste trabalho, dedico esse feito a todos e meu muito obrigado por me acompanharem nessa jornada. Gostaria de agradecer imensamente o apoio incondicional da minha família, sem ela não teria sido possível a minha permanência em São Paulo ao longo dos últimos anos, além do amor e carinho que sempre foi presente em toda a minha vida. Agradeço também o apoio de todos os amigos que tornaram essa mudança total de vida muito agradável e inesquecível. Sou muito grato também a todos os colegas de laboratório que me ajudaram a crescer tecnicamente e academicamente no decorrer dos últimos anos. E por fim, deixo aqui o meu reconhecimento a todos os professores que fizeram parte da minha jornada acadêmica, principalmente aos que tiverem paciência e me orientaram nessa empreitada: Prof. Dr. Paulo Meirelles durante a graduação e o Prof. Dr. Fabio Kon durante este mestrado. Esta conquista não é apenas minha e sim de todos vocês. Obrigado. 



\section{Resumo}

\section{Lucas Kanashiro Duarte. Experimentação baseada em Simulação em Sistemas para}

Cidades Inteligentes: . Dissertação (Mestrado). Instituto de Matemática e Estatística, Universidade de São Paulo, São Paulo, 2019.

Cidades ao redor do mundo enfrentam diversos desafios para proporcionar uma boa qualidade de vida aos seus cidadãos. Sistemas de software vêm sendo desenvolvidos com objetivo de melhorar os serviços e otimizar o uso da infraestrutura da cidade. Desenvolver ambientes de experimentação para esses sistemas na escala de grandes cidades ainda é um desafio, devido ao alto custo e problemas de infraestrutura. Por sua vez, a simulação é um mecanismo que vem sendo utilizado na realização de experimentos em diversas áreas do conhecimento. $\mathrm{O}$ objetivo deste trabalho é auxiliar na construção de um ambiente de experimentação de larga escala e interativo para plataformas de Cidades Inteligentes através de simulação. Para tanto, desenvolvemos uma arquitetura de software visando permitir a integração de plataformas e simuladores de Cidades Inteligentes. Dois estudos de caso demostraram a viabilidade da solução, integrando o simulador InterSCSimulator e a plataforma InterSCity, envolvendo uma série de melhorias em ambas as ferramentas. Apresentamos detalhes de como implementar a arquitetura proposta, além da execução de experimentos na escala da cidade de São Paulo. Acreditamos que a solução nos levou a resultados satisfatórios, tendo em vista que, foi possível realizar experimentos de larga escala através de simulação por meio da implementação da arquitetura apresentada. Portanto, projetamos uma arquitetura de software que poderá servir de base para integração de plataformas e simuladores de Cidades Inteligentes com o intuito de realizar experimentos de larga escala e interativo, visando principalmente questões de desempenho e escalabilidade.

Palavras-chave: Cidades Inteligentes. Experimentação. Simulação. 



\begin{abstract}
Lucas Kanashiro Duarte. Simulation based Experimentation on Smart City Systems: . Thesis (Masters). Institute of Mathematics and Statistics, University of São Paulo, São Paulo, 2019.

Cities around the world face a number of challenges to provide a good quality of life for their citizens. Software systems have been developed with the aim of improving services and optimizing the use of the city's infrastructure. Developing experimentation environments for these systems in the large cities scale is still a challenge due to the high cost and infrastructure problems. In turn, the simulation is a mechanism that has been used to enable experiments in several areas of knowledge. The goal of this work is to assist in the development of a large scale and interactive experimentation environment for Smart Cities platforms through simulation. For this, we developed a software architecture to allow the integration of platforms and simulators of Smart Cities. Two case studies demonstrated the feasibility of the solution, integrating the InterSCSimulator simulator and the InterSCity platform, involving a series of improvements in both tools. We present details of how to implement the proposed architecture, as well as the execution of experiments on the scale of the city of São Paulo. We believe that the solution led us to satisfactory results, considering that it was possible to perform largescale experiments through simulation using the implementation of the presented architecture. Therefore, we have designed a software architecture that can be used as a basis for the integration of Smart Cities platforms and simulators in order to perform large-scale and interactive experiments, primarily focusing on performance and scalability issues.
\end{abstract}

Keywords: Smart Cities. Experimentation. Simulation. 



\section{Lista de Figuras}

3.1 Arquitetura Proposta para Ambiente Integrado de Exerimentação de Plataformas de Cidades Inteligentes . . . . . . . . . . . . . . . . 17

3.2 Diagrama de sequência para uma evento de sensoriamento . . . . . . . . 18

3.3 Diagrama de sequência para uma evento de atuação . . . . . . . . . . . . 19

4.1 Arquitetura do InterSCSimulator . . . . . . . . . . . . . . . . 22

4.2 Componentes do InterSCSimulator . . . . . . . . . . . . . . . . . 24

4.3 Arquitetura da plataforma InterSCity . . . . . . . . . . . . . . 25

4.4 Integração para descoberta de vagas livres próximo do destino da viagem 28

4.5 Integração para publicar dados . . . . . . . . . . . . . . . . . 29

4.6 Mapa de calor com a distribuição das vagas de estacionamento utilizadas no experimento. . . . . . . . . . . . . . . . . 31

4.7 Mapa de calor com a distribuição dos destinos de viagens de carro utilizadas no experimento. . . . . . . . . . . . . . . . . . 31

4.8 Configuração do cluster para o experimento. . . . . . . . . . . . . . . . . 32

4.9 Média da carga de trabalho gerada pelo InterSCSimulator no decorrer do

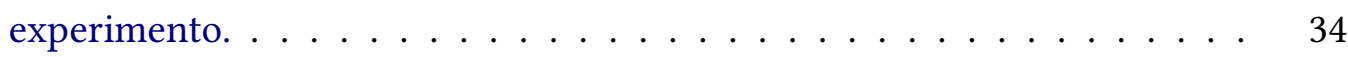

4.10 Dimensionamento automáticos dos microsserviços da plataforma InterSCity. 35

4.11 Taxa de vazão (throughput) média da platafora InterSCity. . . . . . . . . 36

4.12 Tempo de resposta médio da platafora InterSCity. . . . . . . . . . . . . 36

4.13 Exemplo de Placa de Mensagem Variada. . . . . . . . . . . . . . . . . 37

4.14 Integração para publicar dados de posicionameto de carros . . . . . . . . 40

4.15 Integração para atuação em Placas de Mensagens Variadas . . . . . . . . 41

4.16 Mapa viário da cidade utilizado para validação. . . . . . . . . . . . . . 42

4.17 Trajeto esperado do cenário 1 do experimento. . . . . . . . . . . . . . 43

4.18 Trajeto esperado do cenário 2 do experimento. . . . . . . . . . . . . . . 44

4.19 Trajeto esperado do cenário 3 do experimento. . . . . . . . . . . . . . 44

4.20 Média da distância percorrida pelos carros no experimento. . . . . . . . . 45

4.21 Média da duração das viagens simuladas no experimento. . . . . . . . . . . 46 
4.22 Posicionamento das PMVs no experimento de tráfego inteligente de carros. 47

4.23 Local dos eventos de fechamento de via no experimento de tráfego de carros inteligente. . . . . . . . . . . . . . . . 48

4.24 Média da duração das viagens de carros no experimento. . . . . . . . . . 49

4.25 Média da duração das viagens de carros afetadas por fechamento de vias e/ou PMVs no experimento. . . . . . . . . . . . . . . . 50

\section{Lista de Tabelas}

2.1 Caracterização dos trabalhos relacionados . . . . . . . . . . . . . . . 


\section{Sumário}

1 Introdução 1

1.1 Motivação . . . . . . . . . . . . . . . . . . . 3

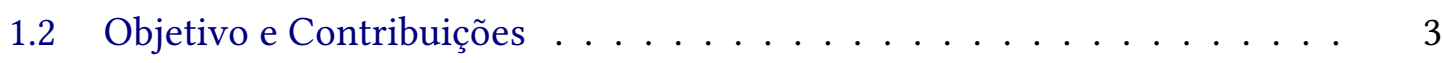

1.3 Organização do Trabalho . . . . . . . . . . . . . . 4

2 Trabalhos Relacionados $\quad 5$

2.1 Ambientes de Experimentação para Plataformas de Cidades Inteligentes 5

2.2 Simulação e Cidades Inteligentes . . . . . . . . . . . . . . . . 9

2.3 Integração de Ferramentas para prover Ambiente de Experimentação . 10

3 Proposta de Solução $\quad 13$

3.1 Requisitos da Solução . . . . . . . . . . . . . . . . . . . . . . . 13

3.2 Arquitetura . . . . . . . . . . . . . . . . . 15

3.2.1 Integração Simulador-Plataforma . . . . . . . . . . . 16

4 Estudos de Caso $\quad 21$

4.1 Ferramentas . . . . . . . . . . . . . . . . . 22

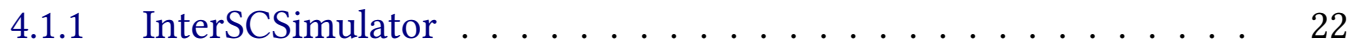

4.1 .2 Plataforma InterSCity . . . . . . . . . . . . . . 24

4.2 Estacionamento Inteligente . . . . . . . . . . . . . . . . . 26

$4.2 .1 \quad$ Implementação . . . . . . . . . . . . . . . . . . . . 26

4.2.2 Experimento . . . . . . . . . . . . . . . . 29

4.3 Tráfego de Carros Inteligente . . . . . . . . . . . . . . . . . . . . . . . . . . . . . . . . . . . . 37

4.3 .1 Implementação . . . . . . . . . . . . . . . . 37

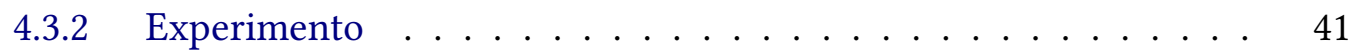

4.4 Discussão . . . . . . . . . . . . . . . . . . . . . 50

4.4.1 Implementação da Solução Proposta . . . . . . . . . . . . . . 50

4.4.2 Experimentos ...................... 52 
5 Conclusão $\quad 55$

5.1 Limitações do trabalho . . . . . . . . . . . . . . . . . . . . 56

5.2 Trabalhos Futuros . . . . . . . . . . . . . . . . . 56

Referências 


\section{Capítulo 1}

\section{Introdução}

A utilização de Tecnologia da Informação e Comunicação (TIC) para solucionar os problemas das cidades está surgindo como uma boa estratégia para mitigar os problemas que são agravados pelo rápido crescimento da população urbana (CHOURABI et al., 2012). Essa abordagem visa otimizar os serviços e uso de recursos da cidade, assim como melhorar a qualidade de vida dos cidadãos (SANTANA, Chaves et al., 2017).

Para que plataformas de Cidades Inteligentes atendam às expectativas de governos e cidadãos na melhoria da qualidade de vida nas cidades, elas precisam ser capazes de lidar com todas as adversidades e complexidade presentes nas cidades modernas. Devem ser flexíveis e capazes de escalar para atender as diferentes demandas no decorrer do dia, além de conseguir lidar com múltiplos aspectos que tornam o contexto de Cidades Inteligentes tão peculiar. Nas cidades, tudo é conectado, um aspecto influencia e é influenciado por diversos outros.

Em uma grande metrópole como São Paulo, milhões de recursos (ônibus, carros, hospitais, estacionamentos, escolas, etc.) deverão ser monitorados e gerenciados em tempo real. Dispositivos de Internet das Coisas (Internet of Things - IoT) poderão enviar e receber dados a todo momento, concorrentemente, com o objetivo de obter dados e atuar sobre os recursos da cidade. Cidadãos e agentes do governo poderão requisitar esses serviços em diferentes horas do dia. Dessa forma, uma plataforma de Cidades Inteligentes deve estar habilitada para atender toda essa demanda.

A realização de experimentos na escala de grandes cidades se apresenta como um meio de validar o funcionamento de plataformas de Cidades Inteligentes em condições reais. Todavia, a realização de experimentos em tais condições não é uma tarefa fácil. Experimentos que fazem uso apenas de scripts para geração de carga de trabalho sintética (usando ferramentas como ApacheBench ${ }^{1}$ ) não exercitam as plataformas em condições reais de uma cidade. Conforme citado anteriormente, praticamente tudo no contexto de uma cidade estará conectado. Apenas enviar dados para a plataforma sem prover um meio de reação interativo não é o suficiente. Por exemplo, ao receber um determinado dado em uma certa circunstância, a plataforma pode ter que atuar de alguma maneira na cidade, $o$

\footnotetext{
${ }^{1}$ https://httpd.apache.org/docs/2.4/programs/ab.html
} 
que alterará o seu estado, modificando o próximo dado a ser enviado para a plataforma. Portanto, esse tipo de experimento é válido, mas não representa uma situação real do cotidiano de uma cidade.

Para solucionar a falta de interação na utilização de scripts para geração de carga de trabalho sintética, podemos fazer uso de testbeds na realização dos experimentos. Esses por sua vez, são plataformas para execução de testes onde, no contexto de IoT, em geral, são implantações de dispositivos reais. O projeto SmartSantander (SANCHEZ et al., 2014) possui um dos testbeds mais famosos na área de Cidades Inteligentes. Vários sensores e atuadores foram implantados na cidade de Santander na Espanha e, com isso, eles se tornaram capazes de realizar experimentos mais realistas. Entretanto, construir testbeds como esse, na escala de uma cidade (mesmo sendo uma cidade pequena), não é trivial. Existem procedimentos, envolvendo governos e um alto custo associado à compra, instalação e manutenção de toda a infraestrutura necessária. Sendo assim, construir testbeds reais na escala de grandes metrópoles do mundo não é uma solução factível na maioria das vezes.

Nesse sentido, apresentamos a simulação como uma saída viável para o problema de experimentar e testar a escalabilidade das plataformas no atendimento do grande volume de requisições. Podemos simular cidades inteiras, implementando modelos realistas capazes de permitir a interação em tempo real com plataformas de Cidades Inteligentes. Tais plataformas visam prover serviços para desenvolvedores de aplicações que desejam interagir de alguma forma com a infraestrutura da cidades, como serviços de integração de dispositivos de IoT, armazenamento e processamento de dados e ciência de contexto (M. DeL EsPoste et al., 2019a). Os diversos recursos da cidade e dispositivos de IoT acoplados aos mesmos são simulados, e uma interface de comunicação entre um simulador e uma plataforma pode tornar a comunicação transparente, ou seja, a plataforma não tem conhecimento se o ambiente é simulado ou não. Ressaltamos que caso o simulador possa executar na escala de grandes cidades, poderá realizar experimentos em cenários realistas. Acrescentamos o fato de nos tornamos capazes de realizar experimentos envolvendo tecnologias que ainda não são amplamente adotadas ou ainda estão em fase de projeto.

Ao fazer uso de um ambiente simulado para realizar experimentos, possibilitamos que sejam reprodutíveis. Utilizar scripts para geração de carga também permitirá reproduzir experimentos (caso os scripts estejam disponíveis). Porém, ao usar testbeds reais contendo dispositivos de IoT, essa característica não poderá ser garantida, haja vista que, ambientes externos podem apresentar grande variabilidade independentemente da execucação de um protocolo (por exemplo, elementos climáticos). A utilização de simulação para resolver problemas similares aos apresentados vem sendo adotada em diversos trabalhos (KARnouskos e De Holanda, 2009) (Fleischer e BArr, 1994) (Dupuy et al., 1990) (Boukerche et al., 2001).

Com o intuito de viabilizar experimentos com plataformas de Cidades Inteligentes, apresentamos nesta dissertação uma proposta para criação de um ambiente simulado de experimentação. Para a construção desse ambiente, fizemos uso de um simulador e de uma plataforma de Cidades Inteligentes, onde ambos são integrados de acordo com o cenário desejado. Para tanto, realizamos a implementação dessa solução utilizando o simulador InterSCSimulator (SANTANA, LAGo et al., 2017) e a plataforma InterSCity (Del Esposte et al., 2017) atraveś de dois cenários de Cidades Inteligentes apresentados como estudo de 
1.1 | MOTIVAÇÃO

caso e descritos posteriormente.

\subsection{Motivação}

O elemento motivador para a execução deste trabalho foi a busca pela melhoria do processo de experimentação de plataformas de Cidades Inteligentes. No decorrer das discussões no nosso grupo de pesquisa, percebemos que realizar experimentos de escalabilidade em plataformas envolvendo o atendimento de diferentes tipos de requisição em tempo real em cenários que se assemelham à realidade ainda constitui-se um desafio. Experimentos realistas são essenciais para validarmos o bom funcionamento dessas plataformas em ambientes de produção.

Conforme dito anteriormente, existem alguns mecanismos que já vêm sendo utilizados na realização de experimentos com plataformas de Cidades Inteligentes, contudo, não proporcionam o nível de interação e a escalabilidade necessária. A solução apresentada neste trabalho reduz os custos quando comparamos a testbeds reais, e ainda nos permite investigar cenários hipotéticos, com tecnologias futuristas ou ainda não passíveis de implantação.

\subsection{Objetivo e Contribuições}

O objetivo central desta pesquisa é definir uma arquitetura para construção de um ambiente de experimentação de larga escala e interativo para plataformas de Cidades Inteligentes através de simulação. As plataformas devem ser capazes de atender uma quantidade cada vez maior de requisições de diferentes tipos de serviços advindas das mais diversas aplicações que visam melhor a vida nas cidades. Experimentos e testes simulados desse tipo de cenário futuro auxiliam a preparar as plataformas para suportar esse grande número de requisições. Para tanto, uma proposta de solução foi projetada visando atender os principais requisitos de um ambiente com essa característica. Este trabalho integra uma ferramenta de simulação capaz de gerar toda essa carga de trabalho a uma plataforma para Cidades Inteligentes com o objetivo de testar o suporte na escala de uma cidade em dois cenários de aplicação.

Durante a realização deste estudo, diversas contribuições foram realizadas tanto para o InterSCSimulator quanto para a InterSCity. Foi possível adicionar novos cenários ao simulador, melhorias nos cenários existentes, além de mecanismos de cache adicionados à plataforma. Ademais, seguindo a ideia de reprodutibilidade e infraestrutura como código ${ }^{2}$ (Infrastructure As Code - $\mathrm{IaC}$ ), automatizamos e disponibilizamos todos os scripts, arquivos de configuração e documentação necessária para a reprodução dos experimentos realizados neste trabalho.

\footnotetext{
${ }^{2}$ https://en.wikipedia.org/wiki/Infrastructure_as_code
} 


\subsection{Organização do Trabalho}

No Capítulo 2 serão apresentados os principais trabalhos relacionados e conceitos envolvidos nesta pesquisa. Uma discussão acerca da proposta de solução é apontada no Capítulo 3. O Capítulo 4 disserta sobre os dois estudos de caso realizados, incluindo as suas implementanções e ferramentas utilizadas. Por fim, as conclusões e possibilidades de trabalhos futuros serão apresentadas no Capítulo 5. 


\section{Capítulo 2}

\section{Trabalhos Relacionados}

Durante a realização desta pesquisa nos deparamos com dificuldades para encontrar uma solução que provesse um ambiente de experimentação para plataformas de Cidades Inteligentes capaz de permitir a interação em tempo de execução (viabilizando a execução de comandos de atuação, por exemplo) em larga escala, pois esses requisitos encontram-se pouco explorados pela academia. Para um melhor entendimento de como esses experimentos estão sendo realizados, serão mostrados relatos de trabalhos que apresentam ambientes de experimentação nessa área e apontadas as suas principais limitações. Alguns trabalhos apontam a simulação como um método que pode solucionar algumas das limitações desses ambientes. Apresentaremos essas discussões buscando explicitar o porquê de adotarmos tal solução.

A título de ilustração, faremos uma breve descrição sobre pesquisas existentes que utilizam a integração com simuladores para a execução de experimentos que se assemelham a contextos reais, demonstrando a viabilidade da solução adotada mesmo que de forma superficial. Em seguida, apresentaremos as principais dificuldades na integração de simuladores e sistemas de software em geral.

\subsection{Ambientes de Experimentação para Plataformas de Cidades Inteligentes}

Apesar dos significativos avanços tecnológicos, dificuldades associadas com a avaliação de plataformas para Cidades Inteligentes sob condições realistas em ambientes experimentais ainda dificultam a sua maturidade e utilização (SANCHEZ et al., 2014). Portanto, encontrar soluções eficazes para melhorar e facilitar a criação de ambientes de experimentação ainda é um desafio.

No contexto de Cidades Inteligentes, onde em grande parte interagimos com dispositivos de IoT (Internet of Things), temos alguns entraves que dificultam a criação desses ambientes de experimentação, sendo os pricipais escala, heterogeneidade de dispositivos, acesso concorrente, mobilidade e reprodutibilidade (GLUHAK et al., 2011) (SANCHEZ et al., 2014). O primeiro deles é a escala desses ambientes, tendo em vista que as cidades e 
suas populações estão em uma constante crescente, os experimentos envolvendo essas plataformas devem ser capazes de refletir essa demanda. $\mathrm{Na}$ infraestrutura física de uma grande cidade, como São Paulo, teremos milhares de dispositivos de IoT de diferentes naturezas monitorando e atuando na cidade e os experimentos, para que sejam realistas, precisam representar essa heterogeneidade de dispositivos. Destacamos que em uma Cidade Inteligente teremos diversas aplicações tentando acessar recursos da infraestrutura da cidade simultaneamente. Esse acesso concorrente deve também estar presente nos ambientes de experimentação. Além disso, a mobilidade é uma característica evidente. Todos esses desafios anteriores dificultam ainda mais a reprodutibilidade desse ambiente.

Podemos encontrar diversos trabalhos que tentaram solucionar os desafios citados, sendo grande parte dessas soluções através de testbeds reais. Nesses testbeds, dispositivos de IoT são implantados no ambiente, conectados através de redes de sensores e monitorados. Todo esse processo tem um custo alto, tanto de aquisição dos equipamentos necessários quanto de mão de obra para execução. Temos testbeds implantados tanto em ambientes abertos quanto em laboratórios.

Grande parte dos testbeds apresentados na literatura foram implantados em cidades da Europa, e cada um deles tem um foco específico. Os testbeds apresentados em Olivares et al., 2013 e CENEDESE et al., 2014 são voltados para experimentos envolvendo redes de sensores, como os nós interagem e o correto funcionamento de todas as camadas de protocolos. Ambos tratam a questão da heterogeneidade de dispositivos e mobilidade; contudo, não mencionam questões de escala do ambiente, acesso concorrente e reprodutibilidade. Encontramos o FIT IoT-LAB (ADjiH et al., 2015), que também é um ambiente de testes focado em redes de sensores como os demais. No entanto, os autores o apresentam como um ambiente de larga escala. Ele possui 2728 nós de baixo consumo conectados a uma rede sem fio e 117 robôs móveis. Levando em consideração que em uma cidade como São Paulo esperamos ter dispositivos na escala de milhões, não acreditamos que essa escala apresentada seja suficiente para a realização de experimentos realistas no contexto de uma grande metrópole.

Ambientes de experimentação voltados especialmente para a heterogeneidade de dispositivos são apresentados em LATRE et al., 2016 e JURASCHEK et al., 2012 na forma de testbeds localizados em Antvérpia na Bélgica, e Berlim na Alemanha, respectivamente. Nesses trabalhos, a heterogeneidade é tratada no nível de protocolos de rede para comunicação e tratamento de dados, considerando que cada dispositivo pode utilizar diferentes protocolos e se comunicar através de diferentes formatos de dados. Mais uma vez, temos o problema de escala que não é explicitado nas apresentações dos testbeds.

Em LANZA et al., 2015, é apresentado uma parte do testbed implantado na cidade de Santander na Espanha, com uma característica muito interessante que não é encontrada na maioria dos outros trabalhos: o seu foco principal é a mobilidade. Ao perceberem que veículos são a melhor forma de obter dados da cidade reduzindo os gastos, já que circulam por vários pontos da cidade no mesmo dia, implantaram sensores em 140 ônibus, táxis e vans para coleta de diversos dados. Ao coletarem dados de diferentes naturezas utilizaram diferentes dispositivos, trabalhando, também, a questão da heterogeneidade. Todavia, todos os desafios foram abordados em uma escala bem menor do que a esperada para uma grande cidade. 
No contexto de Cidades Inteligentes, além da parte técnica, temos também que nos preocupar com o impacto dessa tecnologia na vida das pessoas. O testbed introduzido por NATi et al., 2013, tem o objetivo de viabilizar experimentos centrados no usuário, onde ao invés de ter os dispositivos e softwares envolvidos sob prova, temos o usuário como alvo do experimento. Nesse tipo de ambiente, seria bastante complexo a realização de experimentos em larga escala, tendo em vista que necessitaríamos envolver a população de uma cidade no processo de experimentação. Por isso, esse testbed foi implantado no contexto de um escritório, e não ataca a maioria dos desafios citados nesta seção, como mobilidade por exemplo.

Temos também uma série de testbeds voltados especificamente para apenas uma das áreas de Cidades Inteligentes. A pesquisa de BrAEM et al., 2016 foca na análise da qualidade do ar, CHAPMAN et al., 2015 apresenta um testbed meteorológico, Lu et al., 2010 introduz um ambiente de experimentação envolvendo Smart Grid e AMRUTUR et al., 2017 demontra um testbed de postes de iluminação pública, por exemplo.

Existem também algumas iniciativas que visam realizar a federação de testbeds em diferente localidades. Em MwANGAma et al., 2013 e CoRici et al., 2014 foram federados ambientes de experimentação em Berlim na Alemanha e na Cidade do Cabo na África do Sul visando balancear a carga de trabalho, tratando de pontos como autenticação, identificação segura e políticas de armazenamento e de redirecionamento.

Além de todos esses ambientes de experimentação apresentados, temos provavelmente o mais conhecido dentre eles, o desenvolvido pelo projeto SmartSantander (SANCHEZ et al., 2014). Esse testbed foi implantado na cidade de Santander na Espanha, e o mesmo visou atacar todos os desafios apresentados nesta seção. Além de ser um ambiente de teste, ele provê serviços para a população da cidade através de aplicações de Cidades Inteligentes, como por exemplo uma aplicação de estacionamento inteligente. A implantação desse testbed só foi possível devido ao total apoio do governo da cidade e financiamento de diversas fontes. Todavia, apesar de ser um dos ambientes de experimentação mais bem sucedidos que temos na literatura, ainda acreditamos que o mesmo não representa a escala de uma grande metrópole como São Paulo, pois sabemos que Santander possui aproximandamente $35 \mathrm{~km}^{2}$ e 175 mil habitantes ${ }^{1}$.

Uma solução diferente da implantação de testbeds como ambiente de experimentação no contexto de plataformas de Cidades Inteligentes foi apresentada em Ali et al., 2015. O CityBench é um benchmark para motores de processamento de fluxo de dados (streaming) presentes nesse tipo de plataforma. Esse becnhmark foi construído através do fluxo de dados em tempo real de múltiplos sensores implantados na cidade de Aarhus na Dinamarca. Essa é uma abordagem interessante, onde seria possível coletar dados em escalas maiores, adicionar dados referentes a mobilidade, de dispositivos heterogeneos, permitindo o acesso concorrente e a reprodutibilidade. Contudo, esse tipo de abordagem não permite que a plataforma interaja com o ambiente de experimentação em tempo de execução, invialibilizando experimentos envolvendo comandos de atuação, por exemplo. Concebemos que para a criação desse conjunto de dados para a contrução do benchmark é necessário ter acesso a dispositivos reais implantados em testbeds reais.

\footnotetext{
${ }^{1}$ https://pt.wikipedia.org/wiki/Santander_(Cant\%C3\%A1bria)
} 
A título de ilustração apresentamos a Tabela 2.1, com um levantamento das principais características que constam nos trabalhos aqui mencionados. Características de cada um dos ambientes de experimentação:

- Uso de dispositivos de IoT: indica se o ambiente de experimentação faz uso ou não de dispositivos reais de IoT.

- Uso de simulação: indica se a simulação é uma técnica utilizada pelo ambiente de experimentação.

- Implantação em laboratório: aponta se o ambiente foi implantado em um ambiente controlado de laboratório, fazendo referência a ambiente fechados (indoor).

- Implantação em ambiente externo: aponta se o ambiente foi implantado em uma área aberta, onde os dispositivos e infraestrutura estão expostos a intempéries.

- Larga escala: sinaliza se o ambiente é considerado de larga escala pelos autores do trabalho, não sendo necessariamente o ponto de vista apresentado neste trabalho, como pode ser visto na discussão feita anteriormente.

- Execução de comandos de atuação: assinala se o ambiente permite a execução de comandos de atuação em tempo de execução, sendo indicado apenas os trabalhos que apresentaram tal característica em suas publicações. Ou seja, alguns dos trabalhos não indicados ainda podem possuir essa capacidade, contudo, a mesma não foi apresentada de forma clara.

\begin{tabular}{|c|c|c|c|c|c|c|}
\hline $\begin{array}{c}\text { Ambiente de } \\
\text { Experimentação }\end{array}$ & $\begin{array}{c}\text { Uso de } \\
\text { dispositivos de IoT }\end{array}$ & $\begin{array}{c}\text { Uso de } \\
\text { simulação }\end{array}$ & $\begin{array}{c}\text { Implantação em } \\
\text { laboratório }\end{array}$ & $\begin{array}{c}\text { Implantação em } \\
\text { ambiente externo }\end{array}$ & $\begin{array}{c}\text { Larga } \\
\text { escala }\end{array}$ & $\begin{array}{c}\text { Execução de } \\
\text { comandos de atuação }\end{array}$ \\
\hline I3ASensorBed & $\mathbf{x}$ & $\mathbf{x}$ & $\mathbf{x}$ & $\mathbf{x}$ & & \\
\hline Padova Smart City & $\mathbf{x}$ & & & $\mathbf{x}$ & & $\mathbf{x}$ \\
\hline FIT IoT-LAB & $\mathbf{x}$ & & & $\mathbf{x}$ & $\mathbf{x}$ & \\
\hline City of Things & $\mathbf{x}$ & $\mathbf{x}$ & & $\mathbf{x}$ & & $\mathbf{x}$ \\
\hline Smart Berlin Testbed & $\mathbf{x}$ & & & $\mathbf{x}$ & $\mathbf{x}$ & $\mathbf{x}$ \\
\hline SmartSantander & $\mathbf{x}$ & & & $\mathbf{x}$ & $\mathbf{x}$ & \\
\hline SmartCampus & $\mathbf{x}$ & & & & & \\
\hline $\begin{array}{c}\text { Birmingham Urban } \\
\text { Climate Laboratory }\end{array}$ & $\mathbf{x}$ & & & $\mathbf{x}$ & & \\
\hline SmartGridLab & $\mathbf{x}$ & & & $\mathbf{x}$ & $\mathbf{x}$ & \\
\hline Street Light Poles & $\mathbf{x}$ & & & & $\mathbf{x}$ & \\
\hline OpenMTC & $\mathbf{x}$ & & & & $\mathbf{x}$ & \\
\hline CityBench & & & & & & \\
\hline
\end{tabular}

Tabela 2.1: Caracterização dos trabalhos relacionados

Podemos ver na Tabela 2.1 que praticamente todos os ambientes de experimentação apresentados fazem uso de dispositivos reais de IoT em ambientes externos, fica evidente que seus autores querem reproduzir ao máximo um ambiente real. Os poucos trabalhos que fazem uso de simulação, utilizam-se dessa técnica para auxiliar em contextos específicos, como por exemplo, para simular diversas topologias de rede em um dado cenário. Um trabalho que nos chamou bastante a atenção foi o CityBench, onde não é feito uso de dispositivos reais ou simulação e mesmo assim permite a realização de experimentos em larga escala. Todavia, como discutido anteriormente, o mesmo não permite a interação necessária em ambientes reais. Uma pequena quantidade dos ambientes apresentados 
permitem a execução de comandos de atuação durante experimentos, porém todos os trabalhos que disponibilizam tal funcionalidade demandaram grandes investimentos, fator limitante.

Como pode ser visto, a maioria dos estudos apresentados não provê um ambiente de experimentação para plataformas de Cidades Inteligentes que permita a interação em tempo de execução, possibilitando atuação durante o experimento. As soluções apresentadas não são capazes de realizar experimentos na escala de grandes metrópoles do mundo, como a cidade de São Paulo, apesar de alguns autores afirmarem que os ambientes são de larga escala. Sendo assim, identificamos o potencial deste trabalho: a busca por uma solução viável aos problemas apresentados e os desafios propostos para construção desse ambiente de experimentação através de simulação.

\subsection{Simulação e Cidades Inteligentes}

Devido à complexidade de construção de ambientes de experimentação para plataformas de Cidades Inteligentes apresentada na seção anterior, propomos a utilização de simulação visando solucionar principalmente o problema da escalabilidade e do custo. Além disso acreditamos que ao utilizar essa abordagem, possibilita-se a adição de comandos de atuação no ambiente de experimentação, em tempo de execução, sendo essa uma funcionalidade não apresentada por grande parte de outros trabalhos.

A simulação já vem sendo utilizada na área de Cidades Inteligentes há algum tempo, sobretudo na área de Smart Grid. Em TsAmPASIs et al., 2016, um framework para simulação de smart grid é apresentado visando integrar a modelagem, a contrução e o controle da execução, além de desacoplar o simulador de rede ou de energia desse processo. Esse simulador foi implementado usando componentes discretos. Já em ScHüтte et al., 2011, outro framework de simulação para smart grid foi introduzido. Contudo, o objetivo principal desse trabalho é conseguir integrar modelos de simulação heterogêneos automaticamente em tempo de execução. Ambos os trabalhos não tentam desenvolver modelos de simulação no contexto de Cidades Inteligentes, mas sim integrar modelos existentes e facilitar o processo de desenvolvimento.

Simulação é um tópico em discussão na área de IoT, já que a validação das novas tecnologias dessa área em diferentes cenários é um requisito importante para sua adoção. Os simuladores utilizados na área de IoT são divididos em três categorias segundo CHERNYSHEV et al., 2018: (i) simuladores completos, que visam prover um suporte de ponta a ponta para todos os elementos de IoT; (ii) simuladores com foco em aspectos de processamento de big data; e (iii) simuladores de rede de comunicação. Neste trabalho focamos principalmente na categoria (ii), gerando uma grande massa de dados para plataformas. A simulação de IoT introduz várias questões de aspectos quantitativos e qualitativos (D'ANGELo et al., 2016), a quantidade massiva e a heterogeneidade de dispositivos dificultam essa tarefa. A simulação distribuída e paralela baseada em agentes é o melhor mecanismo para contornar os problemas mencionados (D’ANGELo et al., 2016), já que a possibilidade de execução distribuída e paralela permite a execução de mais elementos dentro da simulação, e a definição de agentes facilita a representação de diferentes dispositivos.

Simuladores de IoT tradicionais não focam na simulação de ambientes de larga es- 
cala (Brambilla et al., 2014). A grande maioria deles são simuladores de rede, que analisam e avaliam o comportamento de objetos inteligentes organizados em uma topologia específica. Como vem sendo discutido, Cidades Inteligentes, em geral, contemplarão ambientes de larga escala, sendo necessário avaliar as plataformas em tais condições. O DEUS é um ambiente de simulação de Cidades Inteligentes de propósito geral, baseado em eventos discretos, que tenta atender principalmente a requisitos de mobilidade e escalabilidade (PICONE et al., 2012). Apesar de um modelo de mobilidade interessante ter sido implementado no DEUS, o experimento apresentado não é de larga escala, atingindo o máximo de 2 mil nós (PiCOne et al., 2012). Por esse motivo, não conseguimos concluir se o DEUS é uma solução viável quanto à escala do ambiente simulado.

Sabendo que o contexto de Cidades Inteligentes envolve múltiplas áreas do conhecimento, ambientes de simulação realísticos muitas vezes podem envolver mais de um simulador. O TraNS é um ambiente de simulação de código aberto que tem como objetivo viabilizar experimentos com VANETs (Vehicular Ad Hoc Networks) (PIóRKowski et al., 2008). Para isso, nessa pesquisa, o simulador de mobilidade SUMO e o simulador de rede NS2 foram integrados para construção desse ambiente realista. O interessante dessa integração é o fato dos simuladores serem capazes de se comunicarem em tempo de execuação, sendo essa a abordagem que implementamos para permitir a interação entre a plataforma e o simulador de Cidades Inteligentes.

A simulação é um mecanismo que vem sendo adotado na área de IoT e, mais especificamente, em Cidades Inteligentes. O objetivo principal é tentar solucionar problemas de escala. A literatura indica que a simulação baseada em agentes e eventos discretos de maneira paralela e distribuída seja o caminho para obtermos uma solução efetiva para simularmos um ambiente como o encontrado em Cidades Inteligentes. Ademais, ficou demonstrado que a simulação pode ser o mecanismo ideal para utilizarmos na contrução do ambiente de experimentação para plataformas de Cidades Inteligentes, permitindo a criação de um ambiente de larga escala e a interação em tempo de execução com outros componentes.

\subsection{Integração de Ferramentas para prover Ambiente de Experimentação}

A abordagem proposta em nosso trabalho envolve a integração entre uma plataforma e um simulador de Cidades Inteligentes. Conforme discussão neste capítulo, a simulação é um mecanismo que pode nos auxiliar na obtenção de ambientes de experimentação de larga escala e que nos permita interagir e atuar em tempo de execução. Entretanto, a integração de sistemas de software não é uma tarefa trivial. A integração de sistemas possui três dimensões: dados, controle e apresentação (WASSERmAn, 1990). Neste trabalho, realizamos a integração nas dimensões de dados e controle. O principal desafio nesse processo de integração é o fato dela ser feita, geralmente, de maneira $a d-h o c$, não havendo uma padronização (WASSERMAN, 1990).

A integração de sistemas tem sido objeto de pesquisa na área de sistemas de informação, visando integrar principalmente dados de múltiplas fontes heterogêneas distribuídas para apresentá-los de forma centralizada e homogênea (GENESERETH et al., 1997). Esse interesse 
surge essencialmente pela necessidade de empresas integrarem seus diversos sistemas para gerar conhecimento baseado em seus dados. Segundo a experiência de pessoas envolvidas com a industria, dois dos principais problemas nesse tipo de integração são o desempenho e a escalabilidade da solução, como apresentado em HAlEvy et al., 2005.

Apesar de padronização parecer ser a solução para o problema de integração de sistemas, ela não é tão simples, por conta dos diferentes propósitos e naturezas dos sistemas. Um trabalho interessante na área de Cidades Inteligentes, especificamente de VANETs, resultou em uma técnica para interconectar simuladores de rede e de trânsito chamada TraCI (Wegener et al., 2008). Devido o vasto número de simuladores desse tipo, foi proposto a implementação de uma interface para cada um dos simuladores, encapsulando o funcionamento dos mesmos. Ao implementar tais interfaces, elas se comunicam através de um protocolo, baseado em cliente-servidor, desenvolvido especificamente para comunicação entre simuladores de rede e de trânsito. Portanto, essa é uma técnica que independe do simulador a ser utilizado, bastando implementar essa interface que se comunicará através de um protocolo específico. Essa experiência nos serviu de inspiração, já que a nossa solução se baseia na integração de uma plataforma e um simulador de Cidades Inteligentes. Todavia, a definição de uma interface específica e de protocolo de comunicação introduzidos pela TraCI só foi possível porque o escopo foi reduzido para VANETs. Como esta pesquisa visa construir um ambiente de experimentação de âmbito geral no contexto de Cidades Inteligentes, desenvolvemos uma arquitetura com diretrizes para implementação de um componente de integração entre os dois sistemas. 



\section{Capítulo 3}

\section{Proposta de Solução}

A solução proposta para permitir a realização de experimentos de plataformas de Cidades Inteligentes em ambientes simulados abrangendo diferentes cenários em diferentes escalas será apresentada neste capítulo. A discussão sobre os requisitos de uma possível solução para esse problema será realizada, levando em consideração as principais dificuldades para a criação de um ambiente como esse. Além disso, uma arquitetura de software para uma solução será apresentada.

\subsection{Requisitos da Solução}

Para a realização de experimentos em ambientes simulados de Cidades Inteligentes temos requisitos em diferentes níveis, desde a capacidade do simulador de representar o contexto de uma cidade, até formas de comunicação que permita a interação entre o simulador e a plataforma de Cidades Inteligentes. Portanto, dividimos os requisitos em fundamentais e de integração.

Para que o simulador possa refletir o contexto de Cidades Inteligentes, onde o sensoriamento de diversos aspectos das cidades já é uma realidade, e a atuação (modificação do estado das cidades) segue uma crescente, consideramos que o simulador possua os conceitos abaixo representados:

- Modelos aderentes à realidade de uma cidade: o simulador deve implementar modelos que representem ao máximo a realidade de uma cidade, e não apenas casos hipotéticos. Por exemplo, modelos de fluxo de automóveis nas vias devem incluir possíveis engarrafamentos.

- Tempo de execução igual ao tempo real: a dinâmica da cidade deve ser simulada em tempo real, ou seja, não deve ser executada nem mais rápida nem mais lenta do que aconteceria em um ambiente real de uma cidade (um segundo na simulação é aproximadamente igual a um segundo real). Esse é um requisito importante, pois o desencadeamento de eventos nas cidades são muitas vezes devido ao processamento de eventos acontecidos anteriormente, e as plataformas devem ter tempo hábil para realizar tais ações, se aproximando as condições que serão enfrentadas no contexto 
real de uma cidade.

- Geração de grande massa de dados: para realizarmos experimentos realistas devemos ser capazes de gerar uma massa de dados na mesma escala de uma grande cidade. Experimentos em escalas menores são úteis na validação de certos cenários, contudo não exercita uma plataforma de Cidades Inteligentes em um contexto real, onde deverá interagir com milhões de sensores, atuadores e usuários.

- Comunicação em tempo de execução: para que esse ambiente integrado seja viável, ambas as ferramentas devem ser capazes de se comunicarem em tempo de execução. Com isso, se torna possível o envio de dados de sensores e comandos de atuação durante a simulação.

Consideramos os pontos apresentados como requisitos fundamentais, o mínimo necessário para conseguirmos de fato representar um ambiente real de uma cidade. Destacamos a necessidade do último ponto ser atendido por ambas as ferramentas. Caso a ferramenta atenda aos requisitos apresentados, se torna possível a simulação de cenários realistas no contexto de Cidades Inteligentes, podendo substituir testbeds reais, em uma escala maior, após a sua integração com a plataforma alvo. Todavia, essa simulação não viabiliza, ainda, a realização de experimentos com plataformas. Para tanto, precisamos atender alguns requisitos de integração entre o simulador e a plataforma em questão.

Para termos um ambiente integrado precisamos definir um meio de comunicação de duas vias, envio e recebimento de dados, em tempo real entre o simulador e a plataforma de Cidades Inteligentes. Além disso, deve haver uma integração semântica e de protocolos de rede que permita às ferramentas se comunicarem de maneira eficaz. Apresentamos a seguir os requisitos de integração necessários para obtermos um ambiente integrado de experimentação para essas plataformas:

- Integração semântica: para que seja possível a comunicação em tempo de execução entre o simulador e a plataforma, ambos precisam entrar em um consenso semântico. Abaixo são apresentados os dois principais conceitos envolvidos e que acreditamos que seja necessário serem representados de alguma forma nas duas ferramentas para que seja possível essa integração.

- Recursos da cidade: qualquer coisa no contexto da cidade (automóveis, aparelhos públicos, vias e etc.), serão objetos de sensoriamento e/ou atuação por parte das plataformas de Cidades Inteligentes.

- Capacidades inerentes a cada recurso da cidade: cada recurso da cidade tem as suas respectivas capacidades, sendo elas de sensoriamento ou de atuação. Essas capacidades usualmente estão atreladas a dispositivos heterogêneos de IoT (Internet Of Things) presentes nos recursos da cidade. Por exemplo, vagas de estacionamento podem ser monitoradas quanto a sua ocupação e semáforos de trânsito podem ter o seu estado modificado através de atuação.

- Interoperabilidade de protocolos de comunicação: as duas ferramentas não precisam ter conhecimento da implementação entre elas para conseguir trocar mensagens.

- Envio de dados de sensoriamento em tempo real: para que as funcionalidades relativas a coleta, armazenamento e processamento de dados possam ser exercitadas pela 
plataforma, precisamos enviar dados de todos os recursos presentes no cenário de experimentação com tais capacidades em tempo real. Quanto maior for a escala do cenário de experimentação mais difícil se torna essa tarefa, pois se faz necessário enviar milhões de dados de sensores simultaneamente através do mesmo canal. Apesar da demanda de tempo real poder tornar-se um problema, ela se faz necessária para que possamos chegar mais próximo de um cenário realista, ou seja, onde recursos sensoriados da cidade poderão não aguardar outros enviarem seus dados, enviando simultaneamte.

- Recebimento de dados de atuação em tempo real: em alguns cenários de experimentação, as plataformas precisarão enviar comandos de atuação para a cidade (neste caso, para o ambiente simulado) em tempo real. Diferente dos dados de sensoriamento, o fluxo de dados de atuação é bem menor. Contudo, esse tipo de dado tem a sua própria peculiaridade, pois o simulador deve ser capaz de consumir esse dado em tempo de execução e alterar o estado do ambiente simulado imediatamente. Isso porque ao modificar de alguma forma o estado do ambiente simulado, influenciamos diretamente os dados de sensores a partir daquele dado momento, e os mesmos continuam sendo enviados para a plataforma em paralelo.

Acreditamos que ao termos um ambiente que atenda tanto os requisitos fundamentais quanto os de integração, se torna possível realizarmos experimentos de larga escala e interativos com plataformas de Cidades Inteligentes sem a necessidade de testbeds reais. Os requisitos fundamentais auxiliarão principalmente na escolha do simulador a ser utilizado, já que, em sua maioria, são requisitos associados à capacidade do simulador de representar um ambiente de Cidades Inteligentes de maneira realista. Já os requisitos de integração serão atendidos pela arquitetura apresentada na seção seguinte. Um ambiente que atenda os requisitos expostos nesta seção nos possibilita realizar experimentos em escalas reais de uma cidade, além de nos permitir simular cenários que ainda não são passíveis de reprodução através de testbeds, simulando tecnologias ainda não existentes e cenários futuristas. Como exemplo, citamos a possibilidade de simularmos um ambiente onde todos os carros da cidade são autônomos e se comunicam através de tecnologia $5 G$.

\subsection{Arquitetura}

Uma arquitetura de software foi desenhada visando atender principalmente os requisitos de integração para construção de um ambiente simulado de experimentação para plataformas de Cidades Inteligentes, e será apresentada nesta seção. Define-se que uma arquitetura de software para um sistema é a estrutura ou estruturas do sistema, que compreende elementos seu comportamento externamente visível e as relações entre eles (Clements et al., 2002). A integração entre sistemas como apresentado no decorrer deste trabalho é uma tarefa complexa e demanda um projeto de software bem elaborado para que seja manutenível a longo prazo.

A solução proposta visa integrar uma plataforma a um simulador de Cidades Inteligentes com a finalidade de permitir experimentos de larga escala e interativos. A integração é feita em duas dimensões: dados e controle. Permitimos a troca de dados em tempo real entre as duas ferramentas, bem como a plataforma controlar e interferir em eventos durante 
a simulação. Grosso modo, a troca de dados permite principalmente simular dispositivos de IoT enviando dados para a plataforma e executar comandos de atuação, sendo esse o meio de alterar o estado da simulação.

Diante da constatação apresentada na literatura, de que simuladores baseados em agentes e eventos discretos são o caminho para uma solução efetiva, decidimos que a arquitetura aqui apresentada será baseada em eventos. Essa arquitetura (Event-Driven Architecture) é um padrão arquitetural que é aplicado no projeto e implementação de sistemas que transmitem eventos entre os componentes e serviços fracamente acoplados ${ }^{1}$ Esse tipo de arquitetura é capaz de detectar eventos e reagir de maneira inteligente (TAYLOR et al., 2009). Toda e qualquer ação que modificar o estado da simulação será considerado um evento. Baseado nesses eventos, a integração envolvendo dados e controle do sistema será realizada.

\subsubsection{Integração Simulador-Plataforma}

A integração entre simulador e plataforma de Cidades Inteligentes envolve principalmente a troca de dados em tempo de execução como foi apresentado neste capítulo. Essa interação para envio e recebimento de dados, à primeira vista simples, se torna complexa quando adicionamos a necessidade de resposta de ambas as partes em tempo real. Por parte do simulador, a rápida reação ao receber um comando de atuação é essencial, sendo esses comandos caracterizados como eventos de atuação. O recebimento desse dado acarretará em uma atualização no estado da simulação, que por sua vez terá impacto direto no pronto envio de dados de sensores. Já para a plataforma, é necessária uma tomada de decisão ágil ao receber diferentes dados de sensores, sendo esses considerados eventos de sensoriamento. Os dados de sensores podem ser, por exemplo, utilizados como entrada para gatilhos de comandos de atuação e processamento em tempo real de eventos complexos.

Além desse desafio, enfrentamos também problemas de interoperabilidade entre o simulador e a plataforma. Usualmente, os conceitos presentes no projeto de cada uma das ferramentas divergem, e essa camada de integração deve ser capaz de traduzir essa semântica para ambas as ferramentas. Outro problema relacionado à interoperabilidade é a forma de transmissão desses dados, mais especificamente os protocolos de comunicação a serem utilizados. Por exemplo, o simulador pode suportar apenas comunicação via protocolo AMQP (Advanced Message Queuing Protocol) e a plataforma prover uma API Restful e conexões via MQTT (Message Queuing Telemetry Transport). Mais uma vez, é papel da camada de integração tornar essa comunicação transparente para ambos os lados, ou seja, a ferramenta não deve se preocupar com qual protocolo será utilizado pela outra e vice-versa.

Diante dessa constatação, a arquitetura de integração adotada utiliza-se de um componente extra intermediando as duas ferramentas, simulador e plataforma, como pode ser visto na Figura 3.1. Apesar de um componente extra adicionar complexidade e consequentemente aumentar o tempo gasto no tratamento desses eventos, ele se faz necessário para solucionar os problemas de interoperabilidade mencionados anteriormente. Entretanto, ele

\footnotetext{
${ }^{1}$ https://en.wikipedia.org/wiki/Event-driven_architecture
} 
deve ser o mais simples possível para que o acréscimo no tempo de envio e recebimento dos dados não aumente consideravelmente. Portanto, utilizar ferramentas (simulador e plataforma) que se assemelhem conceitualmente e que compartilhem pilhas de protocolos de comunicação similares é o ideal, podendo inclusive tornar o componente de integração opcional dentro da arquitetura proposta.

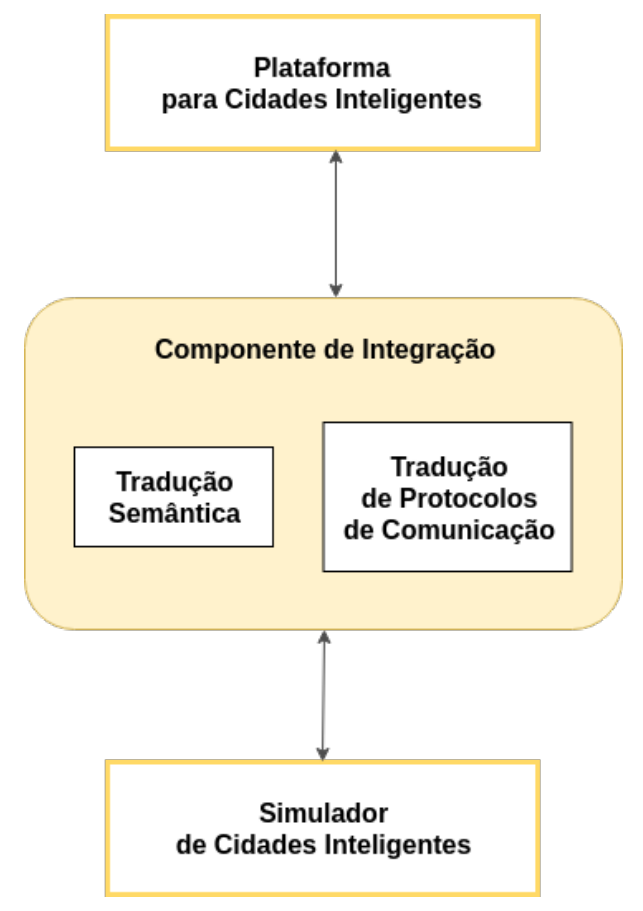

Figura 3.1: Arquitetura Proposta para Ambiente Integrado de Exerimentação de Plataformas de Cidades Inteligentes

Na Figura 3.1, podemos ver os componentes presentes na arquitetura de integração do sistema aqui apresentada. Como elucidado anteriormente, o componente de integração não pode possuir muitas responsabilidades, já que uma complexidade alta pode acarretar em um aumento expressivo no tempo de transmissão dos dados, sendo esse um requisito importante para o sistema. Com relação a plataforma e o simulador envolvidos, esperamos que as ferramentas possuam um módulo de comunicação para suportar o fluxo de dados em tempo de execução.

O componente de integração tem a responsabilidade de solucionar os pontos mencionados anteriormente:

- Tradução semântica entre o simulador e a plataforma

- Interoperação entre protocolos de rede

- Interferência mínima no tempo de envio e recebimento de dados

A interoperabilidade semântica é um problema recorrente na área de Internet das Coisas, haja vista que a heterogeneidade das "coisas" faz a interoperabilidade entre elas um desafio (BARNAGHI et al., 2012). Na arquitetura do ambiente de experimentação aqui apresentado, esse problema tende a ser minimizado, já que temos apenas duas fontes de dados que podem divergir, o simulador e a plataforma. Isso considerando que uma 
mesma ferramenta não possui várias representações semânticas. A representação formal baseada em formatos interpretados por máquina vem sendo considerada uma técnica promissora para integração semântica (BARNAGHI et al., 2012). Todavia, dependendo do nível de compatibilidade das ferramentas, soluções mais simples podem ser adotadas. A realização de simples transformações das mensagens em funções implementadas no componente de integração realiza o mapeamento direto dos conceitos, dado o exemplo. Esse mapeamento direto para transformação de protocolos de rede utilizados pelas ferramentas também é válido, pois o componente de integração pode receber uma mensagem em um protocolo e em seguida repassá-la, após uma possível tradução semântica, através de outro protocolo.

A Figura 3.2 apresenta a sequência de atividades a serem realizadas no momento em que um evento de sensoriamento é gerado pelo simulador. Considerando o ciclo de simulação um atributo que descreve o estado da simulação, e sabendo que um ciclo de simulação corresponde a um segundo, eventos desse tipo podem ser gerados de forma temporizada. Nessa situação, podemos enviar dados de sensores no momento $N$ e quando o estado da simulação mudar e estivermos no ciclo de simulação $N+10$ gerarmos outro evento de sensoriamento. O diagrama de sequência apresentado descreve as atividades a serem realizadas quando um evento do tipo sensoriamento for gerado pelo simulador de Cidades Inteligentes. Inicialmente, após a geração de um evento de sensoriamento, uma mensagem contendo informações sobre o mesmo deve ser enviada para o componente de integração. Ao receber essa mensagem, o componente de integração deve realizar a tradução semântica e de protocolo de rede, caso sejam necessárias, e enviar a mensagem com o evento traduzido para a plataforma. Em um cenário ideal o simulador e a plataforma já possuem compatibilidade semântica e na pilha de protocolos de comunicação, não sendo necessário o componente de integração.

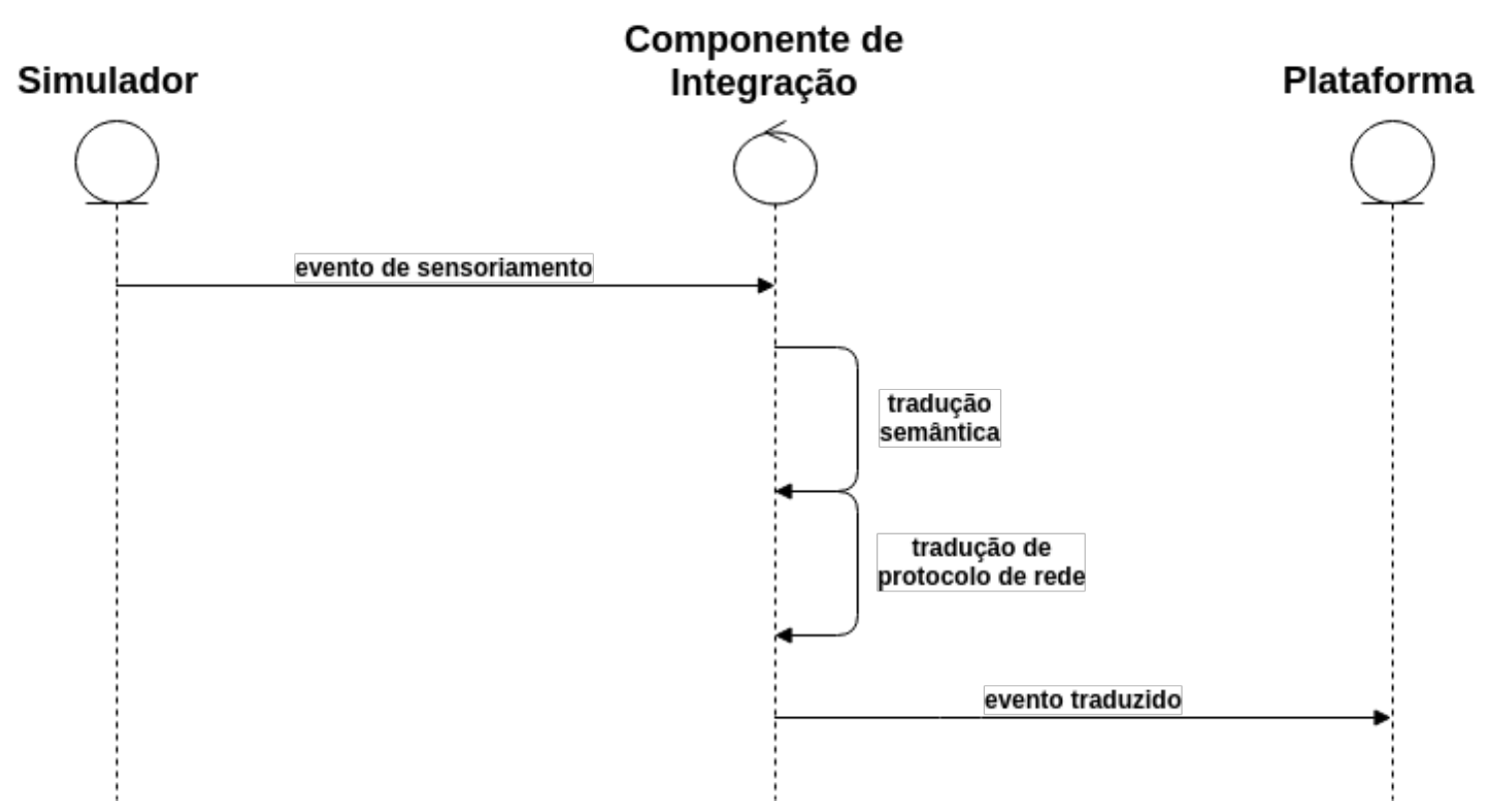

Figura 3.2: Diagrama de sequência para uma evento de sensoriamento

Já na Figura 3.3 outro diagrama de sequência é representado, porém, desta vez demonstrando as atividades a serem executadas quando um evento de atuação é gerado pela 
plataforma. Como já foi mencionado, a partir de uma mudança no estado do ambiente simulado de uma cidade pode surgir a necessidade de atuação. Essa atuação é uma ação que irá interferir no ambiente simulado visando modificar o seu estado de alguma forma. Um exemplo simples no contexto de uma cidade seria um pedestre que deseja atravessar a rua, chegar em um semáforo e, quando isso ocorrer, mudar o estado do semáforo, permitindo a sua passagem. Nesse caso, uma mudança no estado da cidade (chegada do pedestre ao semáforo) foi um gatilho para outra mudança de estado (mudança do semáforo). Similar ao diagrama de sequência apresentado na Figura 3.2, uma mensagem contendo informação sobre o evento de atuação é enviado para o componente de integração, ele traduz semanticamente e o protocolo de rede, caso sejam necessários, e envia essa mensagem traduzida para o simulador.

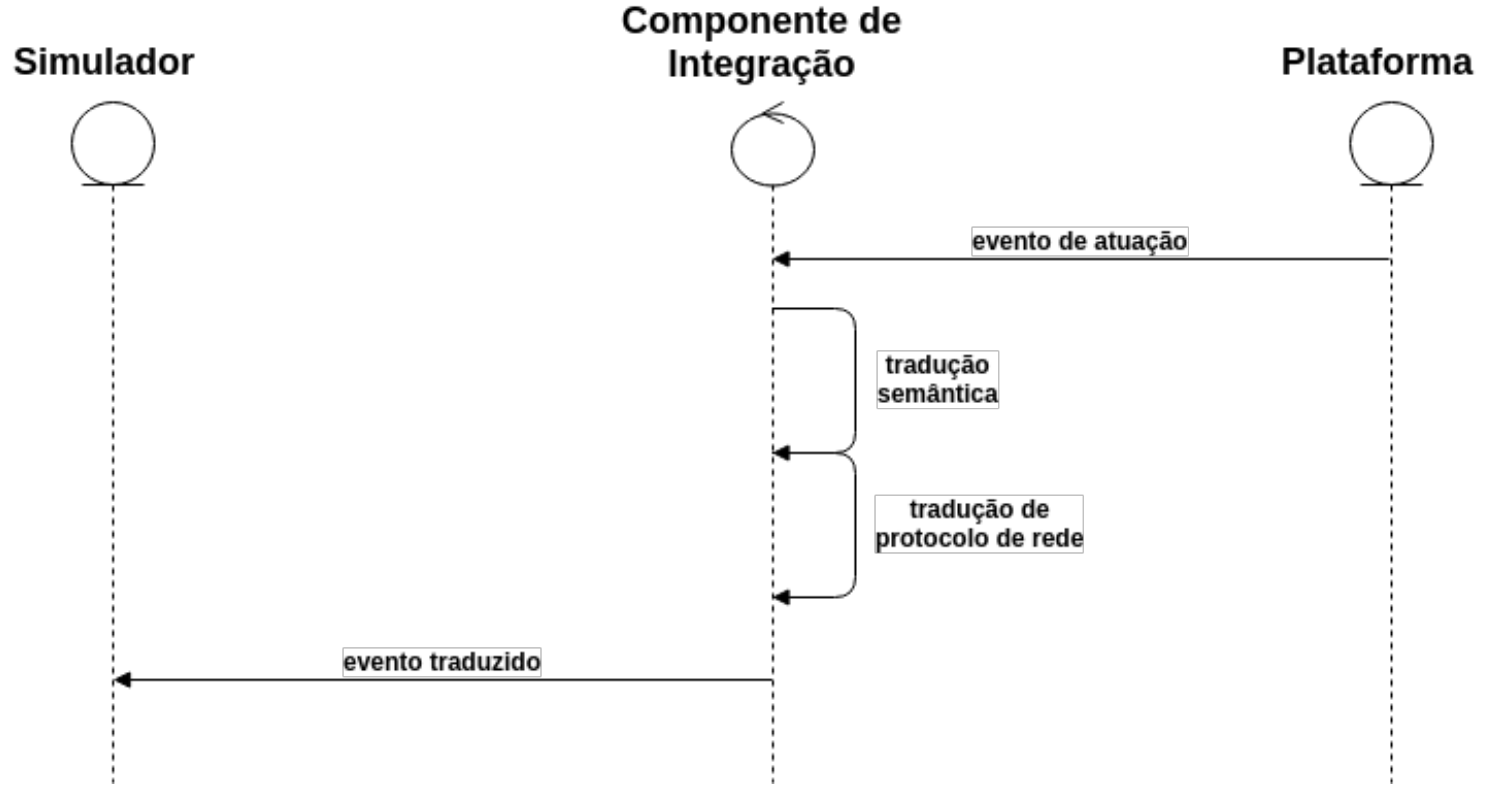

Figura 3.3: Diagrama de sequência para uma evento de atuação

É possível visualizar que o componente de integração tem como único objetivo atender requisitos não funcionais. Ele deve tornar a comunicação do simulador e da plataforma transparente para ambos e adicionando a menor complexidade possível ao sistema. Sendo comunicação transparente a não necessidade de conhecimento da outra ferramenta para se comunicar com ela, já que o componente de integração irá tornar essa troca de mensagens de eventos interoperável.

Em resumo, devemos escolher ferramentas (simulador e plataforma) mais semelhantes possíveis, com o que diz respeito principalmente ao modelo conceitual e aos protocolos de rede utilizados para comunicação; e implementar o componente de integração o mais simples possível, apenas com o objetivo de viabilizar a comunicação entre as ferramentas. 



\section{Capítulo 4}

\section{Estudos de Caso}

Com o intuito de validar a arquitetura proposta foram realizados dois estudos de caso envolvendo diferentes cenários de Cidades Inteligentes em um ambiente simulado de experimentação. Priorizamos implementar cenários de experimentação onde pudéssemos explorar todos os requisitos apresentados no Capítulo 3. Através desses dois experimentos, pudemos validar a solução apresentada para construção de um ambiente simulado de experimentação para plataformas de Cidades Inteligentes. Foi possível exercitar as principais funcionalidades necessárias para a realização de experimentos desse tipo, através da integração do InterSCSimulator e a plataforma InterSCity.

No primeiro cenário, realizamos experimentos no contexto de estacionamento inteligente (conhecido como Smart Parking), onde carros circulam pela cidade e, ao final do seu percurso, procuram por uma vaga de estacionamento disponível mais próxima do seu destino, utilizando-se da plataforma para isso. Nesse cenário, incluímos um novo agente à simulação e implementamos um mecanismo para publicação dos eventos ocorridos e requisição a serviços da plataforma em tempo real e de forma assíncrona.

O segundo cenário de experimentação envolve o tráfego de carros inteligente através da utilização de Placas de Mensagens Variadas (PMVs) espalhadas pela cidade. Nesse cenário, a plataforma identifica trechos de maior trânsito e atua na cidade atualizando as mensagens apresentadas pelas PMVs em tempo real, notificando os motoristas da lentidão no trecho, que por sua vez podem recalcular a sua rota evitando congestionamentos. Para viabilizar esse experimento fizemos uso das melhorias implementadas no primeiro cenário acrescidas de outras tais como: modificação do modelo de trânsito para melhor se adequar a realidade e implementação do mecanismo de recebimento de comandos de atuação em tempo de execução.

A seguir a arquitetura do simulador InterSCSimulator e da plataforma InterSCity serão apresentadas, haja vista que essas foram as ferramentas utilizadas para o desenvolvimento dos estudos de caso. Além disso, cada um dos cenários de Cidades Inteligentes mencionados serão apresentados detalhadamente, visando exemplificar a implementação da arquitetura proposta e os resultados experimentais obtidos. Ao final, realizaremos uma análise crítica sobre os resultados obtidos, apontando possíveis melhorias a serem feitas. 


\subsection{Ferramentas}

O simulador InterSCSimulator e a plataforma InterSCity serão detalhados quanto as suas respectivas arquiteturas. Faremos uma discussão de como os requisitos fundamentais e de integração apresentados no Capítulo 3 serão atendidos em cada ferramenta.

\subsubsection{InterSCSimulator}

O InterSCSimulator é um simulador de código aberto baseado em agentes para Cidades Inteligentes que oferece uma interface simples para definição de cenários de larga escala (Santana, Lago et al., 2017). Pelo fato de ser possível configurar o tempo que dura um ciclo de simulação na ferramenta, ela já atende um dos requisitos fundamentais descritos na Seção 3.1. Com isso, podemos dizer que um ciclo de simulação é igual a um segundo real. É sabido que é necessário termos uma execução com noção de tempo real (um segundo de simulação igual a aproximadamente um segundo real) e permitir a interferência em tempo de execução por terceiros para a construção desse ambiente integrado de experimentação.

Para atingir a escalabilidade mencionada, o InterSCSimulator foi implementado usando a linguagem Erlang. Essa é uma linguagem funcional que visa facilitar a implementação de aplicações de larga escala, paralelas e distribuídas. Algumas características herdadas do modelo de atores, que é implementado pelo Erlang, são: paralelismo, execução distribuída, tolerância a falhas e protocolo de comunicação (SANTANA, LAGO et al., 2017). Essa escalabilidade é importante para que possamos atender o requisito fundamental que diz respeito à capacidade de geração de grande massa de dados para a plataforma. O InterSCSimulator é capaz de simular cenários com milhões de agentes executando simultaneamente, possibilitando trabalhar-se em uma escala realista para cidades de grande porte.

O InterSCSimulator foi implementado por Eduardo Zambom Santana, doutorando do nosso grupo de pesquisa, baseado no simulador de âmbito geral Sim-Diasca. A Figura 4.1 representa a sua arquitetura da seguinte forma: em azul estão os diferentes tipos de agentes que podem existir no ambiente simulado e, em vermelho a definição dos cenários de Cidades Inteligentes. Tudo isso sendo executado no topo do simulador Sim-Diasca.

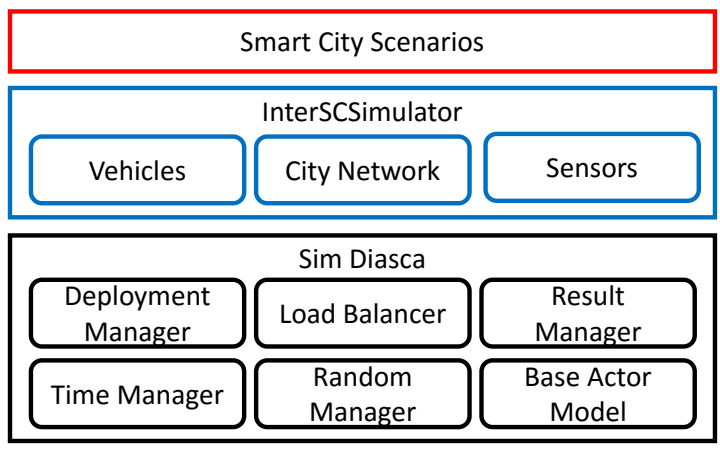

Figura 4.1: Arquitetura do InterSCSimulator

Fazendo um paralelo com um dos requisitos de integração, cada Recurso da cidade 
pode ser modelado como um agente da simulação, ou seja, um carro, uma vaga de estacionamento ou um ponto de parada de ônibus serão representados como agentes (caixas azuis na Figura 4.1). Na definição desses agentes especificamos o seu comportamento a cada passo da simulação. Com isso, podemos descrever quais as Capacidades de cada agente e adotar modelos compatíveis com a realidade das cidades modernas. Por exemplo, podemos determinar que um agente do tipo carro envie sua localização a cada passo da simulação e que ele recalcule a sua rota apenas quando deparado com uma PMV. O interessante dessa arquitetura baseada em agentes é o fato da sua implementação ter um alto grau de independência, onde é preciso apenas a definição das mensagens que serão trocadas em tempo de execução.

No contexto desta dissertação, foi adicionado um novo elemento à arquitetura da ferramenta para troca de dados com sistemas externos em tempo de execução, sendo esse um dos requisitos fundamentais e de integração para obtermos um ambiente realista de experimentação. Esse novo elemento nada mais é do que um novo agente, cujo papel é receber e enviar mensagens de sensores e atuadores, seja no contexto de outros agentes ou de outros sistemas.

Na implementação de um agente do InterSCSimulator, podemos definir diversos comportamentos em diferentes momentos do seu cliclo de vida. É possível especificar o que será feito durante a sua criação, a sua destruição, a sua primeira ação na simulação e durante cada ciclo de execução. Com isso, condições e caminhos dependentes do estado da simulação podem ser definidos para cada um dos tipos de agentes, flexibilizando a implementação dos mais diversos modelos e formas de prover suas capacidades. Essa liberdade para implementação de diversos comportamentos dos agentes nos permite usar modelos realistas e viabilizar as capacidades dos recursos no contexto das cidades, atendendo aos requisitos fundamentais e de integração. Por exemplo, um carro, após a sua partida em direção ao seu destino, calcula a cada ciclo de execução o fluxo de carros na via em que se encontra para o cálculo da sua velocidade naquele instante, além de publicar a sua posição atual. Nesse caso, podemos utilizar os mais diversos modelos matemáticos para calcular o fluxo de carros ou para determinar a sua velocidade, ao passo que a sua capacidade de publicar sua localização georreferenciada também é atendida.

Na Figura 4.2, são apresentados os componentes do simulador. Inicialmente são dadas entradas para a simulação (arquivos XML) que em conjunto formam o cenário a ser simulado. Esse cenário é executado e a saída é criada com todos os eventos ocorridos na simulação. A partir dessa saída, existe a possibilidade de geração de uma visualização em um mapa ou através de gráficos.

Como entrada, o InterSCSimulator recebe três arquivos XML. O config.xml contém parâmetros da simulação: o tempo total, o formato do arquivo de saída e o caminho para o diretório contendo os outros arquivos de entrada e para geração do arquivo de saída. $\mathrm{O}$ grafo representando a infraestrutura rodoviária da cidade é descrito no arquivo map.xml: as vias são representadas pelas arestas e as esquinas entre duas ou mais vias pelos nós. Por fim, as viagens a serem executadas são especificadas no arquivo trips. $x m l$, cada viagem contendo o seu tempo de início, modo de transporte, origem e destino. Todas as ações realizadas pelos agentes são salvas no arquivo output. $x \mathrm{ml}$, podendo haver quatro ações possíveis: 1) início de viagem, 2) saída de uma via, 3) entrada em uma via, e 4) chegada 


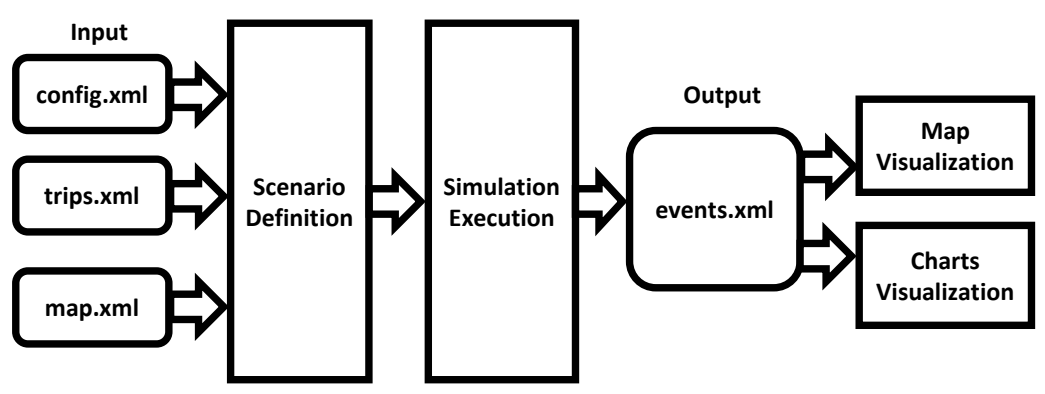

Figura 4.2: Componentes do InterSCSimulator

ao destino final. O tempo, a localização e o modo de transporte utilizado pelo agente são registrados quando essas ações são salvas.

Os modos de transportes suportados até o momento são: carro, ônibus, metrô e a pé. Neste trabalho, além de melhorias feitas nos modelos existentes, novos agentes foram adicionados ao simulador, além da nova possibilidade de publicação e o recebimento de eventos em tempo de execução de maneira assíncrona.

\subsubsection{Plataforma InterSCity}

A plataforma InterSCity é um projeto de código aberto, baseado em microsserviços que visa permitir a pesquisa colaborativa, desenvolvimento e experimentos em Cidades Inteligentes (DeL Esposte et al., 2017). A plataforma foi desenvolvida baseada em uma arquitetura de referência para plataformas de Cidades Inteligentes (SANTANA, CHAVEs et al., 2017), ela provê um conjunto de serviços de alto-nível baseado em nuvem para gerenciar recursos de IoT heterogêneos.

O InterSCity visa solucionar dois dos principais problemas arquiteturais no desenvolvimento de uma plataforma de alta qualidade que possa ser usada na prática, no contexto de Cidades Inteligentes: escalabilidade e evolução do software (DEL Esposte et al., 2017). Escalabilidade é necessária pelo fato da plataforma ter que interagir com um grande número de dispositivos IoT espalhados pela cidade, milhões de usuários e um grande tráfego de dados. Como as cidades mudam constantemente, a questão da evolução é essencial, já que requisitos podem surgir e/ou mudar a qualquer momento. Adaptar a plataforma para modificar e/ou incorporar novas funcionalidades, não deve ser um empecilho. Para resolver esses dois problemas apresentados, foram adotadas as seguintes estratégias:

- Modularidade via microsserviços

- Modelos e dados distribuídos

- Evolução descentralizada

- Reúso de projetos de software livre

- Adoção de padrões abertos

- Comunicação síncrona e assíncrona 
- Serviços livres de estado

A Figura 4.3 apresenta a arquitetura da plataforma InterSCSity. Atualmente, ela é composta de 7 microsserviços: Resource Adaptor, oferece uma abstração para comunicação com os dispositivos IoT; Data Collector, responsável por coletar os dados dos sensores conectados; Actuator Controller, oferece uma interface para atuação junto aos dispositivos de IoT com tal capacidade; Resource Catalog, possui dados estáticos dos recursos da cidade cadastrados; Resource Discovery, provê um serviço de descoberta de recursos; Data Processor, oferece um serviço de processamento de dados em tempo real e histórico; e Resource Viewer, disponibiliza uma visualização simples dos recursos da cidade.

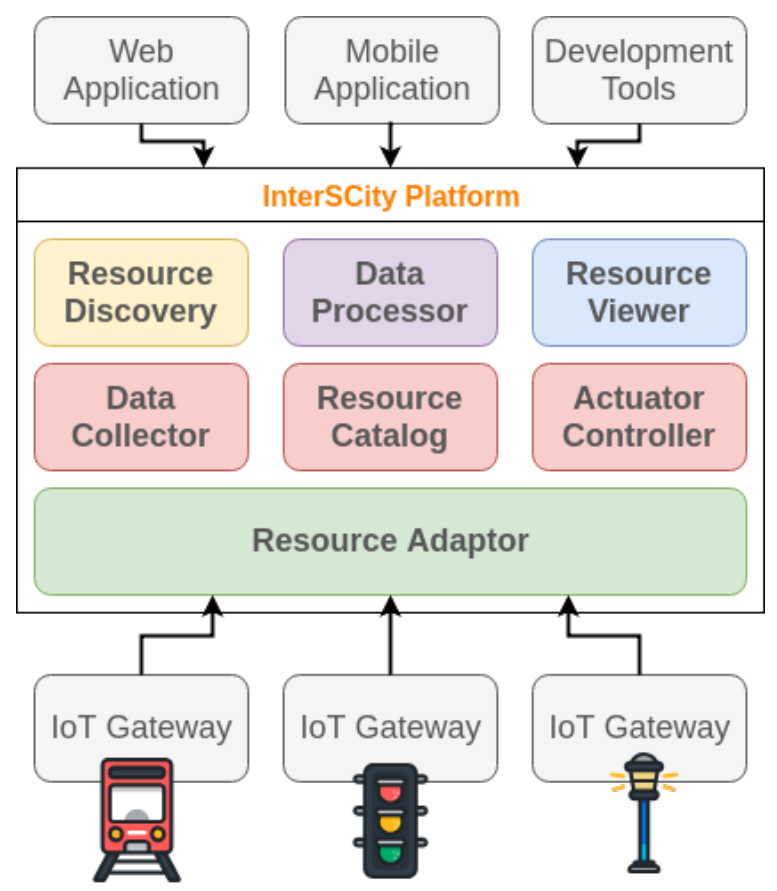

Figura 4.3: Arquitetura da plataforma InterSCity

A comunicação entre esses microsserviços pode se dar de maneira síncrona ou assíncrona, dependendo da situação. A comunicação síncrona é feita via API Restful, ou seja, requisições HTTP; e a assíncrona se dá via RabbitMQ ${ }^{1}$, uma implementação do protocolo AMQP. O objetivo do protocolo AMQP é criar um padrão aberto para troca de mensagens assíncronas interoperável e de larga escala (VInOsKi, 2006). A principal vantagem desse protocolo é permitir que o broker de mensagens tome as decisões de roteamento, não necessitando a aplicação ter conhecimento desse processo (VINOsKI, 2006). Basicamente, componentes que desejam enviar mensagens as enviam para esse broker e ele as encaminha para os componentes que se inscreveram previamente para receber tais mensagens.

A plataforma traz uma abstração chamada Resource, que representa um recurso real da cidade que será de alguma forma conectado a infraestrutura de IoT da cidade, como ônibus, hospital, paradas de ônibus. Cada um desses Resources possuem Capabilities, que podem ser de sensoriamento ou atuação, usualmente vinculados a algum tipo de dispositivo de IoT, como capacidade de medir temperatura ou capacidade de mudar o estado de um

\footnotetext{
${ }^{1}$ https://www.rabbitmq.com/
} 
semáforo. Esses conceitos são os mesmos apresentados na Seção 3.1, como requisitos para a construção de um ambiente integrado de experimentação para Cidades Inteligentes. Como apresentado na seção anterior, semanticamente, esses recursos e capacidades aqui apresentados estarão associados a agentes e à definição de ações durante o seu ciclo de vida no InterSCSimulator.

Nas seções a seguir, serão apresentados os dois estudos de caso envolvendo estacionamento e tráfego de carros inteligente que fizeram uso do InterSCSimulator e da plataforma InterSCity para Cidades Inteligentes.

\subsection{Estacionamento Inteligente}

Neste estudo de caso, simulamos motoristas realizando seus respectivos percursos de carro e ao final procurando uma vaga disponível mais próxima ao seu destino, provavelmente utilizando um aplicativo móvel que se comunica com a plataforma InterSCity. Esse tipo de aplicativo poderia evitar alguns transtornos para os motoristas na árdua missão de estacionar seus carros no centro das grandes metrópoles.

A implementação deste cenário seguindo a arquitetura proposta no Capítulo 3, bem como o experimento realizado, serão discutidos nas seções seguintes.

\subsubsection{Implementação}

Ao resgatar os conceitos de recursos da cidade e capacidades para este cenário, temos os carros e as vagas de estacionamento sendo recursos, onde os carros são capazes de fornecer a sua geolocalização (por exemplo, via GPS) e as vagas de fornecer informação quanto à sua disponibilidade (por exemplo, através de sensores infravermelhos e uma rede de sensores).

Este cenário foi definido com o intuito de realizar experimentos envolvendo o serviço de descoberta de recursos da plataforma InterSCity. Portanto, o aplicativo enviaria a posição do carro naquele momento, o seu destino final e o raio de busca, e a plataforma traria uma lista de vagas de estacionamento disponíveis nas proximidades. Já no InterSCSimulator, foi necessário realizar algumas melhorias para que os requisitos fundamentais fossem atendidos. Um novo agente para gerenciar as vagas de estacionamento da cidade, chamado Parking Controller, foi implementado. Esse agente possui a responsabilidade de gerenciar e armazenar dados referentes às vagas de estacionamento e fazer a interface de comunicação com o componente de integração que será apresentado mais adiante. Além disso, modificamos o modelo de viagem do agente do tipo carro. Anteriormente, o Carro saia de uma origem e percorria o seu trajeto até o destino, agora, ao chegar próximo do seu destino, ele requisita uma vaga disponível mais próxima e se dirige até ela. Com essas melhorias, pudemos simular um cenário que se aproxima da realidade.

Para ilustrar o modelo descrito, apresentamos o ciclo de execução de um agente carro neste cenário:

1. O agente Carro é criado

2. O caminho mais curto entre a origem e o destino é calculado 
3. O agente parte da sua origem no tempo determinado

4. Ao chegar no nó anterior ao seu destino, uma vaga de estacionamento disponível é requisitada ao agente Parking Controller

5. Ao receber a vaga de estacionamento, o seu trajeto é recalculado em direção a ela

6. O agente se direciona e estaciona na vaga descoberta

Um fluxo alternativo a essa execução seria o carro modificar o seu percurso em direção à vaga de estacionamento (disponível até então), e ao chegar a ela outro carro a ter ocupado antes, sendo esse um caso comum nas grandes cidades. Nesse caso, outra vaga de estacionamento é requisitada aumentando o seu raio de busca com o intuito de sempre encontrar vagas disponíveis. Caso o agente do tipo carro necessitar realizar mais de três buscas de vagas disponíveis, o mesmo encerra a sua execução.

Quando o agente Carro por fim estaciona em uma vaga disponível, o agente Parking Controller é notificado e atualiza a sua estrutura de dados indicando que a vaga foi ocupada pelo carro. Esse agente é responsável também por atualizar o estado da vaga de estacionamento na plataforma.

Agora pensando nos requisitos de integração, o simulador precisa requisitar a plataforma em busca de vagas disponíveis mais próximas e atualizar o estado das vagas de estacionamento. A plataforma InterSCity provê uma API Restful para comunicação com seus serviços (como o de descoberta de recursos), e o estado dos seus recursos podem ser atualizados através da própria API ou via protocolo AMQP. Esse levantamento é importante para a tomada de decisão de quais as responsabilidades e como será implementado o componente de integração. Tendo em vista que a complexidade do componente de integração deve ser a menor possível, e a não existência de um meio de publicação de eventos em tempo de execução no InterSCSimulator, decidimos utilizar o RabbitMQ (implementação do protocolo $\mathrm{AMQP}$ ) na implementação desse novo meio de comunicação. Com isso, o simulador pode atualizar o estado das vagas diretamente na plataforma de forma assíncrona, sem necessidade de auxílio do componente de integração. As requisições HTTP feitas ao serviço de descoberta da plataforma foram realizadas pelo componente de integração, principalmente pelo fato de requisições HTTP serem síncronas, o que poderia travar a simulação na espera por uma resposta.

Para facilitar o entendimento da integração realizada, dividiremos a explicação em duas partes: a primeira visando a requisição de vagas disponíveis mais próximas do carro ao serviço de descoberta da plataforma InterSCity; e a segunda apresentando o fluxo de atualização do estado de uma vaga de estacionamento (ocupada ou disponível) baseada na simulação.

A Figura 4.4 apresenta a integração realizada para utilização do serviço de descoberta provido pela plataforma InterSCity. O componente de integração foi chamado de Parking Spot Discoverer, e foi implementado como um agente Erlang que consegue se comunicar com os agentes da simulação via troca de mensagens. $\mathrm{O}$ uso do componente de integração se fez necessário para que a simulação exerça a carga que aplicações exerceriam utilizando o protocolo HTTP para acessar a API Restful, podendo inclusive paralelizar a realização de tais requisições. Como dito, requisições HTTP são síncronas, e sua realização dentro 
da simulação atrasaria consideravelmente a sua finalização. Devido as restrições de ciclo de vida dos agentes da simulação, eles ficariam bloqueados enquanto aguardariam a resposta da plataforma. Antes de chegarmos a tal solução, implementamos uma versão onde o próprio simulador realizava requisições HTTP para a plataforma em tempo de execução, entretanto, essa solução gerou um enorme gargalo. Descrevemos abaixo o fluxo de atividades apresentado na Figura 4.4.

1. Ao chegar a um nó, antes do seu destino, o Car solicita a vaga de estacionamento para o agente Parking Controller, passando a sua localização como parâmetro.

2. O agente Parking Controller envia a localização para o Parking Spot Discoverer que solicita a vaga disponível mais próxima, em um raio de 500 metros.

3. O Parking Spot Discoverer faz uma requisição HTTP para o serviço de descoberta da plataforma que retorna a vaga em questão. Caso não seja encontrada uma vaga disponível (não ocupada) em um raio de 500 metros, esse raio é multiplicado por dois até que se encontre uma vaga disponível.

4. O identificador da vaga é retornado para o agente Parking Controller e ele marca a vaga como utilizada em uma estrutura de dados mantida no simulador.

5. O identificador da vaga é recebido pelo agente Car e a rota é recalculada para chegar até ela.

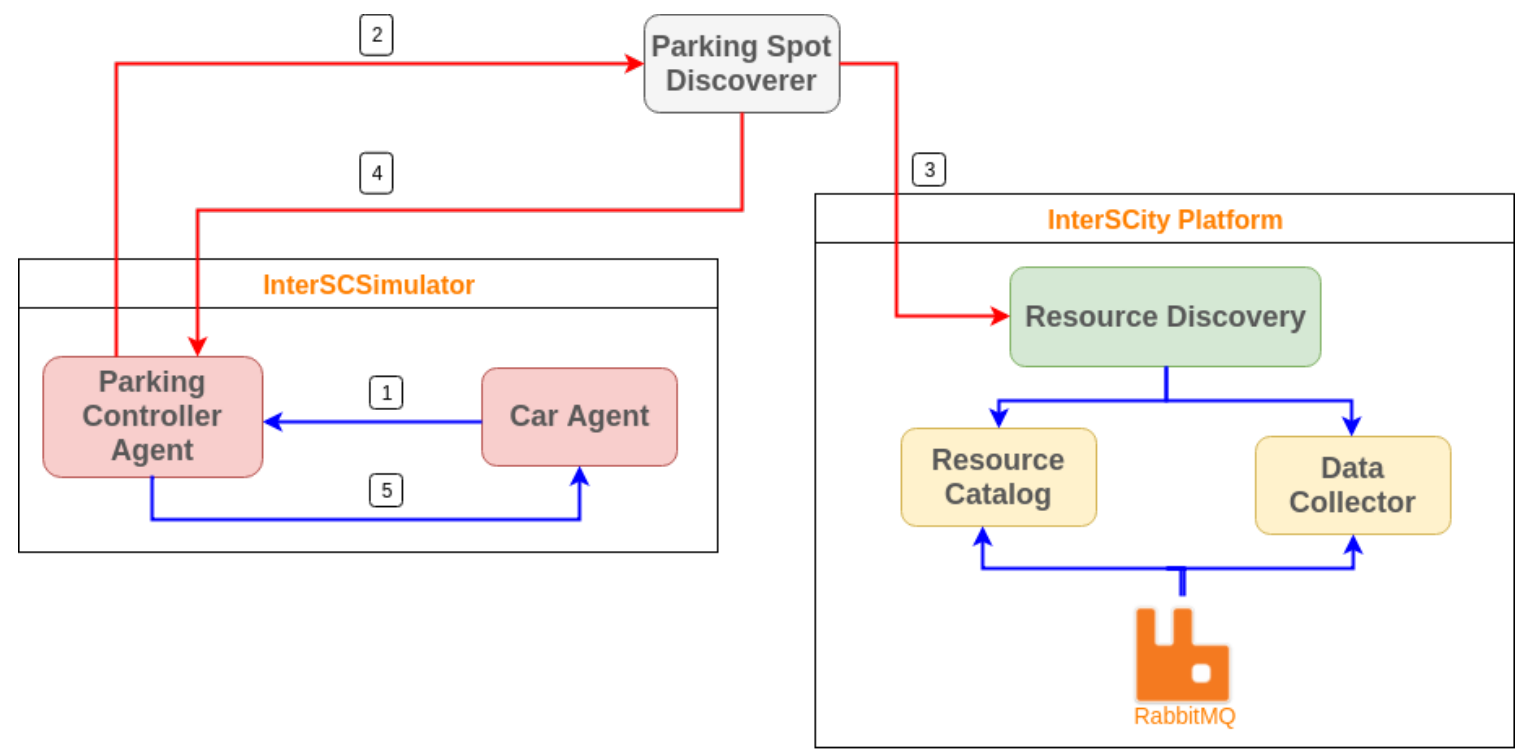

Figura 4.4: Integração para descoberta de vagas livres próximo do destino da viagem

A Figura 4.5 apresenta a integração realizada com o intuito de atualizar o estado das vagas de estacionamento na plataforma baseado nos acontecimentos da simulação. Como foi adicionado a funcionalidade de publicação dos eventos da simulação via RabbitMQ para os interessados, não foi necessário a utilização do componente de integração, já que a plataforma também utiliza o mesmo protocolo para divulgação dos seus dados entre os microsserviços. O fluxo apresentado na Figura 4.5 contém os seguintes passos.

1. O agente Car estaciona na vaga do estacionamento e notifica o Parking Controller. 
2. O Parking Controller informa, via RabbitMQ, que a vaga está ocupada usando o seu identificador.

3. O RabbitMQ repassa esse dado para os microsserviços Resource Catalog e Data Collector.

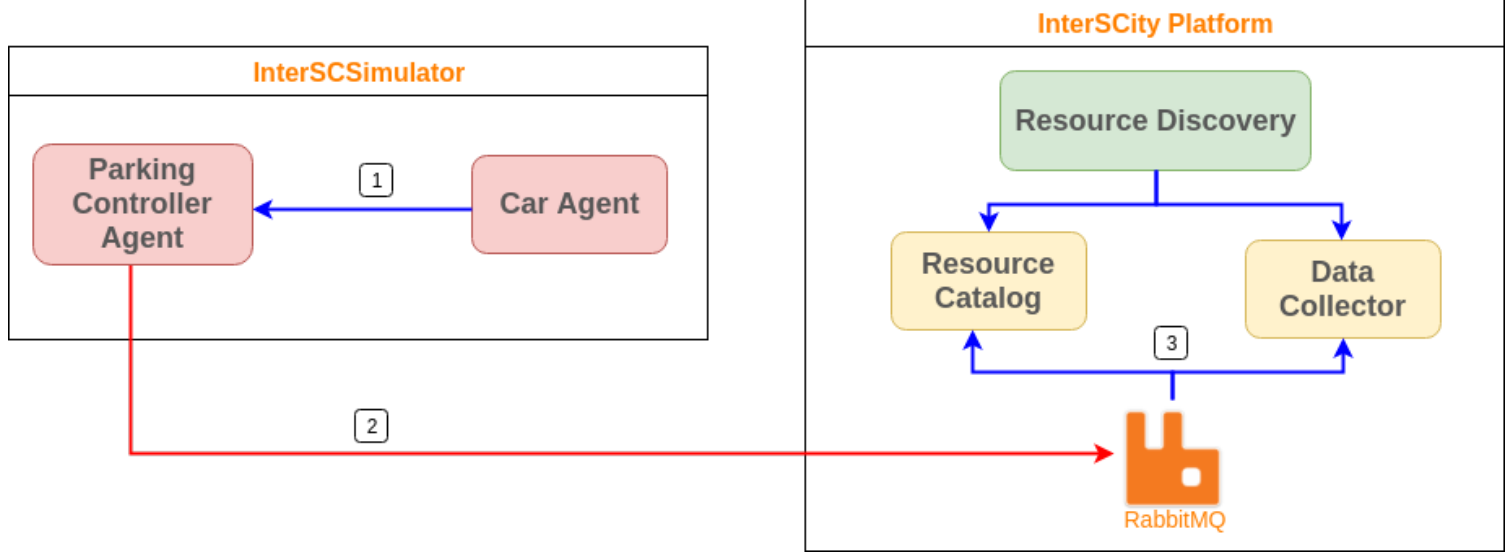

Figura 4.5: Integração para publicar dados

Vale ressaltar que as atividades 2 e 3 apresentadas na Figura 4.5 também são executadas quando a vaga é liberada. Após dez minutos que o agente está estacionado na vaga, o agente Parking Controller libera a vaga na estrutura de dados mantida dentro do simulador e informa o ocorrido para a plataforma. Com isso, a plataforma atualiza os dados da vaga quando ela é ocupada e quando liberada. Esse tempo para liberação das vagas é fixo, já que não sabemos o tempo que cada carro fica estacionado, sendo esse um ponto de melhoria do nosso modelo.

Após a implementação da arquitetura descrita, fomos capazes de executar experimentos de larga escala no contexto de estacionamento inteligente. Os resultados obtidos serão apresentados na próxima seção.

\subsubsection{Experimento}

Neste experimento, tentamos verificar a escalabilidade dos microsserviços envolvidos da plataforma InterSCity, para isso utilizamos dados reais de uma das maiores metrópoles do mundo: São Paulo. Dados abertos da cidade de São Paulo foram utilizados para a definição do cenário de simulação do ambiente integrado. Utilizamos dados extraídos da pesquida OD (Origem-Destino) realizada pela Companhia de Metrô da cidade de São Paulo e do OpenStreet Maps para a definição de cenário. A seguir, esses dados, bem como suas fontes, utilizados na configuração do experimento serão detalhados:

- Pesquisa Origem-Destino (OD): criamos as viagens de carro simuladas com base na pesquisa OD realizada pela Companhia de Metrô de São Paulo em 2007. ${ }^{2}$ Essa pesquisa descreve as viagens de 200.000 pessoas e extrapola os dados para toda a população da cidade (mais informações podem ser encontradas nos artefatos

\footnotetext{
${ }^{2}$ Pesquisa Origem-Destino - https://transparencia.metrosp.com.br/dataset/pesquisa-origem-edestino/resource/dd9382bf-fbbe-4ca4-bd32-bf6150a59c4b
} 
gerados pela pesquisa ${ }^{3}$ ). A pesquisa inclui informações sobre a origem, o destino, o meio de transporte e a hora de partida. Esses dados foram utilizados para definir o comportamento dos agentes do tipo carro na simulação. Para gerar a carga de trabalho para a plataforma, simulamos o tráfego em São Paulo durante um dos horários de pico, das 5 h40 às 8 h40. Na pesquisa OD, há 492.976 carros que começam suas viagens durante o intervalo de tempo considerado.

- OpenStreet Maps: para criar o grafo viário da cidade de São Paulo usado na simulação, usamos o mapa do OpenStreet Maps. Esse mapa contém todas as ruas e junções da cidade, em conjunto com um vasto número de atributos, como comprimento, capacidade e velocidade limite. Tais informações são usadas pelo simulador para definir as rotas percorridas pelos carros durante a realização de suas viagens, bem como simular o impacto do tráfego na velocidade dos carros.

- Vagas de Estacionamento: criamos as vagas de estacionamento na simulação baseado nos dados obtidos através do OpenStreet Maps e do Zona Azul ${ }^{4}$ (serviço de estacionamento rotativo da cidade de São Paulo). Informações de 467.741 vagas de estacionamento foram coletadas, elas foram derivadas a partir de dados de estacionamentos obtidos através do OpenStreet Maps, onde é possível obter a capacidade máxima (número de carros), e de vagas individuais do Zona Azul.

Nas Figuras 4.6 e 4.7, são apresentadas as distribuições das vagas de estacionamento e destinos de viagens de carros, respectivamente, utilizadas nesse experimento. Os destinos apresentados na Figura 4.7, são referentes a todas as viagens realizadas no decorrer de toda a simulação. É importante notar que a distribuição das vagas de estacionamento baseada nesses dados reais está mais concentrada no centro da cidade do que os destinos das viagens. Isso pode levar a situaçãoes onde o agente do tipo carro pode realizar mais de três tentativas de busca de vagas disponíveis e ainda sim não conseguir estacionar. Nesse caso, o usuário do aplicativo pararia de utilizá-lo e o agente do tipo carro terminaria sua execução, como apresentado na Seção 4.2.1.

Os passos a seguir foram executados no decorrer desse experimento:

1. Execução de uma instância em modo de produção da plataforma InterSCity em um ambiente de nuvem. Esse ambiente proporciona maior flexibilidade para variação do número de microsserviços em tempo de execução.

2. Habilitação do mecanismo de elasticidade automática (auto-scaling) na plataforma do provedor do serviço de computação em nuvem para os microsserviços da plataforma baseado na variação de carga de trabalho.

3. Configuração do simulador em um ambiente isolado da plataforma. Assim, o gasto de recursos computacionais do simulador não interfere no uso da plataforma.

4. Realização da simulação do cenário de estacionamento inteligente.

5. Monitoramento do desempenho e o uso de recursos da plataforma durante toda a simulação.

\footnotetext{
${ }^{3}$ Todos os artefatos da pesquisa de Origem-Destino - https://transparencia.metrosp.com.br/sites/default/files/Pesquisa\%20C

${ }^{4}$ http://www.cetsp.com.br/consultas/zona-azul/mapa-zona-azul/mapa-zona-azul.aspx
} 


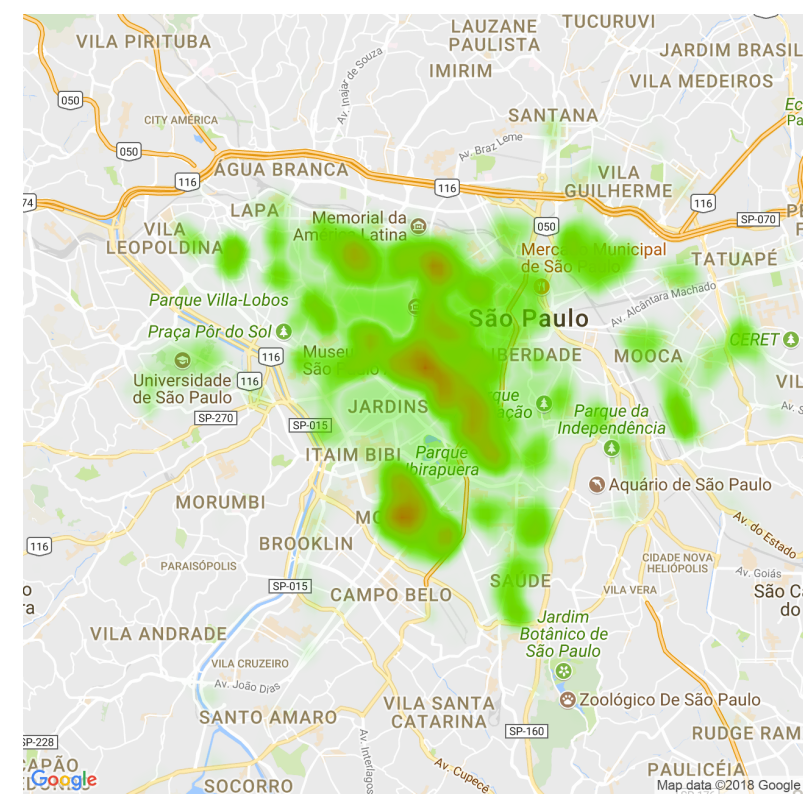

Figura 4.6: Mapa de calor com a distribuição das vagas de estacionamento utilizadas no experimento.

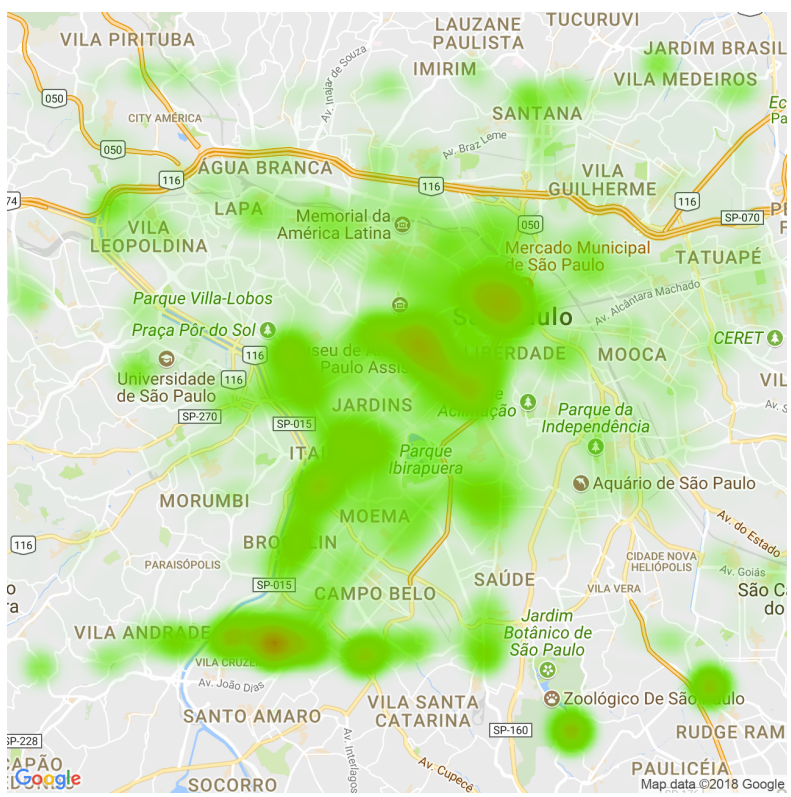

Figura 4.7: Mapa de calor com a distribuição dos destinos de viagens de carro utilizadas no experimento.

6. Análise dos resultados obtidos.

Inicialmente, foi necessária a configuração de ambas as ferramentas em conjunto com seu componente de integração em um ambiente de nuvem. Os microsserviços da plataforma InterSCity, o simulador InterSCSimulator e ferramentas auxiliares foram implantados na forma de contêineres Docker ${ }^{5}$. Utilizamos a infraestrutura provida pelo Google Cloud

\footnotetext{
${ }^{5}$ https://www.docker.com/
} 
Platform (GCP) ${ }^{6}$ para a realização do experimento, sendo o ambiente de nuvem ideal para a execução da plataforma InteSCity, como visto na Seção 4.1.2. No contexto do GCP, fizemos bastante uso do Google Kubernetes Engine (GKE), sendo esse um serviço que provê um ambiente gerenciado e de produção para implantação de contêineres de aplicações. O Kubernetes foi utilizado principalemte para automatizar a reinicialização, a replicação e dimensionamento do número de contêineres. Além disso, o Kubernetes traz uma vantagem para a reprodutibilidade do experimento que é a especificação da infraestrutura como código, garantindo a correta aplicação das regras de implantação. Todo o código fonte utilizado para a realização desse experimento está disponível como software livre na web 7.

Nós dividimos o cluster utilizado em cinco diferentes pools de máquinas virtuais para que o Kubernetes pudesse gerenciar os contêineres no contexto apropriado. Na Figura 4.8, são apresentados os pools de nós, contendo o número e o tipo de máquinas virtuais utilizadas por cada um no GCP ${ }^{8}$. O pool da plataforma possui 25 máquinas do tipo n1-standard-2 (2 CPUs virtuais e 7.5GB memória) e executa os microsserviços da plataforma InterSCity. Existem três conjuntos de nós adicionais (representados em azul) compostos por n1-high-2 máquinas (2 CPUs virtuais e 13GB de memória), que executam os serviços de suporte da plataforma InterSCity. Ambos MongoDB e PostgreSQL têm 5 nós sendo executados de maneira distribuída, instâncias tolerantes a falha de seus respectivos sistemas de banco de dados. O RabbitMQ possui uma máquina dedicada em um pool isolado. MongoDB é implementado usando a estratégia de conjunto de réplicas (replica set), onde operações de leitura são distribuídas entre nós secundários (escravos), e operações de escrita são sempre executadas no nó primário (mestre). A mesma estratégia é adotada na implantação do PostgreSQL, para otimizar as operações de leitura executadas pelo Resource Catalog. Finalmente, o InterSCSimulator é executado em sua própria máquina n1-highmem-16 (16 CPUs virtuais e 104 GB de memória), isoladas do resto do serviços.

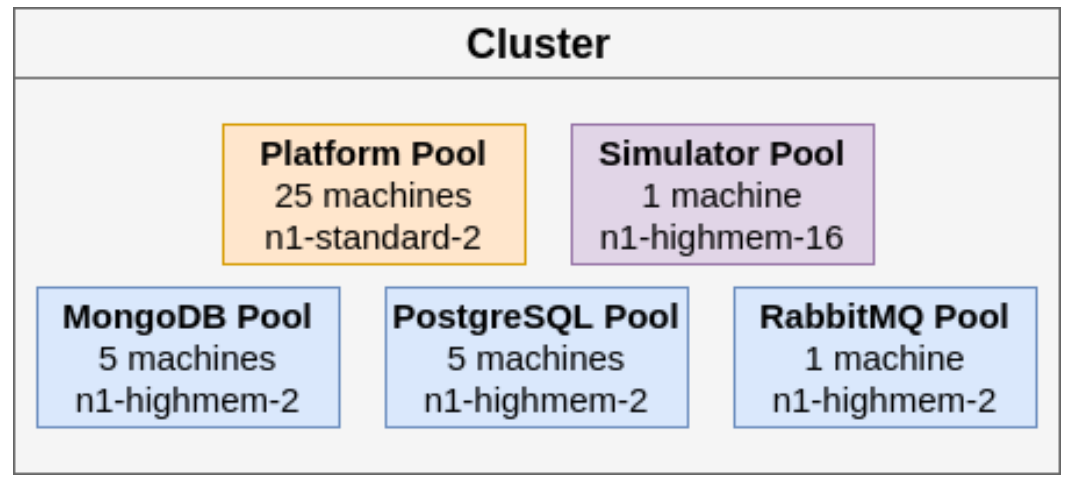

Figura 4.8: Configuração do cluster para o experimento.

Para o conjunto de nós da plataforma, o Kubernetes pode programar a implantação de vários contêineres para a mesma máquina, dependendo da disponibilidade de recursos computacionais. A distribuição de contêineres nos 25 nós pode diferir de uma rodada do experimento para a outra, e é uma variável que não controlamos durante o experimento.

\footnotetext{
${ }^{6}$ https://cloud.google.com/

${ }^{7}$ https://github.com/LSS-USP/interscity-k8s-experiment

${ }^{8}$ https://cloud.google.com/compute/docs/machine-types
} 
Para avaliar o impacto de tais variações na análise, realizamos 15 rodadas desse experimento e verificamos a variabilidade dos resultados.

Como estávamos interessados em avaliar a escalabilidade da plataforma considerando um cenário de Cidades Inteligentes com uma carga de trabalho variável, usamos dimensionamento automático (auto-scaling) para o Resource Catalog, Resource Discovery, Data Collector, já que eles são projetados para escalar horizontalmente. Para esse propósito, especificamos um valor alvo de $60 \%$ de uso da CPU para cada um desses serviços, permitindo que o sistema aumente ou diminua o número de contêineres por serviço baseado nisso. O sistema balanceia a carga de trabalho para corresponder ao valor alvo de uso da CPU, considerando o uso médio da CPU dos contêineres em execução, que é medido a cada 30 segundos. Inicialmente, cada serviço tem quatro contêineres, que é definido como o número mínimo de contêineres em execução. Esse número pode aumentar à medida que os recursos computacionais ficarem disponíveis no pool de nós da plataforma. Os contêineres são executados por trás de um serviço de balanceamento de carga.

Embora possamos nos beneficiar das propriedades de elasticidade do GCP, adicionando e removendo automaticamente nós ao cluster através da sua funcionalidade de dimensionamento automático, isso introduziria outro nível de incerteza em nosso experimento, já que, na nossa experiência, o tempo levado para criar novas máquinas virtuais pode variar consideravelmente. Sabendo disso, criamos todos os nós previamente, antes de iniciar o experimento, mantendo-os em execução ao longo de todo experimento.

Como dito anteriormente, executamos 15 rodadas de experimentos, onde cada uma durou 3h, correspondendo ao horário de pico da manhã da cidade de São Paulo descrito no início desta seção. Na Figura 4.9, podemos ver a carga de trabalho média gerada pela simulação durante todo o experimento e o seu desvio padrão (linhas pretas no topo de cada barra). Vale notar que nos primeiros 80 minutos de simulação, temos um crescimento constante da carga de trabalho. No intervalo aproximado de uma hora, entre 60 e 120 minutos, observamos o período de maior carga do experimento, considerando que o pico máximo de requisições ocorre após 80 minutos, correspondendo a mais de 113.000 requisições em 10 minutos. No total, mais de um milhão de requisições foram realizadas para a plataforma durante o tempo de experimento. Considerando que para responder cada uma dessas requisições requer um conjunto complexo de operações com várias etapas internas, isso se traduz em uma carga computacional muito alta.

A Figura 4.10 mostra a criação e destruição dinâmica de contêineres da plataforma InterSCity devido à aplicação da estratégia de dimensionamento automático em uma única rodada do experimento. A replicação inicial das instâncias de Kong (balanceador de carga) foi suficiente para suportar toda a carga de trabalho durante todo o experimento, já que ele executa apenas a tarefa leve de encaminhar as requisições de entrada aos microsserviços apropriados. Por sua vez, os três microsserviços da plataforma, que são responsáveis por processar as requisições de fato, foram replicados de acordo com o aumento da carga de trabalho. Portanto, o número de contêineres para cada um desses serviços variou de $4 \mathrm{a}$ 25. É importante mencionar que o mecanismo de elasticidade da plataforma InterSCity também reduziu o número de contêineres à medida que a demanda diminuiu. Como pode ser visto na Figura 4.10, dentre os microsserviços da plataforma, o Data Collector foi o microsserviço que consumiu menos tempo de CPU. 


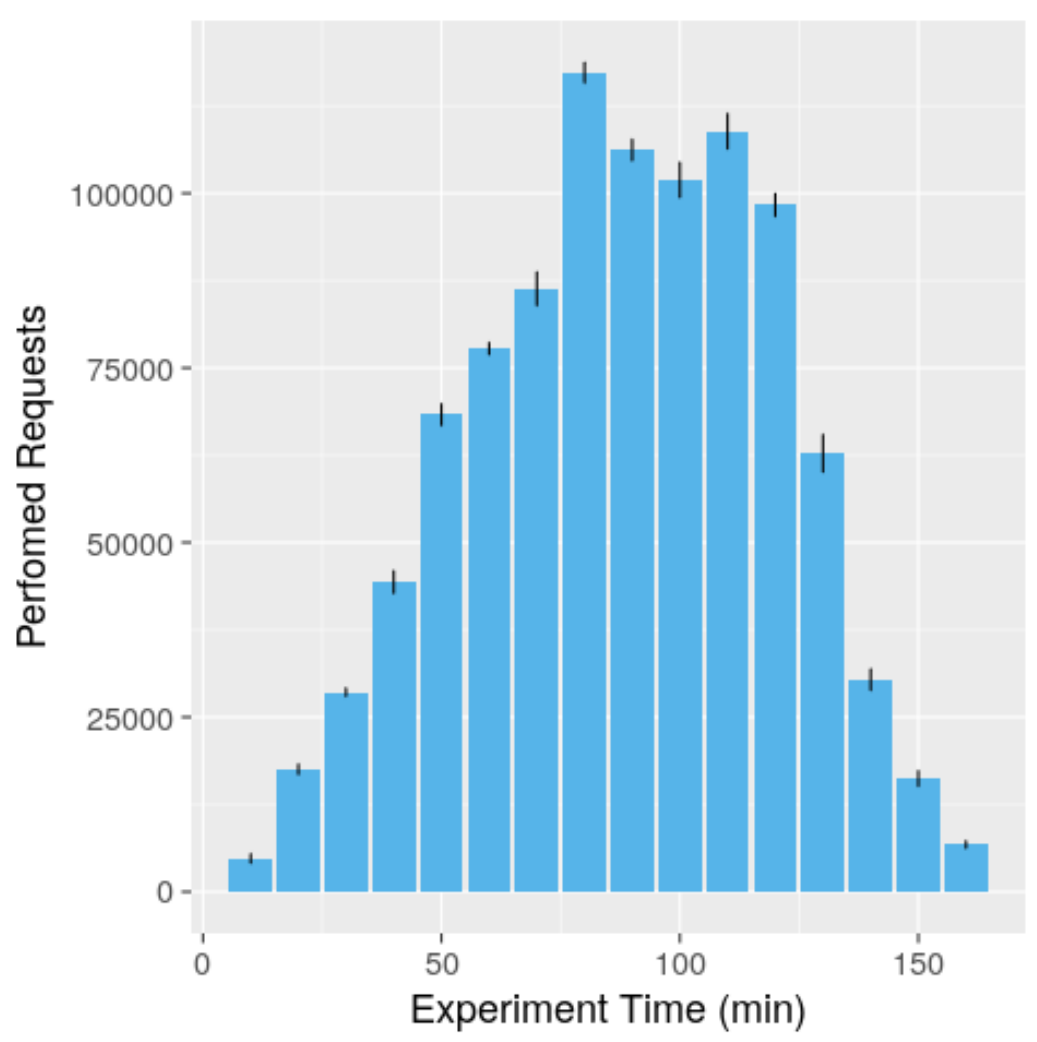

Figura 4.9: Média da carga de trabalho gerada pelo InterSCSimulator no decorrer do experimento.

A Figura 4.11 mostra a taxa de vazão (throughput) média da plataforma InterSCity ao longo da duração do experimento. A taxa de vazão é definida como a taxa de respostas bem sucedidas recebidas pelo componente de integração. $O$ resultado indica que a taxa de vazão corresponde de perto à carga de trabalho gerada, como pode ser visto comparando as Figuras 4.9 e 4.11. A plataforma foi capaz de lidar com a demanda variável graças à sua escalabilidade e funcionalidade de dimensionamento automático, descritos na Seção 4.1.2. No entanto, devemos mencionar que a taxa de vazão não correspondeu exatamente à carga de trabalho gerada, pois algumas requisições falharam, representando em média quase $0,6 \%$ de todas as requisições. As requisições com falha incluem aquelas que tiveram respostas com um código de erro HTTP, bem como aquelas que não foram concluídos devido a recusa de conexão ou timeout. Todavia, consideramos que, ser capaz de lidar com, em média, mais de $99,4 \%$ das requisições sob alta carga é satisfatório; um usuário típico perceberia uma falha a cada 200 requisições, o que é muito bom para este tipo de aplicação de Cidades Inteligentes em tempo real.

Outro aspecto fundamental da avaliação de um sistema é analisar o desempenho da plataforma para lidar com requisições de aplicações com uma carga de trabalho variável. A esse respeito, estamos interessados principalmente em analisar a degradação do desempenho e verificar se a plataforma está sendo dimensionada adequadamente para atender seus clientes dentro de tempos de resposta aceitáveis. Para tanto, coletamos o tempo de resposta do ponto de vista do cliente, como mostrado Figura 4.12. Durante a maior parte do experimento, a plataforma foi capaz de responder em menos de um segundo. No entanto, diferente da taxa de vazão, o impacto do maior período de demanda no tempo de resposta 


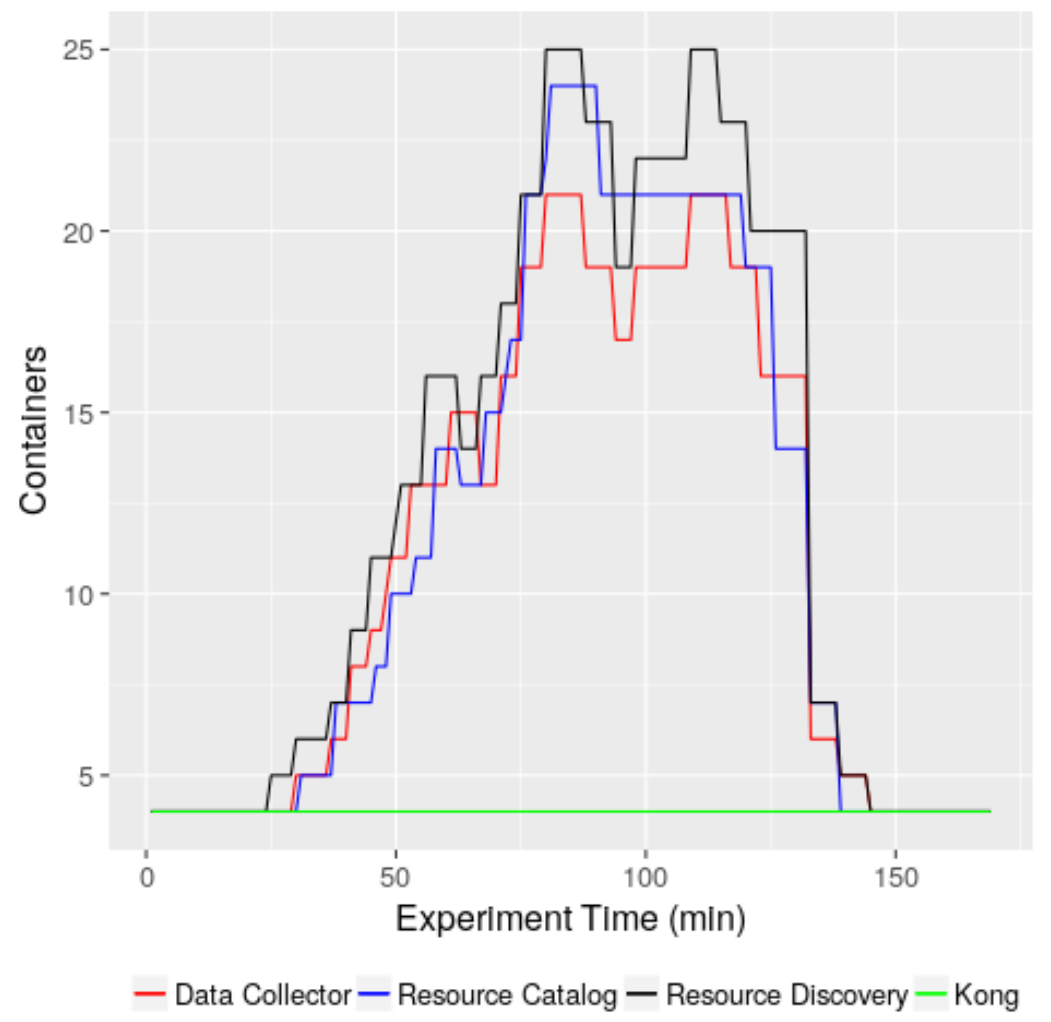

Figura 4.10: Dimensionamento automáticos dos microsserviços da plataforma InterSCity.

observado é perceptível, uma vez que, durante um intervalo curto (após 110 minutos de execução), o tempo médio de resposta foi maior que 1 segundo. O tempo de resposta voltou para 500 milisegundos depois disso. Entretanto, podemos ver que, mesmo em períodos de alta carga, o tempo de resposta foi mantido abaixo de 2 segundos, o que é um resultado muito bom para esse tipo de aplicação, já que segundo BHATTI et al., 2000 são necessários 10 segundos de atraso para um usuário de um serviço web se sentir incomodado.

Devemos ter em mente que a distribuição de contêineres nos nós disponíveis podem impactar o tempo de resposta, pois vários contêineres podem competir por recursos computacionais se estiverem sendo executados na mesma máquina. Além disso, embora o sistema realize a tarefa de dimensionamento automático a cada 30 segundos, não temos controle sobre o tempo que leva para um container ser criado, implantado e ficar pronto para receber novas requisições. Por outro lado, essa distribuição também pode introduzir um efeito benéfico devido à possível implantação de serviços que constantemente interagem uns com os outros na mesma máquina, reduzindo a latência de rede e imprevisibilidade.

Ao final desse estudo de caso, percebemos que não exercitamos todos os requisitos apresentados para a construção de um ambiente simulado e integrado para experimentação de plataformas de Cidades Inteligentes. Por isso, realizamos um segundo estudo de caso, onde a atuação no ambiente simulado se fez necessária, apresentado na seção seguinte. 


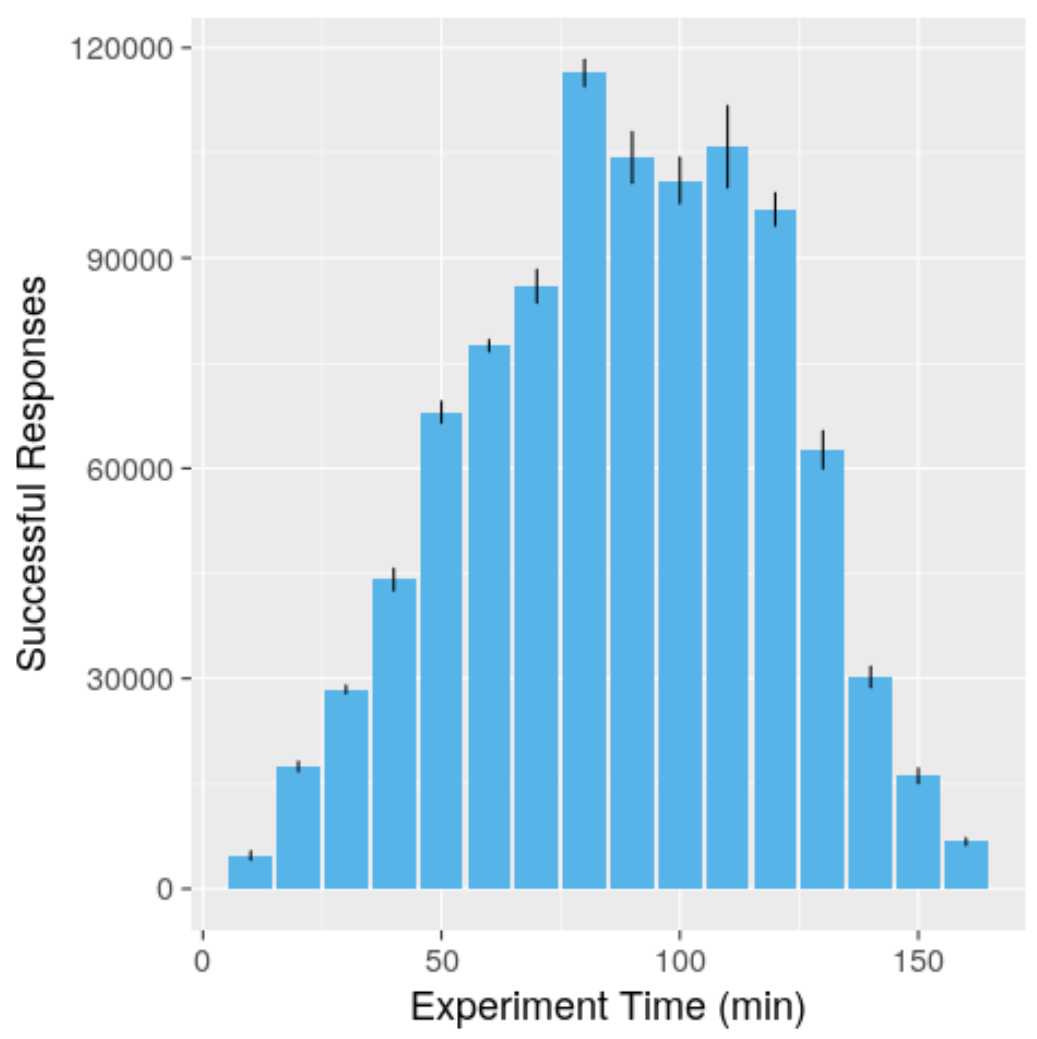

Figura 4.11: Taxa de vazão (throughput) média da platafora InterSCity.

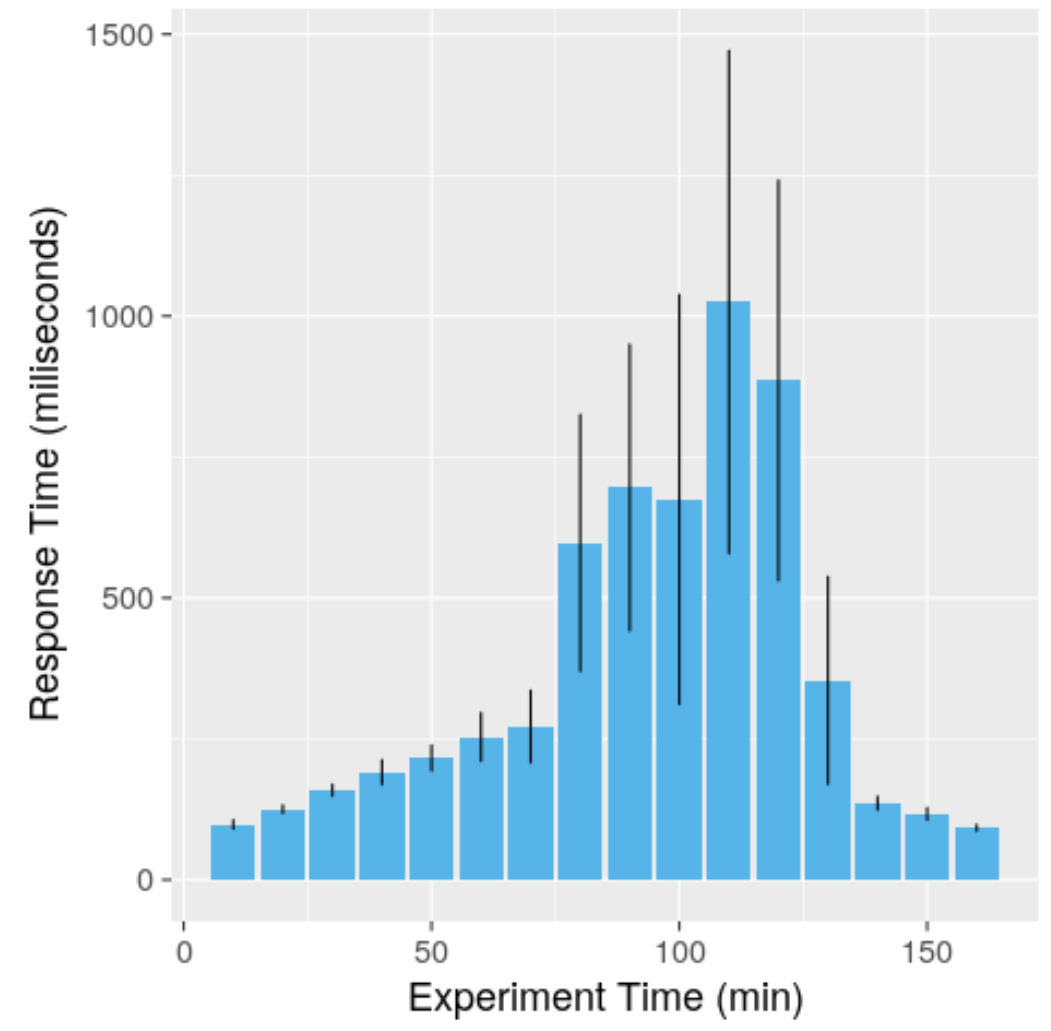

Figura 4.12: Tempo de resposta médio da platafora InterSCity. 


\subsection{Tráfego de Carros Inteligente}

Com o objetivo de exercitar o envio de comandos de atuação da plataforma para o ambiente simulado, que não foi explorado no cenário de estacionamento inteligente, definimos um novo cenário. Neste caso, visamos identificar trechos em vias da cidade com tráfego de carros anômalo (devido ao fechamento de ruas, acidentes, desastres naturais e etc.) e notificar previamente os motoristas para evitarem passar naquele trecho através de Placas de Mensagens Variadas (PMVs). Veja na Figura 4.13 uma PMV. Consideramos aqui uma anomalia uma variação considerável na velocidade média dos carros que trafegam naquele trecho de via naquele horário. Essas PMVs são posicionadas em pontos estratégicos da cidade e apresentam alertas aos motoristas em tempo real sobre possíveis anomalias no trânsito. E, com isso, motoristas podem mudar o seu percurso evitando maiores congestionamentos na cidade.

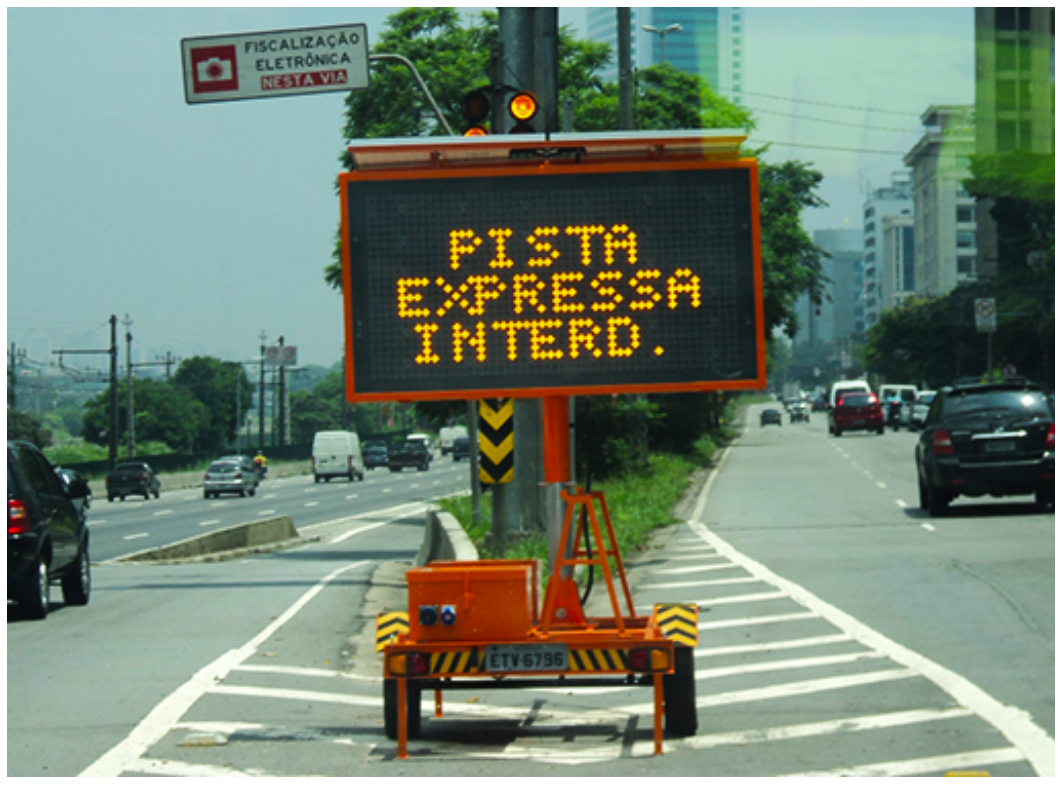

Figura 4.13: Exemplo de Placa de Mensagem Variada.

A implementação deste cenário seguindo a arquitetura proposta no Capítulo 3, bem como o experimento realizado, serão discutidos nas seções seguintes.

\subsubsection{Implementação}

Essencialmente, o cenário de tráfego de carros inteligente funciona da seguinte forma:

1. A plataforma coleta dados históricos de posicionamento dos carros em seus trajetos, a partir desses pontos a velocidade média dos carros é calculada e o método MAD (Median Absolute Deviation - Desvio Absoluto da Mediana)(Leys et al., 2013) é utilizado para definir limiares (thresholds) de velocidade média para cada trecho de via da cidade em cada horário, sendo esses limiares valores de velocidade média aceitáveis em um dia comum. Para isso, o ambiente simulado envia dados de posicionamento georreferenciado dos carros a cada ciclo de execução, simulando por exemplo um 
dispositivo que contém um sistema de GPRS (General Packet Radio Service) + GPS (Global Positioning System). Com uma série de pontos de onde o carro passou em cada instante, se torna possível calcular a sua velocidade média, logo obtemos a velocidade média de carros que passaram naquele trecho naquele dado momento durante todo o dia. Tendo esses limiares calculados usando o MAD, a plataforma se torna capaz de identificar anomalias na velocidade média dos carros em tempo real, verificando se a variação naquele instante extrapola ou não o que foi identificado com os dados históricos.

2. Ao identificar uma anomalia de trânsito em algum trecho, a plataforma identifica as PMVs mais próximas do incidente e atualiza a sua mensagem informando os motoristas do ocorrido.

3. Caso o motorista passe por uma PMV contendo essa mensagem, ele verifica se o trecho mencionado faz parte do seu percurso. Sendo verdade, ele recalcula a sua rota evitando maiores congestionamentos na região.

Nesse cenário de experimentação, o novo serviço de processamento de dados (históricos e de tempo real), que não está no escopo deste trabalho, e o envio de comandos de atuação da plataforma InterSCity puderam também ser testados. Além disso, foi possível finalizar a validação da arquitetura proposta para a criação de um ambiente para experimentação em plataformas de Cidades Inteligentes, implementando a atuação em tempo real no ambiente simulado.

Para realizar experimentos envolvendo essas funcionalidades da plataforma InterSCity, foi necessário implementar o conceito de PMVs, eventos de fechamentos de via e de processamento de comandos de atuação em tempo de execuação no InterSCSimulator. Foi utilizada a publicação de eventos (dados de sensores) implementado para o cenário anterior, já que para o funcionamento do serviço de processamento de dados em tempo real da plataforma precisamos enviar a cada ciclo de execução da simulação o posicionamento de todos os carros presentes. Essas funcionalidades são essenciais para atender os requisitos fundamentais para esse cenário.

O modo de publicação de dados em tempo de execução no InterSCSimulator foi refatorado para melhor atender ambos os cenários implementados. Como visto no cenário anterior, a publicação de eventos da simulação se dava através do agente Parking Controller (como pode ser visto na Figura 4.5), já que até então o único tipo de evento publicado pelo simulador era a atualização da disponibilidade de uma vaga de estacionamento. No intuito de permitir que outros agentes da simulação também pudessem publicar os seus eventos, um novo agente chamado Publisher foi criado, removendo essa responsabilidade anteriormente atribuída ao agente Parking Controller. Agora, qualquer agente da simulação que deseje publicar um evento deve apenas enviar uma mensagem ao Publisher com o conteúdo do evento. Desse modo, o agente do tipo carro envia a cada ciclo de execução uma mensagem a um agente Publisher contendo sua localização, tornando-se capaz de pulicar a sua posição.

Visando tornar factível a simulação de eventos de fechamento de vias na cidade, adicionamos o conceito de eventos de trânsito ao InterSCSimulator. Um novo arquivo de entrada para o simulador e um novo agente foram adicionados. O novo arquivo de 
entrada (chamado por padrão events.xml), contem uma lista de eventos de fechamento de via que serão agendados na simulação. Como pode ser visto na Listagem 4.1, cada evento é representado por uma lista de atributos separados por ponto e vírgula (";"), e os atributos são os seguintes: (i) o tipo do evento de trânsito (close_street para fechamento de vias e reduce_capacity para redução da capacidade de vias); (ii) o número identificador da via a ser fechada (aresta no grafo da cidade); (iii) o número do ciclo de simulação onde deve ser iniciado o evento; (iv) o número de ciclos de simulação que deve durar o evento; (v) a porcentagem da capacidade do fluxo de carros que ainda estará em funcionamento, usada no caso de um fechamento parcial do trecho (se o evento for de fechamento de via deve-se utilizar o valor 0). O novo agente chamado Events Manager é responsável por agendar todos esses eventos no início da simulação e alterar o grafo da cidade no momento programado. Quando o trecho da via é fechado, a aresta do grafo da cidade é removida momentaneamnte até o evento ser encerrado, impedindo assim a possibilidade de passagem de qualquer carro. Quando o evento apenas reduz a capacidade de fluxo de carros da via, modificamos a sua capacidade para atender o que foi programado até o evento ser encerrado. Essa capacidade é um atributo dado àquela aresta do grafo.

1 close_street; $4 ; 5 ; 1 ; 600 ; 0$

2 reduce_capacity;6;7;1;600;20

Listing 4.1: Arquivo de entrada contendo os eventos de fechamento de vias

Para a representação das PMVs no InterSCSimulator, foi criado um agente chamado PMV Manager. Seu papel é atualizar as mensagens de PMVs. As PMVs em si foram implementadas como atributos de vértices do grafo da cidade (sendo os vértices o encontro de duas ou mais vias). Nesse atributo, é guardada uma lista de trechos de vias (arestas) onde foram encontradas alguma anomalia no trânsito. Os agentes do tipo carro, ao passar por um vértice que contém esse atributo, verificam se alguma das arestas ali presentes fazem parte do seu trajeto ou não. Caso positivo, o seu percurso é recalculado. Caso contrário, ele se mantém inalterado.

A última implementação no InterSCSimulator necessária para atender os requisitos apresentados seguindo a arquitetura proposta foi o recebimento de comandos de atuação e seu processamento em tempo de execução. Essa funcionalidade é fundamental para a atualização das PMVs em tempo de execução pela plataforma. Diante disso, mais um novo agente foi criado para ficar à espera desses comandos enviados pela plataforma: o Listener. Como um comando de atuação pode ser enviado a qualquer momento, foi necessário criar esse novo agente, cuja única responsabilidade é receber esse comando e armazená-lo em uma estrutura de dados, para que outros agentes não ficassem bloqueados (bloqueando também a simulação) a espera de tal acontecimento. Ou seja, esse agente fica em um laço (loop) infinito a espera de uma mensagem que é enviada via AMQP (mesmo protocolo utilizado para publicação dos dados). Por essa ser uma nova funcionalidade, decidimos utilizar o mesmo protocolo e a mesma tecnologia utilizada pela plataforma InterSCity visando reduzir o problema de interoperabilidade. O RabbitMQ, que já vinha sendo utilizado pela plataforma para envio de comandos de atuação, foi selecionado como ferramenta para tratamento de eventos da simulação, tanto para publicação quanto para recebimento. Quando um comando é recebido, no caso uma aresta de trecho anômalo a ser atualizada em uma PMV, o Listener armazena essa mensagem em uma estrutura de 
dados que é acessada no próximo ciclo de execução pelo PMV Manager que, por sua vez, atualiza o atributo da referida PMV (vértice no grafo).

Após a apresentação das funcionalidades e melhorias implementadas, as duas vias de fluxo de comunicação entre o simulador e a plataforma serão apresentadas a seguir. $\mathrm{Na}$ Figura 4.14, os passos para a publicação dos dados de posicionamento de cada um dos carros a cada ciclo de execução são expostos.

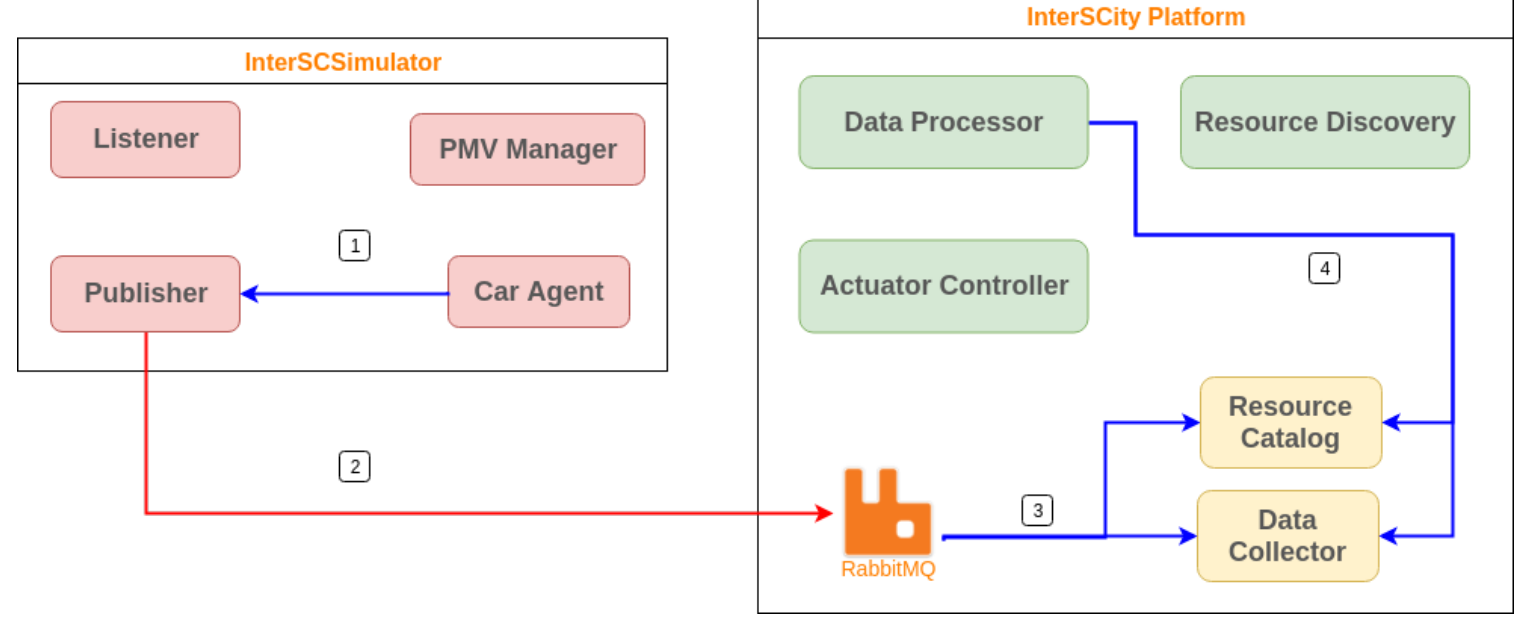

Figura 4.14: Integração para publicar dados de posicionameto de carros

1. O agente do tipo carro a cada ciclo de execução envia uma mensagem para o agente Publisher contendo a sua posição naquele dado momento.

2. O agente Publisher se conecta ao broker do RabbitMQ e publica uma mensagem contendo: o identificador do carro, o seu posicionamento e o timestamp.

3. Os microsserviços Resource Catalog e Data Collector são notificados e recebem tais dados. O Resource Catalog atualiza o último dado monitorado daquele carro, e o Data Collector atualiza a sua base de dados contendo todas as medições.

4. O microsserviço Data Processor acessa dados armazenados por esses outros serviços com o intuito de definir limiares para velocidade média de vias (dados históricos), ou para identificar anomalias no trânsito (fluxo de dados em tempo real).

Já na Figura 4.15, é apresentado o fluxo para atualização da lista de trechos anômalos de vias em PMVs, representando aqui um comando de atuação no ambiente simulado. Lembrando que o gatilho para a execução desse processo é o serviço de processamento de dados identificar alguma anomalia no trânsito.

1. O Data Processor, ao identificar uma anomalia no trânsito em determinado ponto da cidade, requisita ao Resource Discovery as PMVs mais próximas daquele ponto, para que elas possam ser atualizadas.

2. Ao serem identificados as PMVs, o Data Processor envia os identificadores das PMVs e do trecho anômalo para o Actuator Controller.

3. O Actuator Controller formata essas mensagens e as publica em um dos canais do RabbitMQ. 


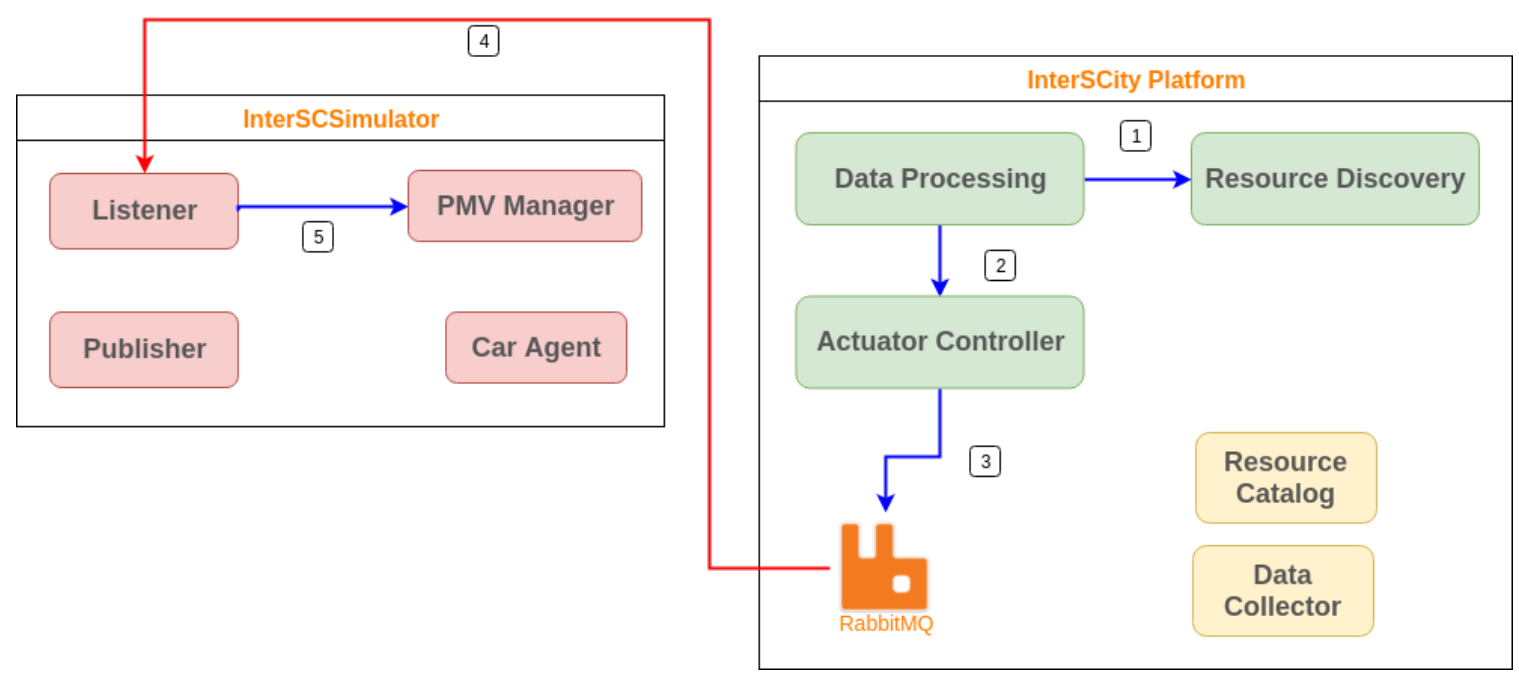

Figura 4.15: Integração para atuação em Placas de Mensagens Variadas

4. O agente Listener, cujo único papel é esperar por esse tipo de mensagem, a recebe e a armazena em uma estrutura de dados compartilhada pelos agentes do simulador.

5. O agente $P M V$ Manager verifica a presença dessa nova mensagem na estrutura de dados compatilhada, e atualiza o atributo que representa a PMV no vértice do grafo viário da cidade, adicionando mais esse trecho para a lista presente ou criando-a caso não exista nenhum outro trecho.

Um ponto interessante desse segundo cenário, foi a não necessidade de um componente de integração, já que ambas as ferramentas se comunicam através do mesmo protocolo (inclusive a mesma ferramenta) e conseguem representar os mesmos conceitos de maneira equivalente. Esse é o cenário ideal para criação de um ambiente simulado de experimentação para uma plataforma de Cidades Inteligentes, já que não foi essencial a implementação desse componente extra que, como discutido, traria mais complexidade para o sistema, podendo aumentar o tempo de resposta entra as ferramentas. Claro que tudo isso foi possível porque neste mesmo trabalho fizemos toda a implementação dos requisitos fundamentais apresentados, portanto, tivemos a oportunidade de tomar as decisões técnicas que facilitaram a integração entre as duas ferramentas.

\subsubsection{Experimento}

Esse experimento consistiu em três cenários. Conforme descrito na Seção 4.3.2, limiares (thresholds) de velocidade média para cada trecho de via em cada horário do dia deveriam ser definidos. Portanto, o primeiro cenário consistiu na simulação do trânsito da cidade sem nenhum evento de fechamento de via, ou seja, o trânsito normal da cidade. Para tanto, a aplicação de detecção de anomalias foi capaz de, com os dados de posicionamento de carros enviados a cada ciclo de execução, definir esses tais limiares através do método MAD. O segundo cenário, consistiu em simular o trânsito de carros na cidade com alguns eventos de fechamento de vias (representando ruas alagadas, acidentes de carro, etc.). Nesse cenário, simulamos o comportamento caótico visto nas grandes cidades, onde vias são interditadas e interferem diretamente no tráfego dos carros. No último cenário, simulamos 
o mesmo comportamento do segundo cenário, mas adicionamos as PMVs para auxiliar os condutores de carros a contornar tais situações. Tendo em vista que os limiares já haviam sido definidos, a aplicação, sem ter conhecimento prévio dessas vias fechadas, detectava automaticamente esses trechos e notificava os motoristas através da atualização de mensagens nas PMVs. O objetivo desses três cenários era verificar o impacto do uso de PMVs no tempo de duração médio das viagens de carro em situações de incidentes que inviabilizam a utilização de certas vias em uma cidade.

Para verificar o bom funcionamento desse cenário no ambiente simulado, dividimos esse experimento em dois. Na primeira parte, realizamos um experimento numa escala menor e com dados fictícios, visando meramente a validação do comportamento esperado e interação entre os componentes. Na segunda parte, utilizamos dados abertos da cidade de São Paulo, aumentando a escala do experimento e se aproximando de um cenário mais realista. $\mathrm{O}$ código fonte para a execução do experimento e a análise apresentada, nesta seção, estão disponíveis em nosso repositório aberto ${ }^{9}$.

\section{Validação}

Nesse experimento inicial de validação, os três cenários com o que diz respeito ao número de eventos de fechamento de via e PMVs, se deram da seguinte forma:

1. Sem eventos de fechamento de via e sem PMVs

2. Com um evento de fechamento de via e sem PMVs

3. Com um evento de fechamento de via e uma PMV

Foram executadas 20 iterações de cada um dos cenários, onde cada iteração corresponde a 10 minutos de simulação. Em todos os cenários, utilizamos um grafo com 8 vértices e 16 arestas, como pode ser visto na Figura 4.16. O grafo é direcionado, onde cada aresta na verdade representa duas, sendo uma entrando e outra saíndo de seus vértices, ou seja, simbolizam vias de mão dupla.

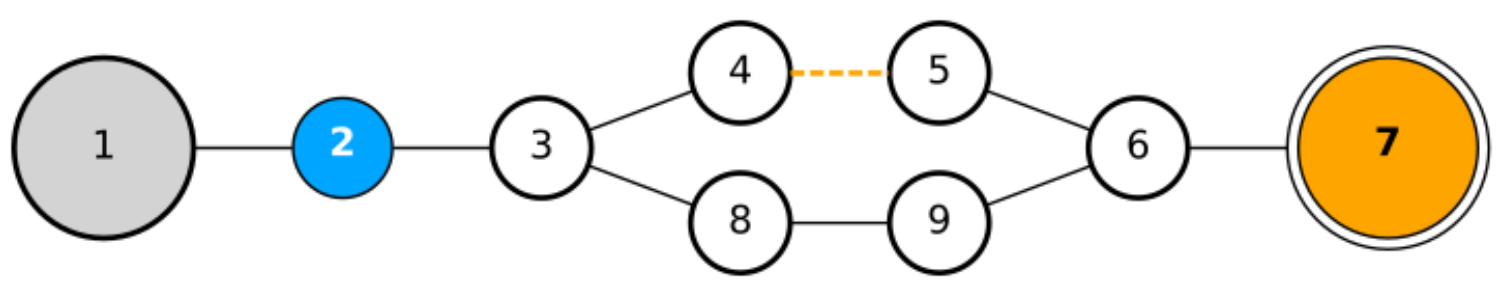

Figura 4.16: Mapa viário da cidade utilizado para validação.

O grafo da Figura 4.16 retrata o mapa viário da cidade simulada da seguinte forma:

- Os vértices representam início e/ou fim de uma ou mais ruas.

- As arestas representam segmentos de vias da cidade.

- Todas as arestas possuem comprimento 1. Por isso, a cada ciclo de simulação, caso seja possível, um carro percorre uma aresta.

\footnotetext{
${ }^{9}$ https://github.com/LSS-USP/pmv_experiment/blob/master/Analysis.ipynb
} 
Além disso, adotamos a seguinte forma para separar vértices e arestas que desempenham papel importante neste experimento:

- A aresta pontilhada amarela representa a via da cidade que será fechada durante a simulação (essa aresta só será afetada nos cenários que posssuem tal evento).

- O vértice 1 (em cinza) representa a origem de todas as viagens simuladas.

- O vértice 7 (em alaranjado) representa o destino das viagens.

- O vértice 2 (em azul) representa o local da cidade que contém uma PMV que alertará os motoristas sobre possíveis anomalias nas vias.

Em todas as iterações de todos os cenários, simulamos um total de 100 carros realizando viagens partindo do vértice 1 até o 7, onde metade dos carros partem no início da simulação e o restante após 50 ciclos de execução. Como o intuito desse experimento era validar o comportamento da implementação do ambiente de experimentação como um todo, antes de apresentar os resultados obtidos, descrevemos o resultado esperado para cada um dos cenários a seguir.

Na Figura 4.17, pode-se ver o caminho esperado que os carros percorrecem no primeiro cenário do experimento, onde não há a presença de eventos de fechamento de vias, e muito menos PMV. As arestas em roxo representam o trajeto do carro, as demais arestas não utilizadas foram removidas do grafo a título de legibilidade. Note que ao chegar no vértice 3 , ele sempre optará o caminho seguindo pelo vértice 4 . Isso acontece porque todas as arestas possuem o mesmo comprimento (ambos são um caminho mais curto até o destino), sendo critério de desempate o menor índice.

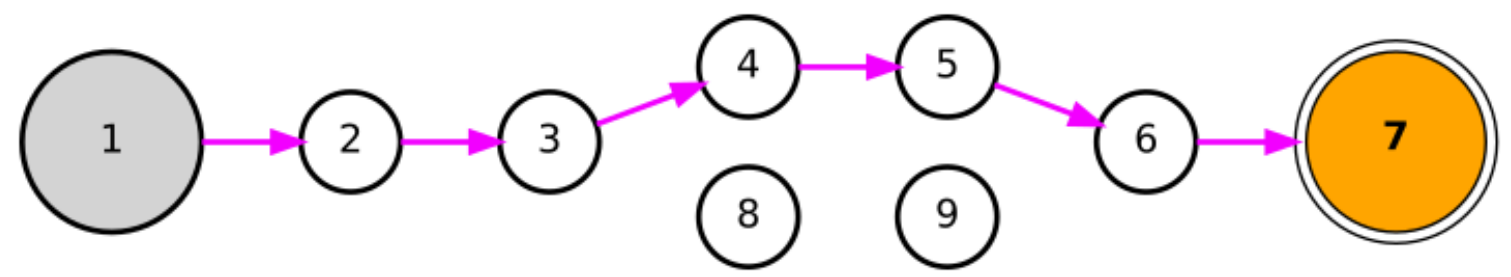

Figura 4.17: Trajeto esperado do cenário 1 do experimento.

Na Figura 4.18, o trajeto esperado para que o carro percorra no cenário 2 do experimento é apresentado. Nesse cenário, temos uma via fechada, sendo ela entre os vétices 4 e 5 , e nenhuma PMV para auxiliar os motoristas. Em roxo podemos ver as arestas que serão percorridas inicialmente; em cor preta, as arestas que faziam parte do caminho inicialmente calculado, mas que não foram percorridas devido ao fechamento da via (aresta tracejada); e em cor verde, o caminho recalculado após se deparar com o fechamento de via no vértice 4.

Por fim, na Figura 4.19, temos a dinâmica esperada para o cenário 3, onde existe o fechamento da via. Contudo, a PMV se faz presente para notificar os condutores de veículos. Mais uma vez, a via representada pela aresta 4 -> 5 é fechada, e a PMV é posicionada no vértice 2 representado em azul. Utilizamos aqui a mesma notação anterior. A aresta roxa representa o caminho inicialmente calculado e que foi percorrido; as arestas pretas faziam parte do caminho inicial, mas nesse caso não foram percorridas devido ao fechamento da 


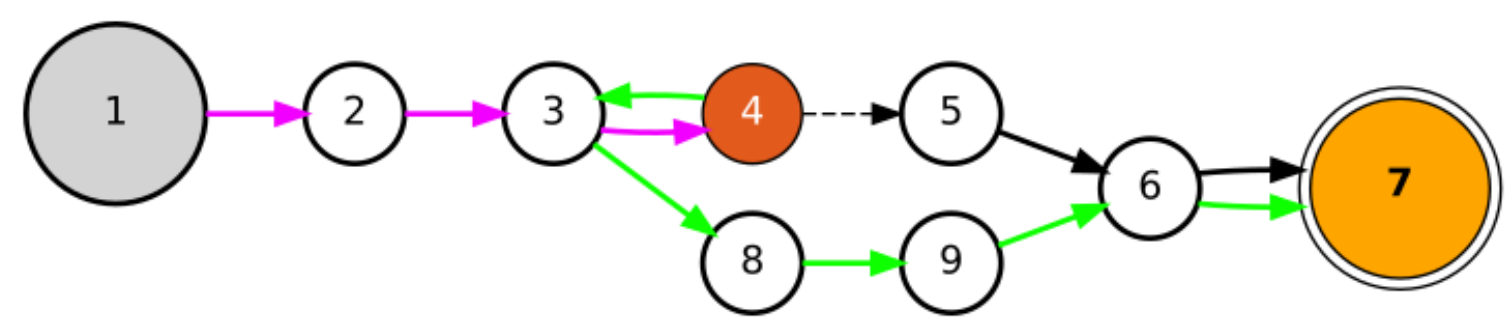

Figura 4.18: Trajeto esperado do cenário 2 do experimento.

via e da PMV; e as verdes simbolizam o novo caminho recalculado após o motorista ter sido notificado pela PMV. No modelo implementado, ainda assim, era esperado que alguns carros percorresem o fluxo apresentado na Figura 4.18, já que acreditamos que nem todos os motoristas que vissem a notificação iriam de fato mudar o seu trajeto.

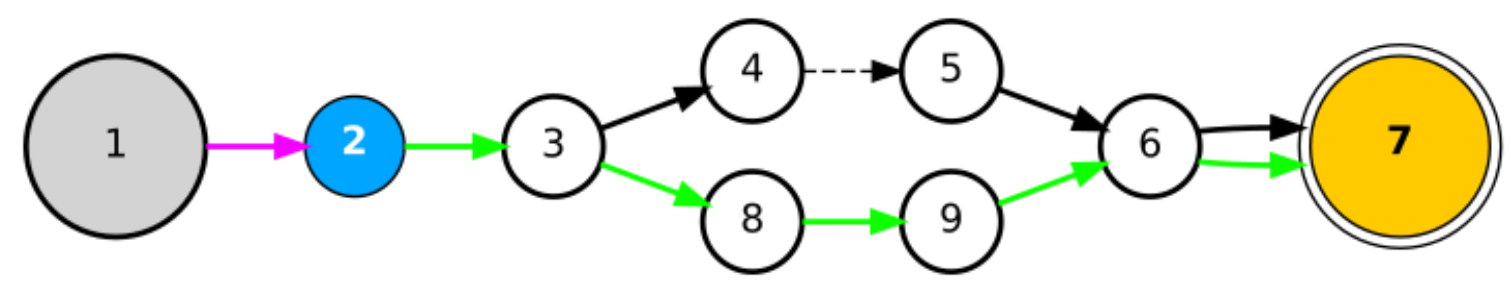

Figura 4.19: Trajeto esperado do cenário 3 do experimento.

Os três cenários desse experimento foram realizados em dois laptops com 8 CPUs virtuais $(1.80 \mathrm{GHz})$ e $8 \mathrm{~GB}$ de memória RAM. Diferente do experimento apresentado na Seção 4.2.2, o foco desse experimento não é analisar o desempenho da plataforma, mas sim uma análise funcional. Os passos para execução desse experimento de validação foram os seguintes:

1. Executar uma instância em modo de produção da plataforma InterSCity em um laptop.

2. Executar uma instância em modo de produção do simulador InterSCSimulator no outro laptop.

3. Configurar rede local entre os laptops, conectados de maneira cabeada via ethernet.

4. Realizar a simulação do cenário de tráfego inteligente de carros.

5. Analizar os resultados obtidos ao final da simulação.

A Figura 4.20, apresenta a distância média percorrida pelos carros simulados nos três cenários deste experimento. De acordo com as nossas hipóteses, esperávamos que os carros no cenário sem evento de fechamento de via e sem PMV para notificar os motoristas, percorressem 6 arestas, no cenário com evento e sem PMV percorressem 8 arestas e no cenário com evento e PMV percorressem entre 6 e 8 arestas (alguns veículos ignoram as notificações). Nossas hipóteses foram confirmadas, conforme o gráfico.

Uma análise semelhante foi realizada com a duração das viagens simuladas, como pode ser visto na Figura 4.21. As durações média das viagens simuladas nos três cenários do experimento são apresentadas no gráfico. Uma viagem dura sempre 2 ciclos de execução 


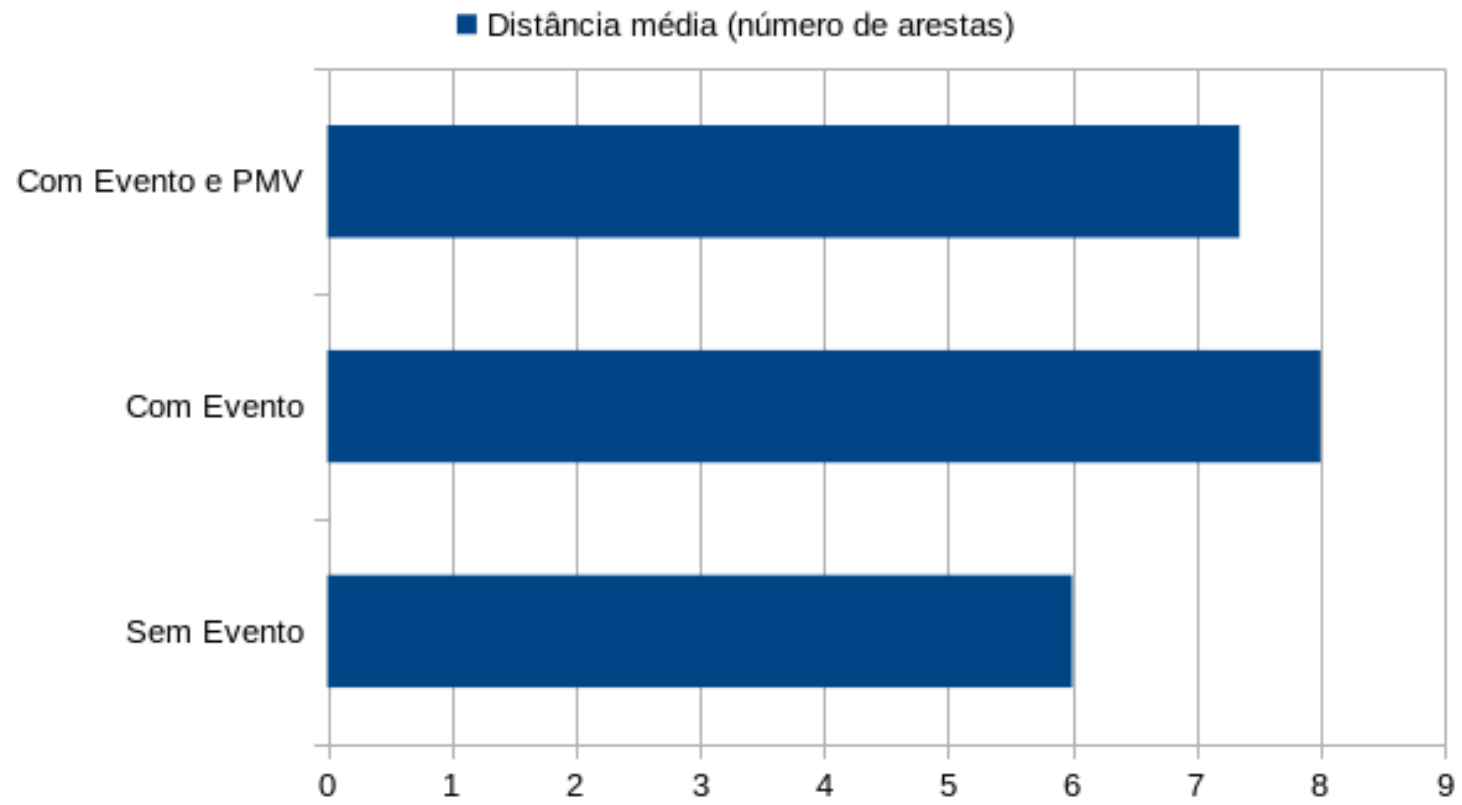

Figura 4.20: Média da distância percorrida pelos carros no experimento.

(criação e destruição do ator) mais o tempo utilizado para percorrer as arestas (uma aresta por ciclo de execução, já que possuem comprimento unitário) e o recálculo de um caminho dura um ciclo. Por isso, esperávamos que para o cenário sem evento de fechamento de via durasse 8 ciclos (2 pelo ciclo de vida +6 arestas); o cenário com evento e sem PMV, para informar os motoristas, durasse 11 ciclos ( 2 pelo ciclo de vida +8 arestas +1 pelo recálculo da rota); e o cenário com evento e PMV durasse entre 9 ciclos (2 pelo ciclo de vida +6 arestas +1 pelo recálculo) para motoristas que seguissem as instruções da PMV, e 11 ciclos ( 2 pelo ciclo de vida +8 arestas +1 pelo recálculo) para os motoristas que ignorassem a PMV. Nossas hipóteses mais uma vez foram confirmadas, como pode ser visto na Figura 4.21 .

Com isso, pudemos verificar os requisitos fundamentais e de integração, apresentados na Seção 3.1, para este cenário de tráfego de carros inteligentes. O modelo implementado no simulador correspondeu ao esperado e a comunicação entre as ferramentas foi validada, principalmente com o que diz respeito à atuação no ambiente simulado, sendo esse um trabalho pioneiro.

\section{Cidade de São Paulo}

Tendo em vista que a implementação dos modelos utilizados para este cenário e a integração estavam funcionando dentro do esperado, realizamos um outro experimento, envolvendo o mesmo cenário de tráfego inteligente de carros, mas dessa vez em uma escala maior, com dados abertos da cidade de São Paulo.

Dividimos esse experimento em três cenários novamente, quanto ao número de eventos de fechamento de via e PMVs. Eles se deram da seguinte forma:

1. Sem eventos de fechamento de via e sem PMVs 


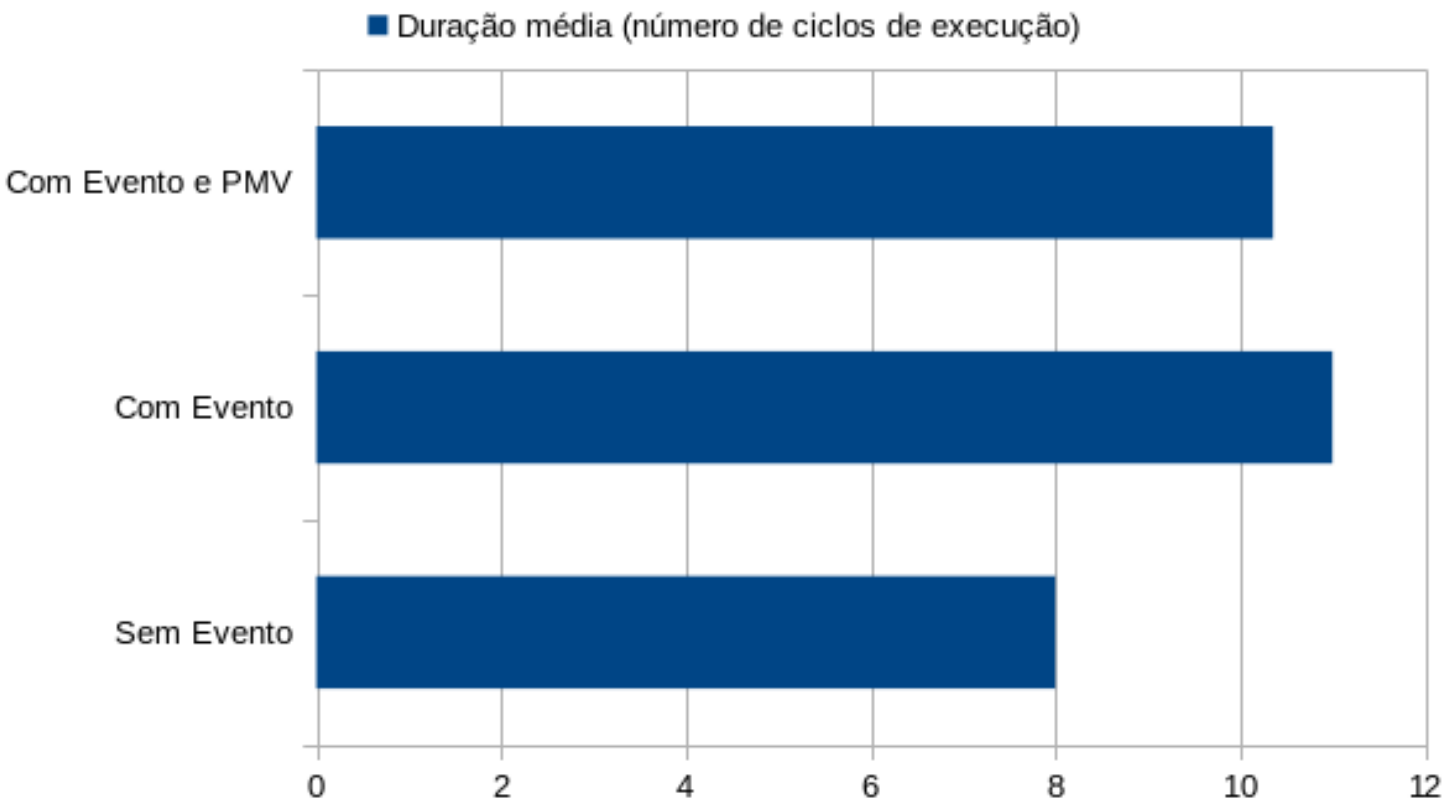

Figura 4.21: Média da duração das viagens simuladas no experimento.

2. Com eventos de fechamento de via e sem PMVs

3. Com eventos de fechamento de via e 7 PMVs

Foram executadas 20 iterações de cada uma dos cenários e, em cada iteração, simulamos 1 hora e 30 minutos. Neste experimento, utilizamos dados do OpenStreet Maps e a pesquisa Origem-Destino realizado pela companhia de metrô da cidade de São Paulo em 2007 para definição do cenário a ser simulado. A seguir mais detalhes sobre esses dados.

Dessa vez, não utilizamos o mapa viário completo da cidade de São Paulo. Realizamos um recorte de um trecho da avenida Rebouças com um raio de $5 \mathrm{~km}$, próximo ao cruzamento da avenida Paulista. O intuito desse recorte era reduzir o escopo do experimento para enfatizar o impacto das PMVs naquela região. Para a criação das viagens de carros a serem realizadas, utilizamos os mesmos dados da pesquisa OD (Origem-Destino) apresentada no experimento de estacionamento inteligente. Contudo, como não utilizamos o mapa completo da cidade, filtramos apenas as viagens em que a origem e o destino pertencessem ao recorte do mapa realizado. Todos os scripts utilizados para filtrar os dados de entrada estão disponíveis em nosso repositório aberto ${ }^{10}$.

- OpenStreet Maps: para criar o grafo viário da cidade de São Paulo usado na simulação, utilizamos o mapa do OpenStreet Maps. Este mapa contém todas as ruas e junções da cidade, em conjunto com um vasto número de atributos, como comprimento, capacidade e velocidade limite. Tais informações são usadas pelo simulador para definir as rotas percorridas pelos carros durante a realização de suas viagens, bem como simular o impacto do tráfego na velocidade dos carros.

- Pesquisa Origem-Destino (OD): criamos as viagens de carro simuladas com base

\footnotetext{
${ }^{10}$ https://github.com/LSS-USP/pmv_experiment
} 
na pesquisa OD realizada pela Companhia de Metrô de São Paulo. ${ }^{11}$ Essa pesquisa descreve as viagens de 200.000 pessoas e extrapola os dados para toda a população da cidade. A pesquisa inclui informações sobre a origem, o destino, o modo de transporte e a hora de partida. Esses dados foram empregados para definir o comportamento dos agentes do tipo carro na simulação. Simulamos o tráfego em São Paulo durante o horário das 8 h às 9 h30. Na pesquisa $\mathrm{OD}$, há 2.210 viagens de carro que começam durante o intervalo de tempo considerado e no recorte do mapa feito.

No cenário 3 deste experimento, onde fizemos uso de 7 PMVs, posicionamos os mesmos nas principais vias presentes no recorte do mapa, como pode ser visto na Figura 4.22. Decidimos sinalizar tais vias acreditando que por possuírem um maior fluxo de carros, possivelmente impactariam nas rotas de mais carros.

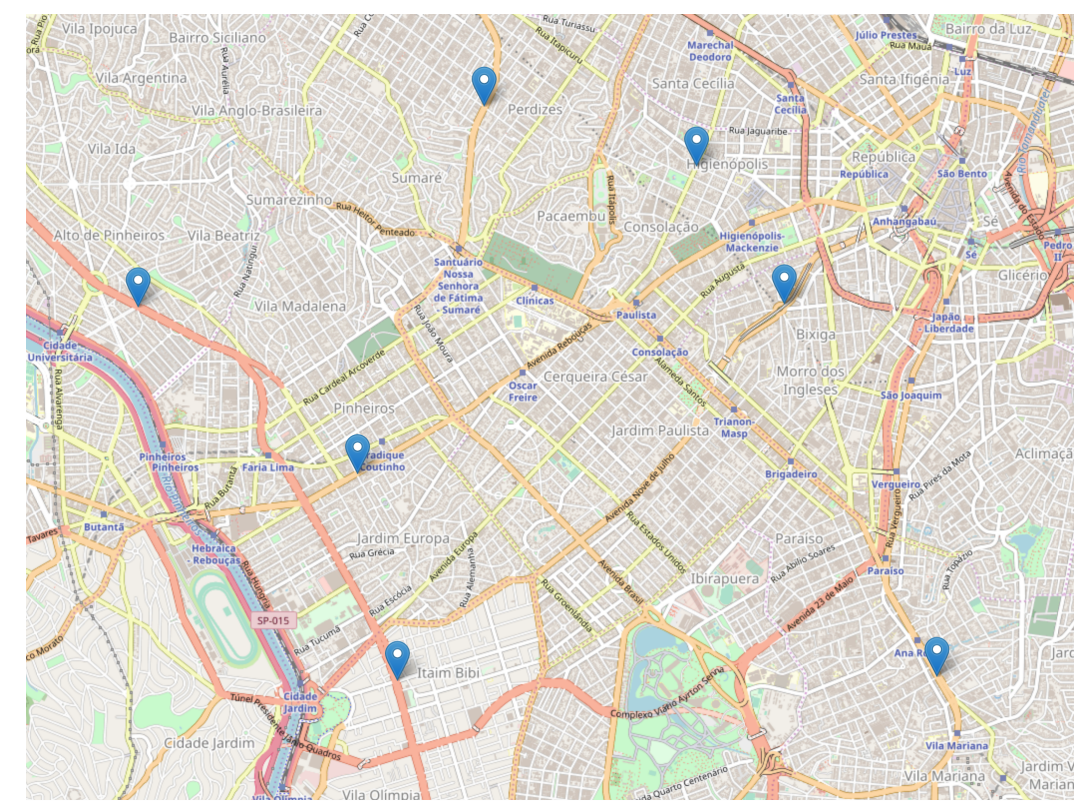

Figura 4.22: Posicionamento das PMVs no experimento de tráfego inteligente de carros.

Na Figura 4.23, pode-se ver os trechos de vias que foram fechadas nos cenários 2 e 3 deste experimento. No grafo do mapa viário da cidade gerado a partir do OpenStreet Maps, uma mesma via é formada de várias pequenas arestas (segmentos de via). Visando enfatizar um evento como um acidente de carro fatal ou um possível alagamento na região, fechamos um conjunto de arestas nas proximidades das avenidas Rebouças e Paulista.

Sabendo o local dos eventos de fechamento de vias e o posicionamento das PMVs, esperávamos que a notificação prévia dos motoristas sobre o acidente reduzisse a média do tempo de viagem dos motoristas com relação a não existência das PMVs. Consideramos que, pelo fato das avenidas Rebouças e Paulista serem bem movimentadas, muitas das viagens simuladas neste experimento passassem por aquele trecho. Contudo, a utilização das PMVs não deveria melhorar a média da duração das viagens em relação ao cenário onde não acontece nenhum evento de fechamento de via.

Os três cenários desse experimento foram realizadas novamente em dois laptops com 8 CPUs virtuais $(1.80 \mathrm{GHz})$ e $8 \mathrm{~GB}$ de memória RAM. Mais uma vez, diferente do experimento

\footnotetext{
${ }^{11}$ Pesquisa Origem-Destino - http://goo.gl/Te2SX7.
} 


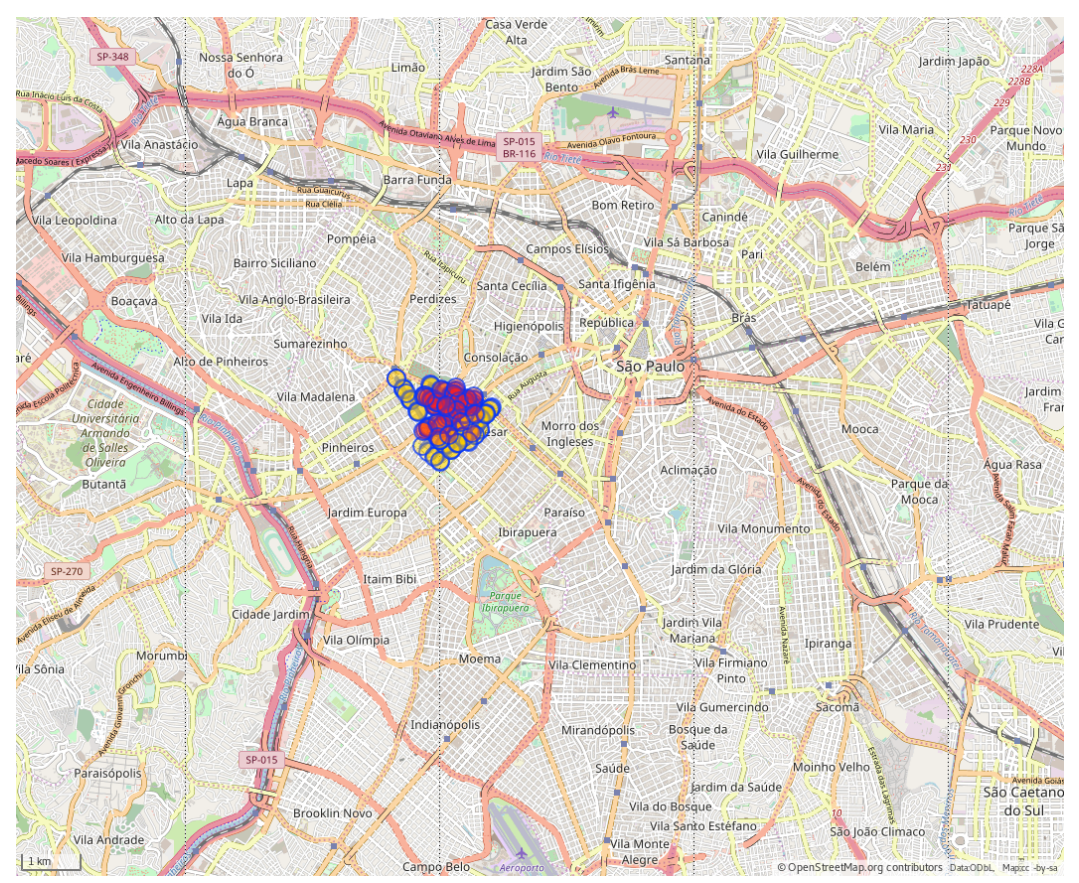

Figura 4.23: Local dos eventos de fechamento de via no experimento de tráfego de carros inteligente.

apresentado na Seção 4.2.2, o foco desse experimento não é analisar o desempenho da plataforma, mas sim uma análise funcional. Os passos para execução desse experimento foram os seguintes:

1. Executar uma instância em modo de produção da plataforma InterSCity em um laptop.

2. Executar uma instância em modo de produção da simulador InterSCSimulator no outro laptop.

3. Configurar rede local entre os laptops, conectados de maneira cabeada via ethernet.

4. Realizar a simulação do cenário de tráfego de carros inteligente.

5. Analisar os resultados obtidos ao final da simulação.

A Figura 4.24, apresenta a duração média das viagens de carro simuladas nos três cenários deste experimento. No eixo X, a duração é apresentada em segundos (ciclo de execução da simulação: 1 ciclo $=1$ segundo), e no eixo $\mathrm{Y}$ os três cenários do experimento. Como podemos ver no gráfico apresentado, em geral, a média do tempo de duração das viagens não passou de 6 minutos. Isso pode ter ocorrido pelo fato das viagens nessa região serem mais curtas, ou por não terem viagens suficientes para gerar congestionamentos, já que filtramos apenas as viagens que se iniciavam e terminavam dentro do recorte do mapa utilizado. Outro fator importante que nos chamou a atenção, foi a média da duração das viagens do cenários 3 (onde existem vias fechadas e o auxilio de PMVs) ser menor do que do cenário 1 (onde não existe qualquer incidente). Após analisar os dados, percebemos que ao recalcular a rota, na presença de uma PMV, os carros se distribuíam de uma melhor forma pela malha viária do cenário utilizado pelo experimento, com isso, 
evitavam congestionamentos que ocorriam anteriormente. Sendo isso um alvo de possível melhoria no simulador, já que ao criar o ator, apenas um dos menores caminhos entre a origem e destino do carro é calculado e utilizado, podendo essa rota coincidir entre múltiplos atores com origem e destinos similares, assim, deixando outros caminhos mais curtos inutilizados. Todavia, como esperado, o cenário 2, onde temos fechamento de vias mas não temos PMVs, teve a maior média de duração das viagens.

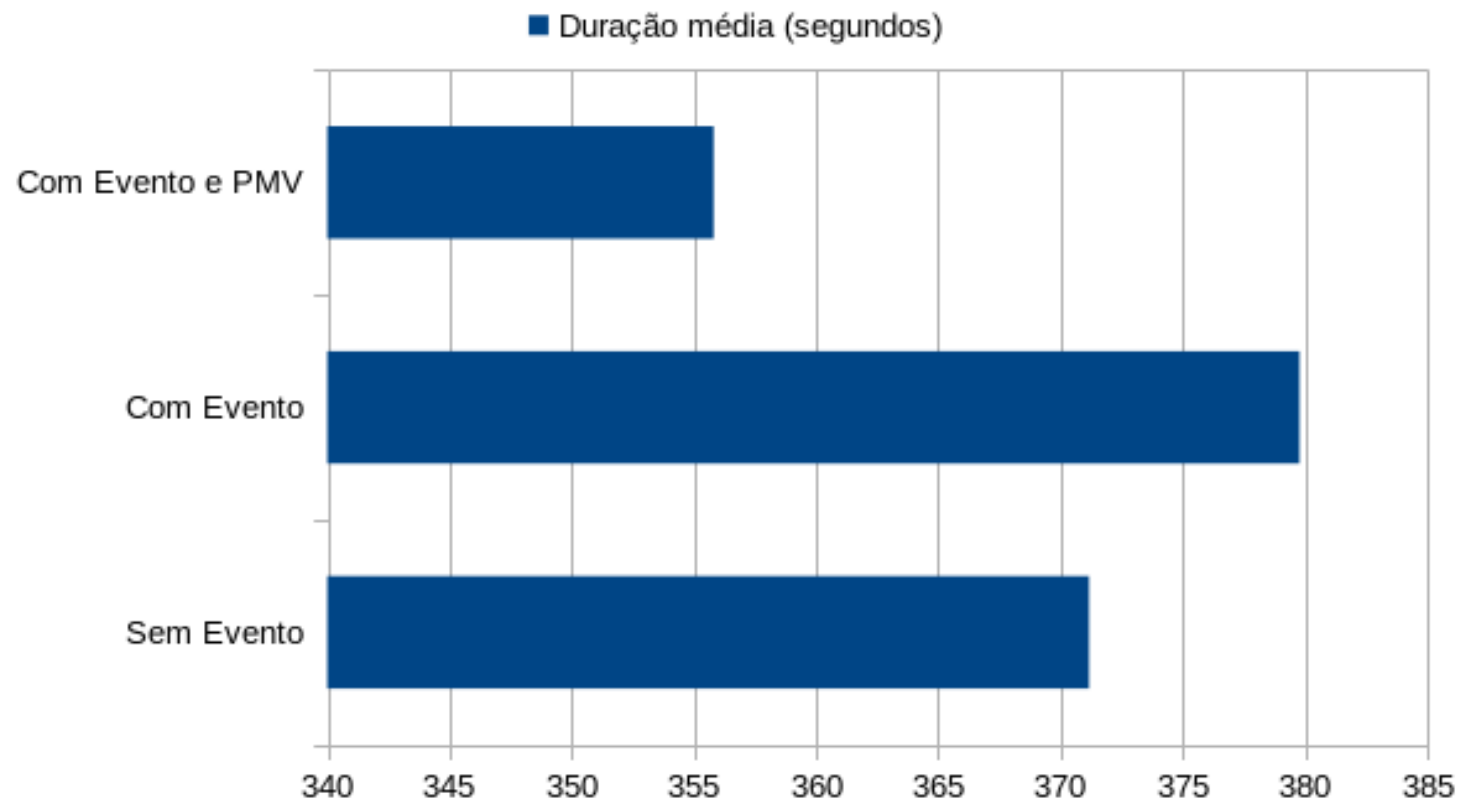

Figura 4.24: Média da duração das viagens de carros no experimento.

Para garantirmos uma melhor acurácia na análise dos resultados obtidos, filtramos apenas as viagens que foram influenciadas de alguma forma pelo fechamento de vias e/ou PMVs. Isso porque percebemos a existência de viagens que não eram modificadas em nenhum dos cenários do experimento, ou seja, a sua duração era sempre a mesma. Na Figura 4.25, apresentamos o mesmo gráfico discutido anteriormente, só que incluindo apenas as viagens que foram afetadas. Agora analisando o gráfico com as viagens afetadas, obtivemos o resultado esperado no início do experimento. O cenário 1, onde não há vias fechadas, teve o menor tempo médio de duração de viagens, sendo esse o nosso limite inferior. $\mathrm{O}$ cenário 2, onde vias foram fechadas, o pior tempo médio de viagem foi obtido, sendo o limite superior. E o cenário 3, onde introduzimos as PMVs para auxiliar os motoristas na decisão da melhor rota a seguir, apresentou um tempo médio de viagem ligeiramente menor do que o cenário 2 e maior do que o cenário 1 .

Contudo, a melhora de aproximadamente $5 \%$ na média do tempo de duração da viagem do cenário 3 com relação ao cenário 2 não foi um resultado expressivo. Avaliamos que alguns fatores podem ter influenciado nesse resultado, sendo a maioria deles voltado para os dados utilizados para a definicação do cenário de simulação deste experimento. $\mathrm{O}$ posicionamento das PMVs pode não ter sido o ideal, já que não foi realizada uma análise prévia de onde passariam a maior parte dos carros. O conjunto de viagens simulados após recortar o mapa da cidade de São Paulo pode não ter sido representativo, a decisão de reduzir o mapa para facilitar a visualização do impacto do fechamento de vias e PMVs 


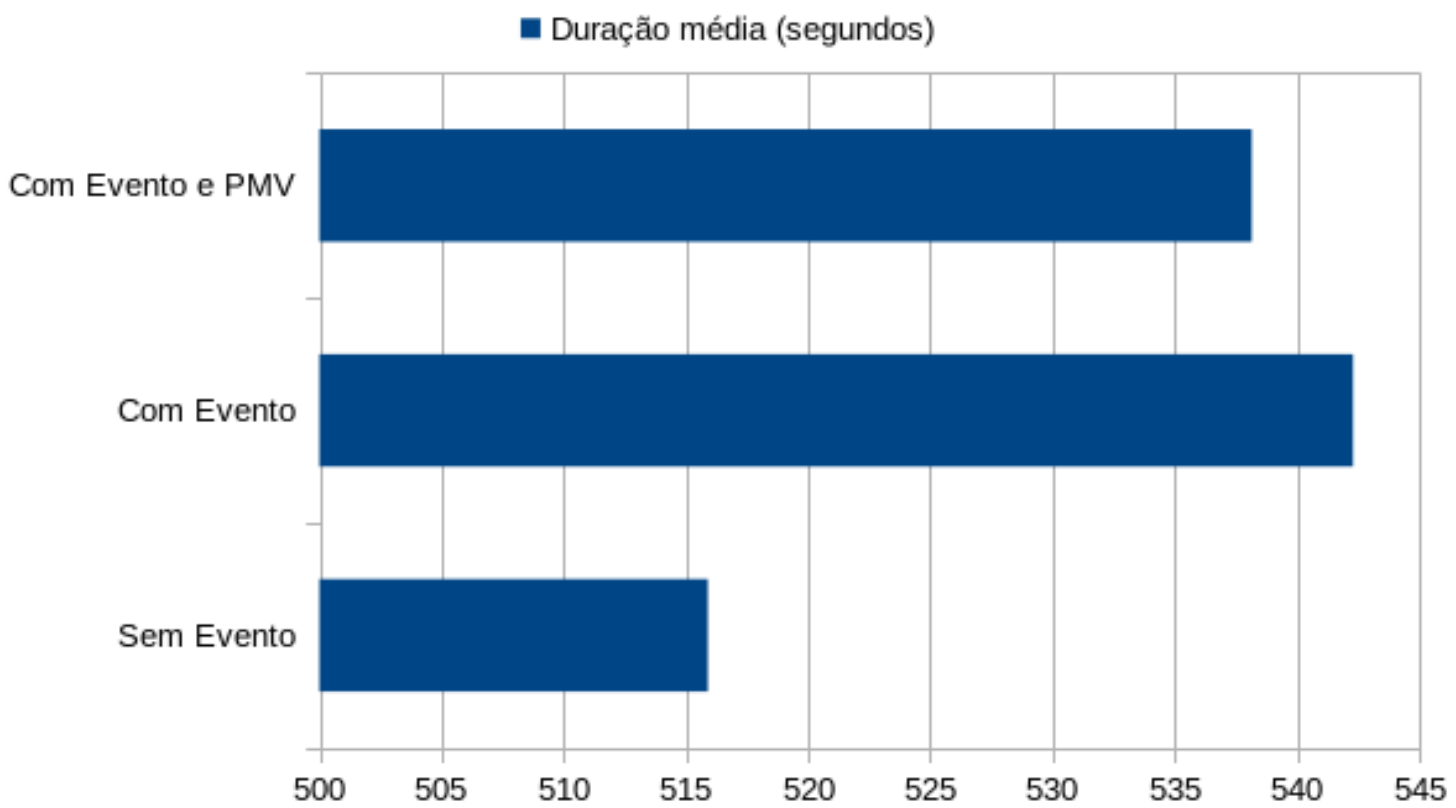

Figura 4.25: Média da duração das viagens de carros afetadas por fechamento de vias e/ou PMVs no experimento.

pode não ter sido boa ideia. Além disso, os resultados obtidos podem ter sido influenciados devido à infraestrutura simples utilizada com apenas dois laptops, já que em cenários realistas muitos recursos computationais são necessários, como memória e largura de banda da rede.

\subsection{Discussão}

Após a realização dos dois estudos de caso apresentados neste capítulo, foi possível perceber que a solução proposta no Capítulo 3 é viável e nos permitiu realizar diferentes experimentos utilizando um ambiente simulado de uma cidade, podendo substituir testbeds reais e aumentando a escala dos experimentos. Contudo, durante a implementação dos dois cenários de Cidades Inteligentes apresentados, algumas adversidades foram encontradas e solucionadas. A fim de contribuir com trabalhos futuros que sigam a solução proposta, uma discussão sobre os principais problemas e dificuldades encontradas será feita nesta seção. O intuito aqui é enfatizar os principais obstáculos a serem enfrentados durante a implementação de novos cenários no ambiente integrado usando o simulador InterSCSimulator e a plataforma InterSCity ou até mesmo envolvendo outras ferramentas, bem como discutir os resultados experimentais alcançados nos estudos de caso.

\subsubsection{Implementação da Solução Proposta}

Como vem sendo discutido no decorrer deste trabalho, a integração de ferramentas não é algo trivial. Apesar de tanto o simulador quanto a plataforma utilizada serem voltados para o contexto de Cidades Inteligentes, na maioria das vezes, elas não são concebidas inicialmente para serem integradas com outras ferramentas. Através dos próprios requisitos 
apresentados podemos antever o maior desafio a ser enfrentado: a interoperabilidade. Essa tanto a nível de comunicação quanto semanticamente.

Como constatado na implementação dos dois cenários apresentados, tentamos ao máximo reduzir a responsabilidade do componente de integração, que ao ser atribuído muitas tarefas pode se tornar um problema. Tanto que não foi necessária a implementação desse componente no segundo estudo de caso, tendo em vista que as ferramentas já atendiam os requisitos de integração. Isso pode ser atribuído ao fato de ambas as ferramentas (InteSCSimulator e InterSCity) serem mantidas pelo nosso grupo de pesquisa, onde tivemos a liberdade de evoluir o que foi preciso nas próprias ferramentas para facilitar a integração. Em um contexto onde não existisse essa flexibilidade, o desafio se tornaria bem mais complexo.

Mesmo assim, enfrentamos problemas principalmente com a escalabilidade da solução. Em experimentos anteriores e isolados, foi demonstrado que ambas as ferramentas eram escaláveis, se comportando bem diante de uma grande carga de trabalho. Entretanto, a integração traz alguns elementos extras que, por menor que sejam, interferem em cenários de larga escala. Em experimentos na escala de uma cidade como São Paulo, qualquer mínimo detalhe é potencializado. Semanticamente não tivemos muitos problemas, já que ambas as ferramentas foram implementadas seguindo conceitos similares, devido a própria sinergia do grupo de pesquisa. Todavia, a comunicação entre as ferramentas foi a raiz da maior parte dos problemas enfrentados.

Inicialmente, tentamos realizar qualquer interação com a plataforma através de requisições HTTP, usando a sua API Restful. Contudo, percebemos que o componente de integração necessitaria de uma complexidade muito maior para tratar todas essas requisições paralelamente sem se tornar um gargalo para o sistema. Por isso, decidimos explorar bastante o protocolo AMQP através da implementação do RabbitMQ. Essa se apresentou uma solução mais simples, já que o broker do RabbitMQ trata todas essas questões de escalabilidade de maneira eficiente, sendo essa uma solução adotada pelo mercado. Além do mais, pelo fato da comunicação via AMQP ser assíncrona e pela própria natureza dos cenários implementados, diferente de requisições HTTP, ela se apresentou uma solução mais adequada, não bloqueando agentes da simulação a espera de respostas. Logo, sempre que possível, transferir responsabilidades para ferramentas de terceiros comprovadamente capazes de atender os requisitos ao invés de implementar a sua própria solução, é desejável.

Nesse processo de melhoria da escalabilidade da solução integrada, várias mudanças foram feitas em ambas as ferramentas. Foram encontrados problemas de escalabilidade antes não evidenciados por outros experimentos isolados, demonstrando que a solução de ambiente de experimentação para plataformas de Cidades Inteligentes atingiu seus objetivos, apontando melhorias nos sistemas que só seriam evidenciadas ao enfrentar cargas de trabalho da magnitude de uma cidade como São Paulo.

Na plataforma InterSCity, implementações envolvendo técnicas para armazenamento em cache de dados mais utilizados foram feitas. Ademais, melhorias envolvendo a automatização da implantação da plataforma foram realizadas. Já no InterSCSimulator, encontramos alguns problemas na implementação dos modelos apresentados que causaram problemas de escalabilidade. Ou seja, dependendo do cenário e de como foi implementado, apenas 
reduzir a complexidade do componente de integração (até mesmo a não existência) ainda não é a solução. Portanto, poder modificar as próprias ferramentas é algo interessante, haja vista que a forma em que os modelos, métodos e funcionalidades foram implementados podem não ter sido testados em ambientes de estresse, tornando-se gargalos durante experimentos de larga escala. Isso evidencia a importância da utilização de ferramentas livres para a construção de ambientes de experimentação para plataformas de Cidades Inteligentes.

Em resumo, além das melhorias pontuais feitas a plataforma InterSCity devido a gargalos encontrados mencionadas no texto, no decorrer deste trabalho implementamos as seguintes funcionalidades/melhorias no InterSCSimulator que servirão de base para implementação de cenários futuros:

- Publicação de eventos de simulação em tempo de execução via RabbitMQ

- Processamento de comandos de atuação em tempo de execução via RabbitMQ

- Evolução do modelo de simulação do agente do tipo carro para atender os dois casos de uso apresentados

- Simulação de vagas de estacionamento, onde essas vagas são sensoriadas quanto a sua ocupação

- Simulação de eventos de trânsito, onde através de um novo arquivo de entrada é possível agendar eventos de fechamento total e parcial de trechos de vias

- Simulação de placas de mensagens variadas (PMV), com isso é possível notificar motoristas previamente de incidentes no trânsito

- Refatoração da leitura dos arquivos de entrada da simulação, não sendo necessário carregar todos os dados de entrada em memória no início da simulação

\subsubsection{Experimentos}

Um ponto importante para a realização de experimentos, e ainda mais envolvendo múltiplas ferramentas, é a automatização desse processo. Tal automatização facilita a execução de várias rodadas do experimento e a reprodução do trabalho por terceiros. Neste trabalho, acreditamos que ambos os estudos de caso foram devidamente automatizados e documentados, favorecendo a continuidade do trabalho.

No primeiro estudo de caso conseguimos evidenciar a escalabilidade horizontal da plataforma InterSCity. Várias melhorias foram realizadas e gargalos solucionados, o que nos demonstrou a extrema importância da realização desse tipo de experimento durante o ciclo de desenvolvimento de plataformas de Cidades Inteligentes. Já no segundo estudo de caso, demonstramos a viabilidade da atuação em tempo de execução em um ambiente simulado, sendo esse um trabalho pioneiro na área de Cidades Inteligentes.

Contudo, como o foco principal do trabalho é prover uma solução de ambiente simulado para a realização de experimentos em plataformas de Cidade Inteligentes, acreditamos que algumas das análises apresentadas nos estudos de caso poderiam ser melhoradas. Ademais, especialmente no segundo estudo de caso, algumas decisões iniciais do experimento 
poderiam ter sido otimizadas, como o posicionamento das PMVs baseado em uma análise mais profunda da movimentação dos carros nas viagens selecionadas para o experimento, o que prejudicou os resultados obtidos. A utilização de laptops para a execução do segundo experimento também contribuiu para o resultado final abaixo do esperado, tendo em vista que esse tipo de experimento requer muitos recursos computacionais.

Em resumo, os estudos de caso foram satifatórios, já que foi possível validar a proposta de solução em dois cenários de Cidades Inteligentes distintos, exercitando as principais funcionalidades que um ambiente de experimentação simulado deve possuir. Portanto, a arquitetura de software proposta poderá servir de base para a integração de novos cenários, seja envolvendo a plataforma InterSCity e o InterSCSimulator ou não. 



\section{Capítulo 5}

\section{Conclusão}

A proposta de arquitetura para criação de um ambiente simulado de experimentação para plataformas de Cidades Inteligentes apresentou-se como uma solução viável, tendo em vista que fomos capazes de realizar experimentos de diferentes naturezas utilizando implementações feitas a partir da sistematização guiada pela solução pensada. Durante a pesquisa, percebemos que a utilização de simulação é uma saída para a realização de experimentos na escala de grandes cidades, sem a necessidade de muitos investimentos em testbeds reais. A experimentação de tecnologias ainda não difundidas ou até mesmo inexistentes, como por exemplo o uso de Placas de Mensagens Variadas (PMVs) notificando motoristas em tempo real sobre problemas no trânsito, carros autônomos, estacionamentos inteligentes, dentre outros, nos aproxima da realidade onde tais tecnologias farão parte do nosso cotidiano, fazendo-nos acreditar nas diversas possibilidades quanto ao investimento na pesquisa de Cidades Inteligentes.

Neste trabalho conseguimos realizar experimentos envolvendo mais de 400 mil agentes simulados, enquanto na literatura encontramos apenas o simulador Deus que não possui experimentos publicados com mais de 2000 elementos simulados (PICONE et al., 2012), o que demonstra a capacidade de realizarmos simulaçãoes de larga escala. Além disso, diferente dos ambientes de experimentação FIT IoT-Lab, SmartSantander e SmartCampus, permitimos a execução de comandos de atuação no ambiente experimental sem a necessidade de uma infraestrutura real de IoT, trazendo uma solução simulada, sendo essa uma solução que não encontramos na literatura.

Concluímos também que a tarefa de criar um ambiente de experimentação envolvendo a integração de ferramentas não é trivial, corroborando com a literatura. Apesar de ambas as ferramentas utilizadas para implementação da arquitetura proposta serem desenvolvidas pelo nosso grupo de pesquisa, encontramos diversos entraves durante o processo. Esses problemas nos mostraram a importância da utilização de ferramentas de código aberto, pois muitas vezes o componente de integração, introduzido pela nossa proposta de solução, não é capaz de solucionar problemas inerentes às ferramentas, necessitando modificálas. Problemas esses que, em geral, são evidenciados somente em cenários similares ao contexto enfrentado por metrópoles, demonstrando a importância da realização desse tipo de experimento durante o ciclo de desenvolvimento de plataformas para Cidades 
Inteligentes.

Ademais, vimos que apenas a existência de um ambiente simulado que permita a realização de experimentos em escalas maiores não soluciona todos os problemas. É necessária a definição precisa do cenário de simulação através de dados reais de cidades. Portanto, esse elemento é de suma relevância. Como apresentado na Seção 4.3.2, os resultados obtidos no segundo estudo de caso não foram melhores devido ao não conhecimento detalhado dos dados de entrada utilizados. Outro ponto importante na realização de experimentos é a automatização desse processo, contribuindo com trabalhos que possam ser derivados através da reprodução dos mesmos, fazendo uso de ferramentas e técnicas de infraestrutura como código (IaC).

Por fim, utilizando o ambiente de experimentação simulado desenvolvido neste trabalho, publicamos o artigo Design and evaluation of a scalable smart city software platform with large-scale simulations(M. Del Esposte et al., 2019b) juntamente com colegas do nosso grupo de pesquisa, na revista Future Generation of Computer Systems edição 93 que será publicada em abril de 2019. Essa publicação em uma revista bem conceituada foi de suma importância para demostrarmos que a abordagem apresentada neste estudo é factível e inovadora na área de Cidades Inteligentes.

\subsection{Limitações do trabalho}

A primeira limitação identificada é o fato da proposta de solução apresentada não ter sido validada com outras ferramentas além do InterSCSimulator e da InterSCity. Essa validação seria interessante para reafirmarmos que a solução proposta tem um âmbito genérico, contemplando quaisquer ferramentas. Ainda sobre a arquitetura de integração, não tivemos a oportunidade de implementar um módulo de tradução semântica, já que ambas as ferramentas tinham conceitos similares implementados. Sabemos que o tal módulo é de suma importância em casos onde as ferramentas não são desenvolvidas pelo mesmo grupo de pessoas.

Além disso, os estudos de casos apresentam algumas limitações, principalmente o que contempla o cenário de tráfego de carros inteligente. Como já foi dito, as entradas para a simulação deveriam ter sido melhor analisadas previamente, o que levou à não obtenção de resultados mais expressivos. Todavia, acreditamos que, apesar dessa limitação, o estudo de caso cumpriu o seu papel que era verificar a viabilidade de execução de experimentos fazendo uso de comandos de atuação no ambiente simulado.

\subsection{Trabalhos Futuros}

Para a continuidade deste trabalho seria interessante a utilização de diferentes ferramentas para a implementação da solução proposta. Ao utilizar uma plataforma e um simulador diferente, poderíamos validar a arquitetura apresentada em um contexto diferente, principalmente com o que diz respeito ao componente de integração, que provavelmente necessitará de um módulo de tradução semântica e mais complexidade embutida em sua implementação. 
Nesse sentido, também seria interessante adicionar novos cenários de Cidades Inteligentes no ambiente já integrado neste trabalho, com o InterSCSimulator e a InterSCity, e realizar novos experimentos. Como foi visto no decorrer da dissertação, novos cenários trazem novos desafios e, portanto, requisitos fundamentais que eventualmente necessitam ser implementados ou evoluídos dentro das ferramentas mencionadas. Quanto mais cenários de Cidades Inteligentes ao ambiente de experimentação InterSCSimulator + InterSCity nós adicionarmos, mais interessante se tornará a nossa solução, além de estarmos avaliando a plataforma InterSCity constantemente em condições realistas.

A utilização de outros protocolos de rede para realizar a comunicação entre o simulador e a plataforma também seria algo interessante. Neste trabalho, utilizamos apenas os protocolos HTTP e AMQP nas implementações dos dois cenários de Cidades Inteligentes, foco do estudo. Protocolos como o MQTT ${ }^{1}$ e CoAP ${ }^{2}$ vem sendo amplamente utilizados para a comunicação com dispositivos IoT, conforme as diversas implementações de plataformas desse tipo.

A tecnologia possui um papel fundamental no desenvolvimento social. É observável a sua presença na resolução de problemas que afetam a sociedade, desde situações simples às mais complexas, o que nos leva a refletir sobre o que o futuro nos guarda em termos de otimização dos recursos das cidades e qualidade de vida dos cidadãos.

\footnotetext{
${ }^{1}$ http://mqtt.org/

${ }^{2}$ http://coap.technology/
} 



\section{Referências}

[ADjin et al. 2015] Cedric Adjin et al. "Fit IoT-LAB: a large scale open experimental IoT testbed". Em: 2015 IEEE 2nd World Forum on Internet of Things (WF-IoT). Dez. de 2015, pgs. 459-464 (citado na pg. 6).

[Ali et al. 2015] Muhammad Intizar Ali, Feng Gao e Alessandra Mileo. "Citybench: a configurable benchmark to evaluate RSP engines using smart city datasets". Em: The Semantic Web - ISWC 2015. Ed. por Marcelo ArenAs et al. Cham: Springer International Publishing, 2015, pgs. 374-389 (citado na pg. 7).

[Amrutur et al. 2017] Bharadwaj Amrutur et al. "An open smart city IoT test bed: street light poles as smart city spines”. Em: Proceedings of the Second International Conference on Internet-of-Things Design and Implementation. IoTDI '17. Pittsburgh, PA, USA: ACM, 2017, pgs. 323-324 (citado na pg. 7).

[BARnaghi et al. 2012] Payam Barnaghi, Wei Wang, Cory Henson e Kerry Taylor. "Semantics for the internet of things: early progress and back to the future". Em: International fournal on Semantic Web and Information Systems (IFSWIS) 8.1 (2012), pgs. 1-21 (citado nas pgs. 17, 18).

[BнAтti et al. 2000] Nina BнAtтi, Anna Bouch e Allan Kuchinsky. "Integrating userperceived quality into web server design”. Em: Computer Networks 33.1 (2000), pgs. 1-16. ISSN: 1389-1286. URL: http://www.sciencedirect.com/science/article/pii/ S1389128600000876 (citado na pg. 35).

[Boukerche et al. 2001] Azzedine Boukerche, Sajal K. Das e Alessandro Fabbri. "Swimnet: a scalable parallel simulation testbed for wireless and mobile networks". Em: Wireless Networks 7.5 (set. de 2001), pgs. 467-486. ISSN: 1022-0038 (citado na pg. 2).

[Brambilla et al. 2014] Giacomo Brambilla, Marco Picone, Simone Cirani, Michele Amoretti e Francesco Zanichelli. "A simulation platform for large-scale internet of things scenarios in urban environments". Em: Proceedings of the First International Conference on IoT in Urban Space. URB-IOT '14. Rome, Italy: ICST (Institute for Computer Sciences, Social-Informatics e Telecommunications Engineering), 2014, pgs. 50-55 (citado na pg. 10). 
[BRAEM et al. 2016] Bart BRAEM et al. "Designing a smart city playground: real-time air quality measurements and visualization in the city of things testbed". Em: 2016 IEEE International Smart Cities Conference (ISC2). Set. de 2016, pgs. 1-2 (citado na pg. 7).

[Cenedese et al. 2014] Angelo Cenedese, Andrea Zanella, Lorenzo Vangelista e Michele Zorzi. "Padova smart city: an urban internet of things experimentation". Em: Proceeding of IEEE International Symposium on a World of Wireless, Mobile and Multimedia Networks 2014. Jun. de 2014, pgs. 1-6 (citado na pg. 6).

[CHAPMAN et al. 2015] Lee CHAPMAN et al. "The birmingham urban climate laboratory: an open meteorological test bed and challenges of the smart city". Em: Bulletin of the American Meteorological Society 96.9 (2015), pgs. 1545-1560 (citado na pg. 7).

[Chernyshev et al. 2018] Maxim Chernyshev, Zubair BAig, Oladayo Bello e Sherali ZEADALLY. "Internet of things (IoT): research, simulators, and testbeds". Em: IEEE Internet of Things fournal 5.3 (jun. de 2018), pgs. 1637-1647. ISSN: 2327-4662 (citado na pg. 9).

[Chourabi et al. 2012] Hafedh Chourabi et al. "Understanding smart cities: an integrative framework". Em: Proceedings of the 2012 45th Hawaii International Conference on System Sciences. HICSS '12. Washington, DC, USA: IEEE Computer Society, 2012, pgs. 2289-2297 (citado na pg. 1).

[Clements et al. 2002] Paul Clements et al. Documenting Software Architectures: Views and Beyond. Pearson Education, 2002 (citado na pg. 15).

[CORICI et al. 2014] Andreea Ancuta CoRICI et al. "An openmtc platform-based interconnected european-south african $\mathrm{m} 2 \mathrm{~m}$ testbed for smart city services”. Em: the first International Conference on the use of Mobile Informations and Communication Technology (ICT) in Africa-UMICTA 2014. 2014, pgs. 35-39 (citado na pg. 7).

[Del Esposte et al. 2017] Arthur de M. Del Esposte, Fabio Kon, Fabio M. Costa e Nelson LAGO. "Interscity: a scalable microservice-based open source platform for smart cities". Em: Proceedings of the 6th International Conference on Smart Cities and Green ICT Systems. 2017 (citado nas pgs. 2, 24).

[D’Angelo et al. 2016] Gabriele D’Angelo, Stefano Ferretti e Vittorio Ghini. "Simulation of the internet of things". Em: 2016 International Conference on High Performance Computing Simulation (HPCS). Jul. de 2016, pgs. 1-8 (citado na pg. 9).

[Dupuy et al. 1990] Alexander Dupuy, Jed Schwartz, Yechiam Yemini e David Bacon. "Nest: a network simulation and prototyping testbed". Em: Communications of the ACM 33.10 (1990), pgs. 63-74 (citado na pg. 2).

[Fleischer e BArr 1994] Kurt Fleischer e Alan H BArr. "A simulation testbed for the study of multicellular development: the multiple mechanisms of morphogenesis". Em: Artificial life III : proceedings of the Workshop on Artificial Life. Vol. 17. Santa 
Fe Institute studies in the science of complexity. 1994, pgs. 389-389 (citado na pg. 2).

[Genesereth et al. 1997] Michael R. Genesereth, Arthur M. Keller e Oliver M. DusCнкA. "Infomaster: an information integration system". Em: Proceedings of the 1997 ACM SIGMOD International Conference on Management of Data. SIGMOD '97. Tucson, Arizona, USA: ACM, 1997, pgs. 539-542 (citado na pg. 10).

[GluhaK et al. 2011] Alexander Gluhak et al. "A survey on facilities for experimental internet of things research”. Em: IEEE Communications Magazine 49.11 (2011), pgs. 58-67 (citado na pg. 5).

[HAlevy et al. 2005] Alon Y. Halevy et al. "Enterprise information integration: successes, challenges and controversies”. Em: Proceedings of the 2005 ACM SIGMOD International Conference on Management of Data. SIGMOD '05. Baltimore, Maryland: ACM, 2005, pgs. 778-787 (citado na pg. 11).

[JURASCHEK et al. 2012] Felix JURASCHEK et al. "Towards smart berlin - an experimental facility for heterogeneous smart city infrastructures”. Em: 2912 IEEE 37th Conference on Local Computer Networks Workshops (LCN Workshops). IEEE. 2012, pgs. 886-892 (citado na pg. 6).

[Karnouskos e De Holanda 2009] Stamatis Karnouskos e Thiago Nass De Holanda. "Simulation of a smart grid city with software agents." Em: fournal of the European Mathematical Society 9 (2009), pgs. 424-429 (citado na pg. 2).

[LANZA et al. 2015] Jorge LANZA et al. "Large-scale mobile sensing enabled internet-ofthings testbed for smart city services". Em: International fournal of Distributed Sensor Networks 11.8 (2015), pg. 785061 (citado na pg. 6).

[LATRE et al. 2016] Steven LATre et al. "City of things: an integrated and multitechnology testbed for IoT smart city experiments”. Em: 2016 IEEE International Smart Cities Conference (ISC2). Set. de 2016, pgs. 1-8 (citado na pg. 6).

[Lu et al. 2010] Gang Lu, Debraj De e Wen-Zhan Song. "Smartgridlab: a laboratorybased smart grid testbed”. Em: 2010 First IEEE International Conference on Smart Grid Communications. Out. de 2010, pgs. 143-148 (citado na pg. 7).

[Leys et al. 2013] Christophe Leys, Christophe Ley, Olivier KLEIn, Philippe Bernard e Laurent LicATA. "Detecting outliers: do not use standard deviation around the mean, use absolute deviation around the median”. Em: fournal of Experimental Social Psychology 49.4 (2013), pgs. 764-766. ISSN: 0022-1031. URL: http://www. sciencedirect.com/science/article/pii/S0022103113000668 (citado na pg. 37).

[M. Del Esposte et al. 2019a] Arthur de M. Del Esposte et al. "Design and evaluation of a scalable smart city software platform with large-scale simulations". Em: Future Generation Computer Systems 93 (2019), pgs. 427-441. IssN: 0167-739X (citado na pg. 2). 
[M. Del Esposte et al. 2019b] Arthur de M. Del Esposte et al. "Design and evaluation of a scalable smart city software platform with large-scale simulations". Em: Future Generation Computer Systems 93 (2019), pgs. 427-441. ISSN: 0167-739X. URL: http://www.sciencedirect.com/science/article/pii/S0167739X18307301 (citado na pg. 56).

[Mwangama et al. 2013] Joyce Mwangama et al. "Testbeds for reliable smart city machine-to-machine communication”. Em: Southern African Telecommunication Networks and Applications Conference (SATNAC). 2013, pg. 339 (citado na pg. 7).

[Nati et al. 2013] Michele Nati, Alexander Gluhak, Hamidreza Abangar e William HEAdLEY. "Smartcampus: a user-centric testbed for internet of things experimentation”. Em: 2013 16th International Symposium on Wireless Personal Multimedia Communications (WPMC). Jun. de 2013, pgs. 1-6 (citado na pg. 7).

[Olivares et al. 2013] Teresa Olivares, Fernando Royo e Antonio M. Ortiz. "An experimental testbed for smart cities applications". Em: Proceedings of the 11th ACM International Symposium on Mobility Management and Wireless Access. MobiWac 13. Barcelona, Spain: ACM, 2013, pgs. 115-118 (citado na pg. 6).

[Picone et al. 2012] Marco Picone, Michele Amoretti e Francesco Zanichelli. "Simulating smart cities with deus". Em: Proceedings of the 5th International ICST Conference on Simulation Tools and Techniques. SIMUTOOLS '12. Desenzano del Garda, Italy: ICST (Institute for Computer Sciences, Social-Informatics e Telecommunications Engineering), 2012, pgs. 172-177 (citado nas pgs. 10, 55).

[Piórkowski et al. 2008] Michal Piórkowski et al. "Trans: realistic joint traffic and network simulator for vanets”. Em: ACM SIGMOBILE Mobile Computing Communications Review 12.1 (jan. de 2008), pgs. 31-33. IsSN: 1559-1662 (citado na pg. 10).

[SANCHEz et al. 2014] Luis SANCHEz et al. "Smartsantander: IoT experimentation over a smart city testbed”. Em: Computer Networks 61 (2014). Special issue on Future Internet Testbeds - Part I, pgs. 217-238. IssN: 1389-1286 (citado nas pgs. 2, 5, 7).

[Santana, Chaves et al. 2017] Eduardo F. Z. Santana, Ana Paula Chaves, Marco Aurelio Gerosa, Fabio Kon e Dejan S. Milojicic. "Software platforms for smart cities: concepts, requirements, challenges, and a unified reference architecture". Em: ACM Computing Surveys 50.6 (nov. de 2017), 78:1-78:37. ISSN: 0360-0300 (citado nas pgs. 1, 24).

[Santana, Lago et al. 2017] Eduardo F. Z. Santana, Nelson Lago, Fabio Kon e Dejan S. MiLojicic. "Interscsimulator: large-scale traffic simulation in smart cities using erlang". Em: Proceedings of the 18th Workshop on Multi-agent-based Simulation. 2017 (citado nas pgs. 2, 22).

[Schütte et al. 2011] Steffen Schütte, Stefan Scherfke e Martin Tröschel. "Mosaik: a framework for modular simulation of active components in smart grids". Em: 
2011 IEEE First International Workshop on Smart Grid Modeling and Simulation (SGMS). Out. de 2011, pgs. 55-60 (citado na pg. 9).

[Taylor et al. 2009] Hugh Taylor, Angela Yochem, Les Phillips e Frank Martinez. Event-driven architecture: how SOA enables the real-time enterprise. Pearson Education, 2009 (citado na pg. 16).

[Tsampasis et al. 2016] Eleftherios Tsampasis, Lambros Sarakis, Helen Catherine LeLIGOU, Theodore ZaHARIADIS e John GarofalaKis. "Novel simulation approaches for smart grids". Em: Fournal of Sensor and Actuator Networks 5.3 (2016). ISSN: 2224-2708 (citado na pg. 9).

[Vinoski 2006] Steve VinOsKi. “Advanced message queuing protocol”. Em: IEEE Internet Computing 10.6 (2006) (citado na pg. 25).

[WASSERman 1990] Anthony I. Wasserman. "Tool integration in software engineering environments”. Em: Software Engineering Environments. Ed. por Fred Long. Berlin, Heidelberg: Springer Berlin Heidelberg, 1990, pgs. 137-149 (citado na pg. 10).

[Wegener et al. 2008] Axel Wegener, Maxim Piórkowski Michałand Raya, Horst Hellbrück, Stefan Fischer e Jean-Pierre Hubaux. "Traci: an interface for coupling road traffic and network simulators". Em: Proceedings of the 11th Communications and Networking Simulation Symposium. CNS '08. Ottawa, Canada: ACM, 2008, pgs. 155-163 (citado na pg. 11). 